Lucas Castro Faria

Rastreabilidade Metrológica de Impulsos de Corrente Elétrica no Brasil

Dissertação de Mestrado

Dissertação apresentada como requisito parcial para obtenção do título de Mestre pelo Programa de PósGraduação em Metrologia (Área de concentração: Metrologia para Qualidade e Inovação) da PUC-Rio.

Orientador: Prof. Carlos Roberto Hall Barbosa 


\title{
Rastreabilidade Metrológica de Impulsos de Corrente Elétrica no Brasil
}

\begin{abstract}
Dissertação apresentada como requisito parcial para obtenção do título de Mestre pelo Programa de PósGraduação em Metrologia (Área de concentração: Metrologia para Qualidade e Inovação) da PUC-Rio. Aprovada pela Comissão Examinadora abaixo assinada.
\end{abstract}

\section{Prof. Carlos Roberto Hall Barbosa \\ Orientador}

Programa de Pós-graduação em Metrologia (PósMQI) Pontifícia Universidade Católica do Rio de Janeiro (PUC-Rio)

Prof. Eduardo Costa da Silva

Departamento de Engenharia Elétrica (DEE) Pontifícia Universidade Católica do Rio de Janeiro (PUC-Rio)

Profa. Elisabeth Costa Monteiro

Programa de Pós-graduação em Metrologia (PósMQI) Pontifícia Universidade Católica do Rio de Janeiro (PUC-Rio)

Prof. José Eugenio Leal

Coordenador Setorial de Pós-graduação do

Centro Técnico Científico (PUC-Rio)

Rio de Janeiro, 19 de setembro de 2014 
Todos os direitos reservados. É proibida a reprodução total ou parcial do trabalho sem autorização da universidade, do autor e do orientador.

\section{Lucas Castro Faria}

Formado em Engenharia de Controle e Automação pela Pontifícia Universidade Católica do Rio de Janeiro no ano de 2011. Mestre em Metrologia pelo programa de pósgradução na área de Metrologia para Qualidade e Inovação da PUC-Rio

Ficha Catalográfica

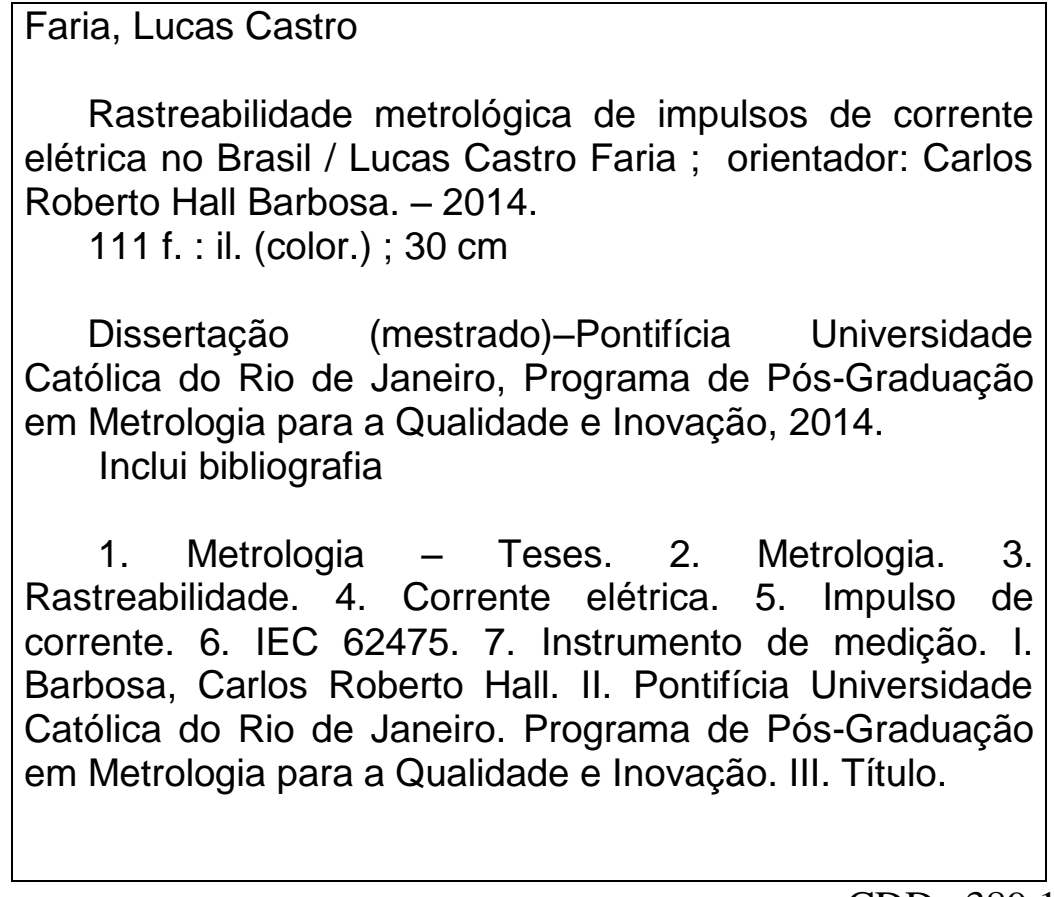

CDD: 389.1 
Dedico esta dissertação a meus pais, Sidney e Patrícia, que deram todo o apoio para esta conquista, passando por momentos difíceis ao meu lado. 


\section{Agradecimentos}

Agradeço à Deus, por me guiar nos caminhos Dele.

À PUC e a CAPES por ter criado um ambiente e estrutura de qualidade de ensino para esse mestrado ser concluido.

Ao meu orientador Prof. Carlos Roberto Hall Barbosa, pela paciência e todo conhecimento transmitido.

Aos meus pastores Silas e Selma Esteves, pelas orações, fé e principalmente pelo amor.

Aos meus pais, que entraram nessa aventura junto comigo e foram parte de cada vitória, até mesmo nos momentos difíceis a presença e amor de vocês estava presente.

À minha irmã, Natália, que manteve seu coração e suas orações por mim em todo momento.

Ao meu irmão, Daniel, que foi, é, e sempre será parceiro nas lutas e nas vitórias, caminhando juntos podemos qualquer coisa.

À equipe técnica e de pesquisadores do laboratório de calibração do CEPEL, Flávio Bittencourt Barbosa, Luiz Carlos de Azevedo e Márcio Thélio Fernandes da Silva que foram motivadores e incentivadores desse trabalho. A dedicação de vocês e ensinamentos transmitidos traçaram as linhas de pesquisa desta dissertação.

Ao coordenador do PósMQI da PUC-Rio, Prof. Maurício Frota, pela dedicação e esforço em formar jovens ricos em conhecimento e pelo cuidado com cada um deles.

Ao meu tutor e mestre, Paulo Viana, por ser um exemplo de pai e mestre. Que eu possa ser, para muitos, aquilo que você foi e é para mim em cada passo da vida acadêmica e profissional. 


\section{Resumo}

Faria, Lucas Castro; Barbosa, Carlos Roberto Hall (Orientador) Rastreabilidade Metrológica de Impulsos de Corrente Elétrica no Brasil. Rio de Janeiro, 2014. 111p. Dissertação de Mestrado - Programa de Pós-graduação em Metrologia (Área de concentração: Metrologia para Qualidade e Inovação), Pontifícia Universidade Católica do Rio de Janeiro.

O para-raios é o principal equipamento de proteção dos transformadores e linhas de transmissão de energia, que estão presentes em todo território nacional, protegendo-os de descargas atmosféricas e sobretensão, evitando grandes perdas de equipamentos e um custo relativamente alto para as concessionárias de energia. O para-raios precisa obter conformidade e certificação em relação à qualidade do material e a suas características de proteção, e um dos ensaios de verificação de desempenho baseia-se na resposta ao impulso de corrente. Contudo, para a realização destes ensaios de desempenho é necessário que haja um sistema de medição acreditado, apto a realizá-los com precisão e rastreabilidade aos padrões de transdutores, ou seja, com níveis de incerteza dentro dos limites aceitáveis, segundo a norma IEC 62475:2010. O Inmetro, que é o Instituto Nacional de Metrologia do Brasil, ainda não possui um Sistema de Medição de Referência (SMR) que possa ser empregado na fiscalização e acreditação de laboratórios que venham a exercer a função de Sistema de Medição Aprovado (SMA), levando a rastreabilidade e conformidade aos padrões de transdutores de corrente elétrica, de modo a produzir equipamentos com confiabilidade e segurança. Assim, essa dissertação faz um levantamento dos níveis de rastreabilidade e um estudo normativo e estrutural de ensaios de impulso de corrente, à luz da norma IEC 62475:2010.

\section{Palavras-chave}

Metrologia; rastreabilidade; corrente elétrica; impulso de corrente; IEC 62475; instrumento de medição. 


\section{Abstract}

Faria, Lucas Castro; Barbosa, Carlos Roberto Hall (Advisor). Metrological Traceability of Electrical Current Impulses in Brazil. Rio de Janeiro, 2014. 111p. MSc. Dissertation - Programa de Pós-graduação em Metrologia (Área de concentração: Metrologia para Qualidade e Inovação), Pontifícia Universidade Católica do Rio de Janeiro.

The surge arrester is the main protection equipment of the power transformers and power transmission lines, which are present throughout the country, protecting them from lightnings and overvoltage, avoiding large equipment failures and a relatively high cost for the power companies. The arrester must obtain conformity and certification regarding the quality of the material and its safety features, and one of the performance verification tests is based on the response to current impulses. However, to realize these performance tests it is necessary to have a measurement system accredited to perform this type of test, with accuracy and traceability of the standard transducers, that is, uncertainty levels within acceptable limits according to IEC 62475:2010. The Brazilian National Institute of Metrology ( INMETRO) does not have a Reference Measuring System (RMS) that can be used in the inspection and accreditation of laboratories that will perform as a Approved Measuring System, giving traceability and conformity to the electrical current transducers standards (Shunts or CTs), so as to produce reliable and safe equipments. Thus, this dissertation surveys the traceability levels and the normative and structural landscape regadring current impulse tests based on IEC 62475:2010.

\section{Keywords}

Metrology; traceability; electrical current; current impulse; IEC 62475:2010; measuring instrument. 


\section{Sumário}

1 Introdução 12

$\begin{array}{ll}\text { 1.1. Objetivo } & 15\end{array}$

1.2. Conceitos Básicos 16

$\begin{array}{ll}\text { 1.3. Estrutura da Dissertação } & 18\end{array}$

2 A Grandeza Corrente Elétrica $\quad 19$

2.1. Definição 20

2.2. Unidade de Corrente Elétrica no SI 21

2.3. Definição do ampere 21

2.4. Tipos de Corrente Elétrica 22

2.5. Níveis de Corrente Elétrica 25

3 Transdutores $\quad 27$

3.1. Shunt de Corrente 27

3.2. TC - Transformador de Corrente 32

$\begin{array}{ll}\text { 3.3. Outros Transdutores } & 37\end{array}$

4 Confiabilidade Metrológica de Impulsos de Corrente 42

4.1. IEC - International Electrotechnical Commission 42

4.2. Ensaios de Impulso de Corrente 47

5 Demanda por Ensaios de Equipamentos com Impulso de Corrente 59

5.1. Para-raios 59

$\begin{array}{ll}\text { 5.2. Aeronaves } & 67\end{array}$

6 Infraestrutura para Calibração e Rastreabilidade de Impulsos de $\begin{array}{ll}\text { Corrente } & 77\end{array}$

$\begin{array}{ll}\text { 6.1. SMRs } & 77\end{array}$

6.2. Sistemas de Medição Aprovados - SMAs 87

6.3. Caracterização de um SMR Nacional para Calibração de 
7 Conclusão e Trabalhos Futuros

106

Referências Bibliográficas 


\section{Lista de Figuras}

Figura 1: Alessandro Volta e a pilha voltaica 19

Figura 2: Estrutura do átomo 20

Figura 3: Definição do ampere 22

Figura 4: Forma de onda do impulso de corrente exponencial (IEC 62475) 25

Figura 5: Shunt e diagrama esquemático 28

Figura 6: Shunt: (1) Porta de entrada da corrente, (2) Conexão Shunt-Terra e (3) Porta de saída do sinal de tensão 29

Figura 7: Especificações do Shunt № 02

Figura 8: Tabela de dimensionamento de Shunts da KDSI 31

Figura 9: Monitoramento da corrente através de um TC 33

Figura 10: TC - enrolado 33

Figura 11: TC - barra 34

Figura 12: TC - janela 34

Figura 13: TC - bucha 35

Figura 14: TC - dividido ou separado 35

Figura 15: Circuito equivalente de um TC 36

Figura 16: Boobina de Rogowski 38

Figura 17: Sensor hall de corrente CC 39

Figura 18: Estrutura interna de um sensor magnético Hall integrado, com concentradores magnéticos gêmeos. 40

Figura 19: Concentradores de campo refletindo o campo na direção vertical. As duas pequenas cruzes sob os concentradores são sensores Hall.

Figura 20: Aplicação de detecção de corrente do Sensor magnético hall de corrente integrado por um condutor de circuito impresso (a) e um condutor de posição livre (b).

Figura 21: Sistema de medição do CA2 46

Figura 22: CEPEL Como SMR e SMA

Figura 23: Forma de onda do impulso de corrente exponencial 48 
Figura 24: Forma de onda do impulso de corrente exponencial oscilação na cauda

Figura 25: Forma de onda do impulso de corrente - retangular, suave

Figura 26: Forma de onda do impulso de corrente - retangular com oscilação

Figura 27: Para-raios de carboneto de silício ( $\mathrm{SiC})$

61

Figura 28: Para-raios de óxido de zinco ( $\mathrm{ZnO})$

Figura 29: Formas de onda idealizadas $A$ e $B$ 69

Figura 30: Formas de onda idealizadas C e D 70

Figura 32: Ensaio T01 no lab. Alta Tensão do CEPEL 73

Figura 33: Ensaio T01 no lab. Alta Tensão do CEPEL 74

Figura 34: Ensaio T02 no lab. de para-raios do CEPEL 74

Figura 35: Ensaio T02 no CEPEL

Figura 36: Ensaio T02 no CEPEL 75

Figura 37: Ensaio T03 76

Figura 38: Sistema de medição de referência de alta tensão alternada e corrente alternada no Lamat $\quad 83$

Figura 39: LAT - Unicamp 93

Figura 40: Sistema gerador de impulsos de corrente da USP 94

Figura 41: Hierarquia do sistema metrológico 95

Figura 42: Pirâmide de rastreabilidade do impulso de corrente 97

Figura 43: Gerador de impulsos EMC 2002

Figura 44: Transdutor do sistema de medição de impulsos de corrente 99

Figura 45: TCs encomendados pelo CEPEL sob especificações 101

Figura 46: Cabo coaxial de malha dupla 102

Figura 47: Atenuador/casador para cabos de $75 \Omega$

Figura 48: Sistema de medição utilizando osciloscópio 103

Figura 49: HIAS743 104

Figura 50: Sistema de medição utilizando HiAS 105 


\section{Lista de tabelas}

Tabela 1: Incerteza do digitalizador $\quad 45$

Tabela 2: Lista dos ensaios específicos com impulso de corrente exponencial 52

Tabela 3: Ensaios aplicáveis em um SMA 56

Tabela 4: Serviços de calibração em alta tensão, fonte MIKES 79

Tabela 5: Faixas de operação do PTB aprovadas pelo BIPM em 201381

Tabela 6: Formas de onda do CPRI $\quad 89$

Tabela 7: Ensaios realizados no LAT - Unicamp 92

Tabela 8: Requisitos de um SMA 96 


\section{Lista de quadros}

Quadro 1: Estrutura Organizacional da IEC em maio de 2014

Quadro 2: Comitês e Subcomitês da IEC 43

Quadro 3: Diferenças entre tecnologias dos tipos de para-raios 65

Quadro 4: Aplicação de forma de onda por métodos de ensaio 72 


\section{Introdução}

O sistema elétrico de potência no Brasil passou por um período de crescimento nas décadas de 70 e 80 com a construção das hidrelétricas de grande porte e novamente está em um período transitório de mudanças, com novas hidrelétricas e linhas de transmissão com recordes de distância.

O Brasil já passou por algumas crises na sua história no setor elétrico, como o apagão e racionamento de 2001, que forçou mudanças e transformações de planejamento e infraestrutura. Em 2012 havia no país 201 hidrelétricas em funcionamento que produziam 78909 MW [1], e muitas estão sendo planejadas e em fase de construção.

A região de maior consumo de energia é a região sudeste e muitas destas hidrelétricas estão na região norte do país, o que exige longas linhas de transmissão de energia.

No Brasil, alguns casos de apagão ou blecaute devido a descargas elétricas já foram registrados [2]. Para diminuir o risco disto ocorrer, o sistema de proteção das redes elétricas ou dos equipamentos deve possuir conformidade e rastreabilidade nos sistemas de ensaios. A principal peça do sistema de proteção dos equipamentos é o para-raios, instalado nos terminais dos transformadores de potência e entre os terminais das linhas de transmissão, distribuídos durante o percurso.

O mau funcionamento do para-raios pode provocar a queda de tensão ou rompimento da linha de transmissão, ficando esta desativada até ser religada, e pode provocar a queima do transformador. Nesta situação a rede é desativada até a troca do equipamento defeituoso, sendo o transformador de potência em alta tensão o principal ativo do sistema elétrico de potência e o mais caro. Assim, a não conformidade do para-raios coloca em risco o funcionamento de todo um sistema.

O Centro de Pesquisa de Energia Elétrica (CEPEL) está diretamente relacionado ao setor elétrico brasileiro, realizando pesquisas nas áreas de baixa, 
média e alta tensão, sendo uma referência em pesquisas e ensaios de alta tensão no Brasil e na América do Sul. Hoje seus laboratórios de alta tensão já são acreditados para calibração de impulso de tensão de até $500 \mathrm{kV}$, além de realizarem calibrações em correntes alternadas, $60 \mathrm{~Hz}$, e ensaios em equipamentos com impulso de tensão de até $4 \mathrm{MV}$. Os laboratórios de calibração do CEPEL ainda não realizam calibração com impulso de corrente, mas estão se estruturando para buscar acreditação perante o Inmetro e poder fornecer certificados de calibração.

Tendo em vista o alcance da conformidade dos ensaios com impulso de corrente no Brasil, essa dissertação foi realizada com a finalidade de levantar informações detalhadas sobre a regulamentação do ensaio e a demanda de clientes produtores que utilizam esse tipo de ensaio, para testar seus produtos. Também fez-se um levantamento da rastreabilidade metrológica do impulso de corrente, identificando e analisando os laboratórios de referência internacional, os laboratórios aprovados em nível internacional e o que existe de suporte para esse ensaio em território nacional.

Foram analisadas também as características de um SMR (Sistema de Medição de Referência) para medição de impulso de corrente e descritos os componentes e níveis de incerteza necessários para que o sistema de medição seja acreditado como um SMR.

\section{1.}

\section{Objetivo}

O objetivo dessa dissertação é traçar a rastreabilidade do impulso de corrente, apresentando a rede de calibração de sistemas de medição com impulso de corrente, normalização de técnicas de ensaio, equipamentos de demanda, órgãos nacionais e internacionais ligados à rastreabilidade dos ensaios e caracterização de um Sistema de Medição de Referência nacional (SMR). A análise destes dados permite que se avalie como está desenvolvida e edificada esta grandeza no país e quais são os próximos passos que podem e devem ser dados para que os equipamentos que necessitam de calibração estejam em conformidade.

Com isso esta dissertação busca responder as seguintes questões: 
- Quais são as camadas da pirâmide de rastreabilidade do impulso de corrente?

- Como seria caracterizado um SMR nacional? Quais são seus elementos e níveis de incerteza necessários? Quais exigências deveriam ser respeitadas para a conformidade do ensaio de calibração de sistemas de medição e de transformadores de corrente?

- Qual é a demanda deste ensaio? Quais são os equipamentos que necessitam deste ensaio e qual a importância deles para o sistema elétrico nacional?

- Quais normas regulam e especificam os elementos dos sistemas de medição e as técnicas aplicadas no ensaio?

Desta forma, o objetivo principal é apresentar uma visão panorâmica do ensaio de impulso de corrente, desde os padrões com menores níveis de incerteza do BIPM, ao equipamento de chão de fábrica ensaiado e certificado quanto à sua conformidade. Além disso, buscou-se evidenciar a estrutura hoje presente e as lacunas que permitem que equipamentos sejam liberados e utilizados sem a devida conformidade.

\section{2.}

\section{Conceitos Básicos}

Descreve-se a seguir algumas definições e conceitos básicos utilizados nessa dissertação. Parte dos conceitos foi retirada do Vocabulário Internacional de Metrologia (VIM) [3] e da norma IEC 62475 [4].

Instrumento de medição: Dispositivo utilizado para realizar medições, individualmente ou associado a um ou mais dispositivos suplementares $[3,4]$.

Sistema de medição: Conjunto de um ou mais instrumentos de medição e frequentemente outros dispositivos, compreendendo, se necessário, reagentes e insumos, montado e adaptado para fornecer informações destinadas à obtenção dos valores medidos, dentro de intervalos especificados para grandezas de naturezas especificadas [3].

Sistema de medição de referência para ensaios de corrente: Sistema de medição com calibração rastreável a padrões nacionais ou internacionais, devendo ter precisão e estabilidade suficientes para uso na aprovação de outros sistemas, 
realizando medições comparativas simultâneas com tipos específicos de ondas e faixas de corrente [4].

Rastreabilidade metrológica: Propriedade de um resultado de medição pela qual tal resultado pode ser relacionado a uma referência através de uma cadeia ininterrupta e documentada de calibrações, cada uma contribuindo para a incerteza de medição [3].

Transformador de corrente: instrumento de transformação no qual a corrente secundária, em condições normais de operação, é substancialmente proporcional à corrente primária e apresenta uma diferença de fase de aproximadamente nula para uma direção apropriada das ligações [4].

Transdutor de medição: Dispositivo, utilizado em medição, que fornece uma grandeza de saída, a qual tem uma relação especificada com uma grandeza de entrada [3].

Calibração: Operação que estabelece, sob condições especificadas, em uma primeira etapa, uma relação entre os valores e as incertezas de medição fornecidos por padrões e as indicações correspondentes com as incertezas associadas; em uma segunda etapa, utiliza esta informação para estabelecer uma relação visando à obtenção de um resultado de medição a partir de uma indicação [3].

INMETRO: Instituto Nacional de Metrologia, Qualidade e Tecnologia Sua missão é prover confiança à sociedade brasileira nas medições e nos produtos, por meio da metrologia e da avaliação da conformidade, promovendo a harmonização das relações de consumo, a inovação e a competitividade do país $[5]$.

Acreditação: Atestação de terceira-parte relacionada a um organismo de avaliação da conformidade, comunicando a demonstração formal da sua competência para realizar tarefas específicas de avaliação da conformidade [29].

Acreditação é o reconhecimento formal por um organismo de acreditação, de que um organismo de Avaliação da Conformidade - OAC (laboratório, organismo de certificação ou organismo de inspeção) atende a requisitos previamente definidos e demonstra ser competente para realizar suas atividades com confiança [30]. 


\section{3.}

\section{Estrutura da Dissertação}

Esta dissertação de mestrado estrutura-se com base nos seguintes 7 capítulos:

Capítulo 1: Introdução (motivação, contexto, objetivo, conceitos básicos e estrutura da dissertação).

Capítulo 2: Grandeza corrente elétrica, definição e padrão SI do Ampere, tipos de corrente elétrica, e níveis de teste e de operação da corrente elétrica.

Capítulo 3: Medição de corrente elétrica, os transdutores utilizados para medição de corrente, Shunt, Transformador de Corrente (TC) e outros transdutores de corrente como bobina de Rogowski e sensores de Efeito Hall.

Capítulo 4: Estruturas de confiabilidade metrológica para o Impulso de Corrente, um resumo da Comissão Eletrotécnica Internacional (IEC), detalhes das principais normas vinculadas ao ensaio com Impulso de Corrente, resumo direcionado sobre o ensaio com Impulso de Corrente da norma IEC $62475 \mathrm{High}$ current test techniques - Definitions and requirements fot test currents and measuring systems.

Capítulo 5: Os equipamentos e dispositivos que formam a demanda de objetos alvos para o ensaio de impulso de corrente. As principais normas e regulamentos relacionados aos equipamentos. Ensaios realizados em para-raios, aeronaves e transformadores de potência.

Capítulo 6: Infraestrutura para calibração e rastreabilidade metrológica com impulso de corrente.

- A estrutura internacional de Sistemas de Medição de Referência (SMR), MIKES e PTB, e projeção futura de um SMR nacional, Inmetro e CEPEL.

- Sistemas de Medição Aprovados (SMA) internacionais e nacionais, laboratórios que possuem estrutura de ensaio com Impulso de Corrente.

- Caracterização da infraestrutura de um SMR nacional e mapeamento da pirâmide de rastreabilidade metrológica do impulso de corrente.

Capítulo 7: Conclusões e recomendações 


\section{2}

\section{A Grandeza Corrente Elétrica}

A unidade padrão da grandeza corrente elétrica é o Ampere, uma das sete unidades de base do Sistema Internacional de unidades (SI) [5]. O primeiro registro de uma fonte de corrente elétrica estável foi no final do século XVIII quando Alessandro Volta (Figura 1) inventou a primeira pilha, que foi chamada de pilha voltaica, que consistia em uma série de discos de cobre e de zinco alternados, separados por pedaços de papelão embebidos por água salgada. Após esta invenção as investigações e pesquisas sobre a corente elétrica cresceram cada vez mais.

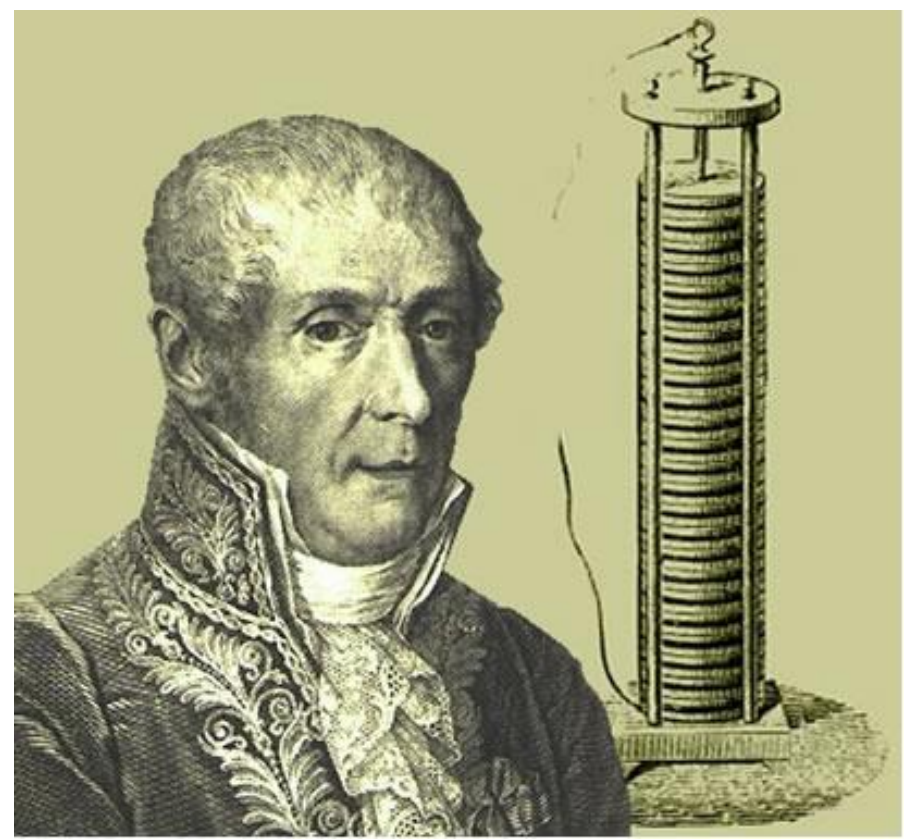

Figura 1: Alessandro Volta e a pilha voltaica

Neste capítulo será realizada uma pesquisa das características e avanços nas pesquisas relacionadas à grandeza corrente elétrica. 


\section{1. Definição}

Todos os átomos são compostos por partículas subatômicas denominadas prótons, nêutrons e elétrons, tendo estas cargas positivas, neutras e negativas, respectivamente. A carga do elétron, uma de suas propriedades básicas, é -1,603 x $10^{-19}$ coulombs, sendo o coulomb (C) a unidade de carga no Sistema Internacional de Unidades (SI). A Figura 2 apresenta a estrutura atômica.

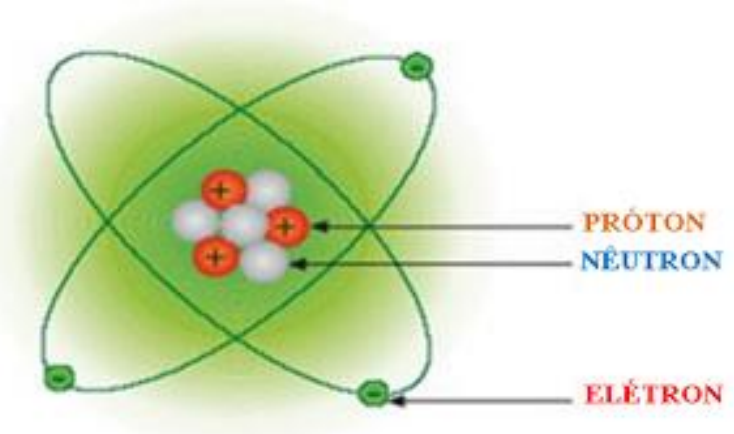

Figura 2: Estrutura do átomo

Os elementos químicos condutores são aqueles cujos elétrons de valência estão fracamente ligados ao átomo, podendo facilmente transicionar para a banda de condução. Um exemplo é o cobre, que possui somente um elétron na última camada, assim como o ouro e a prata. Tais elementos químicos são denominados metais, e as estruturas metálicas exibem uma grande quantidade de elétrons livres, que são compartilhados entre os diversos átomos que as compõem. Tais estruturas são comumente denominadas condutores elétricos.

A corrente elétrica é associada ao movimento dos elétrons em um condutor, causado pela diferença de potencial elétrico entre as extremidades do condutor. $\mathrm{O}$ potencial elétrico pode ser entendido de forma análoga ao potencial gravitacional, que aumenta à medida que o corpo se desloca no sentido contrário à força gravitacional, e faz com que o corpo, se solto, retorne ao ponto de menor potencial gravitacional. Já os elétrons, por terem carga negativa, movem-se do ponto de potencial elétrico menos positivo para o ponto de potencial elétrico mais positivo.

Contudo, tradicionalmente a corrente elétrica é representada pelo movimento de cargas positivas. Assim, o fluxo de corrente convencional, que é oposto ao fluxo de elétrons, ocorre do potencial mais positivo para o potencial 
menos positivo (dessa forma mantendo diretamente a analogia com o potencial gravitacional). Esta convenção foi criada por Benjamim Franklin, o primeiro grande cientista americano a estudar a eletricidade, sendo o responsável pela criação do primeiro para-raios [37].

Assim, a corrente elétrica pode ser definida como o movimento ordenado de partículas carregadas eletricamente (elétrons) que na natureza se encontram livres e em agitação conforme as condições térmicas do ambiente.

A corrente elétrica é quantificada pela taxa de variação temporal da carga elétrica em um determinado ponto, representada pela equação (1)

$$
i=\frac{d q}{d t}
$$

\section{2.}

\section{Unidade de Corrente Elétrica no SI}

O ampere (A) foi adotado como unidade da grandeza intensidade de corrente elétrica no $9^{\circ}$ CGPM (Conferência Geral de Pesos e Medidas de 1948), em homenagem a André M. Ampère (1775-1836), sendo um ampere equivalente a um coulomb (C) por segundo:

$$
1 \mathrm{~A} \equiv 1 \mathrm{C} / \mathrm{s}
$$

Convencionalmente, o símbolo da grandeza corrente elétrica é $I$ ou $i$. A corrente elétrica é uma das 7 grandezas de base do SI, sendo usada para definir diversas outras grandezas derivadas, como a tensão elétrica (ou diferença de potencial elétrico), a resistência elétrica e a carga elétrica.

\section{3.}

\section{Definição do ampere}

O ampere é a intensidade de uma corrente elétrica constante que, se mantida em dois condutores paralelos, retilíneos, de comprimento infinito, de seção circular desprezível, e situados à distância de 1 metro entre si, no vácuo, produz entre estes condutores uma força igual a $2 \times 10^{-7}$ newton por metro [5]. A Figura 3 ilustra a definição do Ampere. 


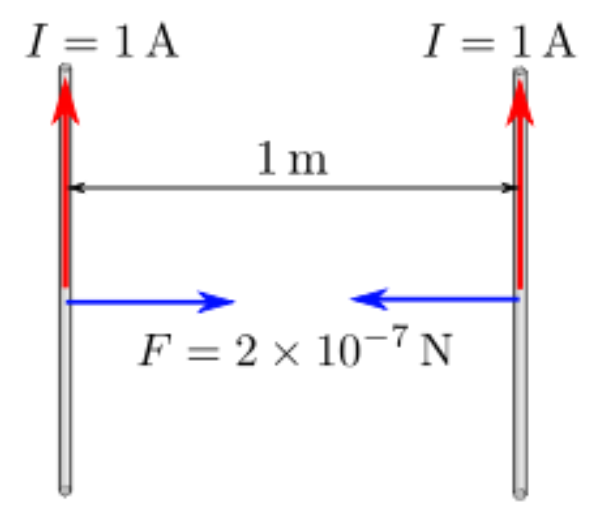

Figura 3: Definição do ampere

A análise da unidade ampere deixa claro que a reprodução prática se torna extremamente complicada e com nível de incerteza alto. Desta forma o BIPM recomenda que o ampere seja realizado através das unidades watt, ohm e volt.

A reprodução com o nível de incerteza mais baixo até então realizado se dá por meio do método chamado Balança de Watt [7], com nível de incerteza relativa de $3,6 \times 10^{-8}$ que foi alcançado pelo US National Institute of Standards and Technology (NIST). Outra realização do ampere ocorre por meio das unidades volt e ohm, respectivamente das grandezas tensão e resistência elétrica. Desta forma, usando o Efeito Josephson e o Efeito Hall Quântico [6,7], que permitem a realização das unidades de tensão e resistência, é possível chegar a uma realização da unidade de corrente com uma incerteza baixa, sendo esse método o mais utilizado nas calibrações e ensaios de análise da grandeza corrente [6].

\section{4.}

\section{Tipos de Corrente Elétrica}

É comum a corrente elétrica ser diferenciada entre corrente alternada (CA) e corrente contínua (CC), mas existe também o impulso de corrente, que era caracterizado como um tipo de corrente alternada, mas suas características são bem distintas. Desta forma, atualmente o impulso de corrente é reconhecido como um tipo de específico de corrente.

Nesta subseção serão apresentadas estas diferenças e características únicas de cada tipo de corrente. 


\subsection{1. \\ Corrente Contínua - CC}

Nos laboratórios internacionais, com base no modelo do efeito Josephson, para se alcançar um nível de tensão na ordem de $1 \mathrm{~V}$ é necessário utilizar um circuito "chip" com capacidade de distribuição da fonte de microondas para alguns milhares de junções (para $1 \mathrm{~V}$ precisa-se de cerca de 3600 junções, e para 10 V é necessário um "array" com 20000 junções). A tensão gerada por esse efeito é uma tensão em corrente contínua e, para ser utilizado como padrão para tensão em corrente alternada, é utilizado um transferidor térmico padronizado e calibrado por um dos institutos acreditados pelo BIPM. Essa é a base para a reprodução do volt pelo SI [5].

A corrente contínua CC é a corrente elétrica que flui pelo condutor sempre no mesmo sentido, ou seja, sempre positiva ou negativa, e com intensidade constante, sendo geralmente representada por $I$.

A energia elétrica utilizando corrente contínua, criada por Thomas Edison no século XIX, não permitia a utilização de transformadores e demandava uma grande quantidade de cabeamento para a transmissão da energia na rede urbana. Por isso é muito comum o uso da corrente contínua em circuitos elétricoeletrônicos pequenos, alimentados por baterias ou fontes de tensão contínuas.

Recentemente, pesquisas revelam que, para grandes distâncias (acima de $1000 \mathrm{~km}$ ), a transmissão com corrente CC apresenta um melhor custo benefício.

\subsection{2.}

\section{Corrente Alternada - CA}

A corrente alternada, ou CA, é uma corrente elétrica que alternadamente percorre o condutor em um sentido e posteriormente no sentido contrário. Foi criada por Nikola Tesla no final do século XIX e disputou o mercado norte americano com Thomas Edison. Com o passar do tempo ficaram claras as vantagens do uso da corrente alternada nas indústrias e para a transmissão com baixa perda de energia entre a usina produtora e as cidades e indústrias consumidoras da energia elétrica. A forma mais simples de alternância é a onda senoidal, que pode ser representada conforme a equação (3).

$$
i_{\mathrm{s}}=I_{\mathrm{m}} \cdot \operatorname{sen}(\omega t)
$$


De modo que $I_{\mathrm{m}}$ é a amplitude em amperes, $\omega$ é a frequência angular em $\mathrm{rad} / \mathrm{s}$. A senóide é uma função periódica no tempo, possuindo a seguinte propriedade:

$$
x(t+T)=x(t)
$$

para qualquer valor de $t$, onde $T$ é o período de oscilação.

O recíproco de $T$ é a frequência de oscilação, definida na equação (5), representada por $f$, onde

$$
f=\frac{1}{T} .
$$

A unidade que representa a grandeza frequência no SI é o hertz $(\mathrm{Hz})$ em homenagem ao cientista Heinrich Hertz. A relação entre a frequência angular e a frequência de uma senóide é

$$
\omega=2 \pi f=\frac{2 \pi}{T} .
$$

A unidade da frequência angular $\omega$ no SI é o radiano por segundo ( $\mathrm{rad} / \mathrm{s})$.

Se a corrente senoidal possui um ângulo de fase $\phi$, medido em radianos, e $I_{\mathrm{m}}$ é a corrente máxima, a corrente é dada pela expressão:

$$
i_{\mathrm{s}}=I_{\mathrm{m}} \cdot \operatorname{sen}(\omega t+\phi) \text {. }
$$

O ângulo de fase e a frequência angular são normalmente medidos em radianos, entretanto também podem ser expressos em graus, desde que fique bem claro qual notação está sendo usada.

Os ensaios com corrente alternada em alta tensão recebem uma sigla diferenciada (ATCA ou HVAC), assim como os ensaios com corrente contínua em alta tensão (ATCC ou HVDC).

\subsection{3.}

\section{Impulso de Corrente Elétrica}

O impulso de corrente elétrica é uma variação brusca da corrente elétrica, seja de maneira crescente (por exemplo, da corrente nula até um valor positivo, ou de uma corrente negativa até corrente nula) ou de maneira decrescente (por exemplo, da corrente nula até um valor negativo, ou de uma corrente positiva até a corrente nula).

Ocorre naturalmente no caso de descargas atmosféricas ou de descargas eletrostáticas. O impulso de corrente também pode ser produzido a partir de um 
gerador de impulsos, que consiste em carregar capacitores em paralelo, alimentados por uma fonte de corrente contínua, e posteriormente descarregar os capacitores no terminal de alta tensão do objeto sob ensaio.

O impulso elétrico ideal é definido como um ponto de amplitude infinita em um tempo infinitesimal, mas a forma de onda de um impulso de corrente realizado em laboratório assemelha-se ao impulso elétrico atmosférico, com crescimento rápido até atingir o ponto de amplitude máxima e uma descarga lenta. A Figura 4 apresenta um exemplo de impulso de corrente típico.

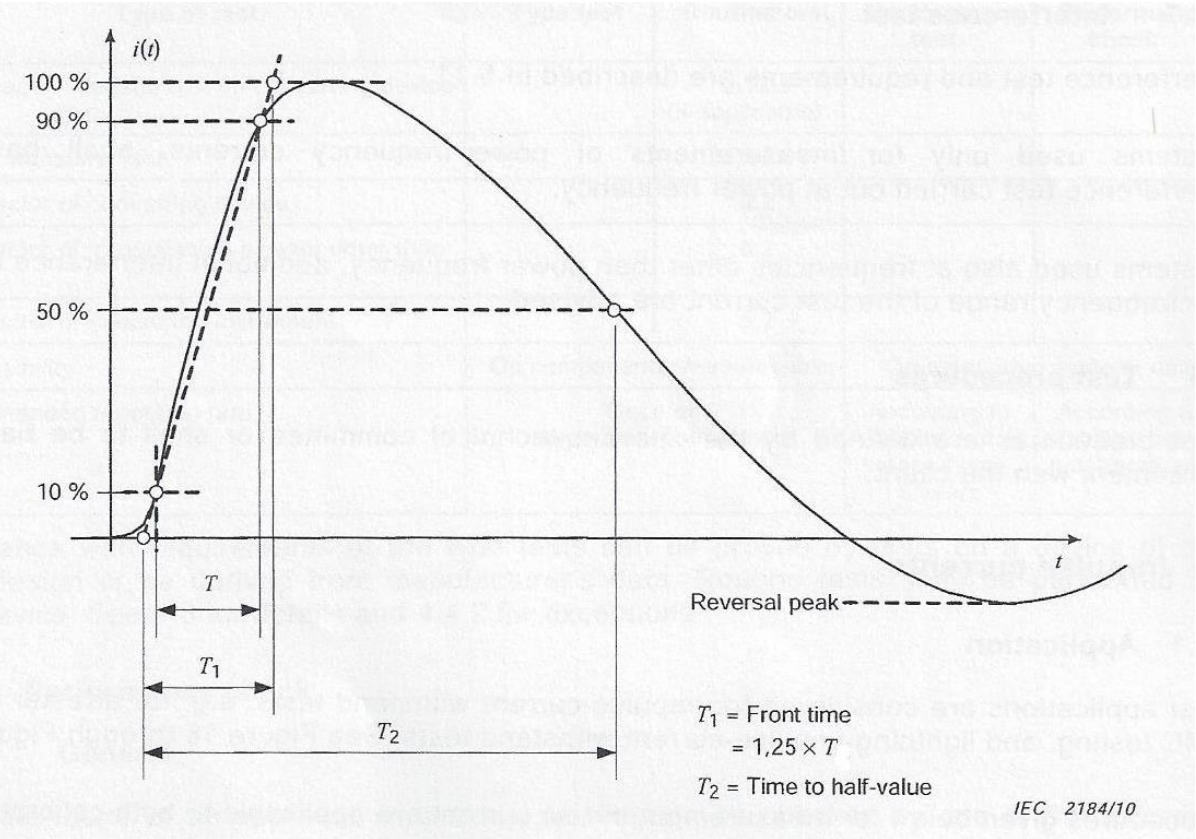

Figura 4: Forma de onda do impulso de corrente exponencial (IEC 62475)

\section{5 .}

\section{Níveis de Corrente Elétrica}

Os níveis de corrente no ensaio são diretamente ligados ao objeto alvo de calibração e as suas condições de trabalho. Portanto, existem os considerados ensaios de baixa corrente e alta corrente. A NR 10 da ABNT [32] define como sendo de alta tensão os ensaios acima de $1000 \mathrm{~V}$ em corrente alternada e $1500 \mathrm{~V}$ em corrente contínua, ensaios de baixa tensão entre $50 \mathrm{~V}$ e $1000 \mathrm{~V}$ em corrente alternada e entre $120 \mathrm{~V}$ e $1500 \mathrm{~V}$ em corrente contínua, e ensaios de extra-baixa tensão com menos de $50 \mathrm{~V}$ em corrente alternada e $120 \mathrm{~V}$ em corrente contínua. Contudo, não há uma definição formal para os níveis de ensaios de corrente, 
sendo, portanto, comumente considerados como de alta corrente os ensaios acima de 100 A, seja em CA ou CC.

O nível de corrente durante os ensaios é requisito para segurança dos equipamentos de medição e para o nível de incerteza no cálculo dos parâmetros. 


\section{3 \\ Transdutores}

Um transdutor de corrente é um dispositvo que fornece uma grandeza de saída, geralmente tensão, em resposta a uma grandeza de entrada, corrente, com uma relação especificada.

Existe uma variedade de transdutores de corrente no mercado mundial e alguns possuem as características específicas para realizar as medições demandadas por um sistema de medição com impulso de corrente, características estas como: bom tempo de resposta para altas frequências, alta sensibilidade, entre outras que serão apresentadas nos modelos de transdutores neste capítulo.

Neste capítulo serão apresentados alguns dos modelos mais encontrados na indústria elétrica e nos laboratórios de pesquisa.

\section{1.}

\section{Shunt de Corrente}

O shunt de corrente é um dos transdutores para medição de corrente utilizados em ensaios de impulsos de corrente [7,33,34].

Trata-se basicamente de um resistor de precisão, com valor resistivo baixo (tipicamente na faixa de décimos de ohms), que é conectado em série com o circuito no qual se deseja medir o impulso de corrente elétrica. É importante que o shunt seja posicionado no final do circuito, ou seja, um de seus terminais de saída deve estar conectado ao terra do circuito. Um instrumento de medição (voltímetro ou osciloscópio) é colocado em paralelo com o shunt, conforme ilustrado na Figura 5, a fim de se relacionar a corrente que flui pelo shunt com a tensão que aparece em seus terminais. 

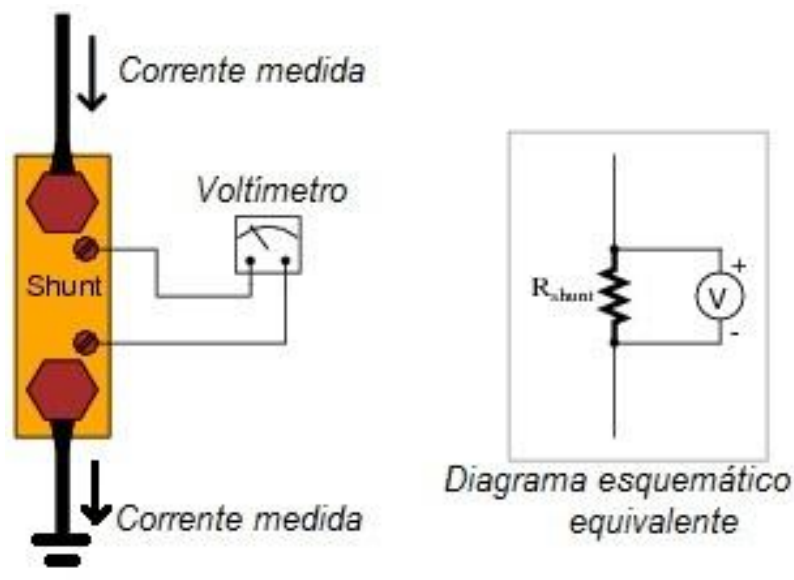

Figura 5: Shunt e diagrama esquemático

No sistema de medição para impulso, o voltímetro na Figura 5 é dotado de uma interface gráfica de precisão que é capaz de fornecer uma indicação visual dos dados resultantes do ensaio e apresentar as oscilações e variações da corrente no impulso gerado no ensaio. É importante que essa interface gráfica esteja satisfatoriamente isolada do sistema, para não permitir passagem de corrente pela mesma. Caso a corrente do ensaio passe pela interface, o resultado do ensaio estará comprometido e o equipamento poderá sofrer avarias. Desta forma a impedância de entrada da interface deverá ser significativamente superior à do shunt, de modo a garantir que a corrente passe inteiramente pelo shunt.

A Figura 6 é um exemplo de shunt utilizado nos laboratórios do CEPEL. 


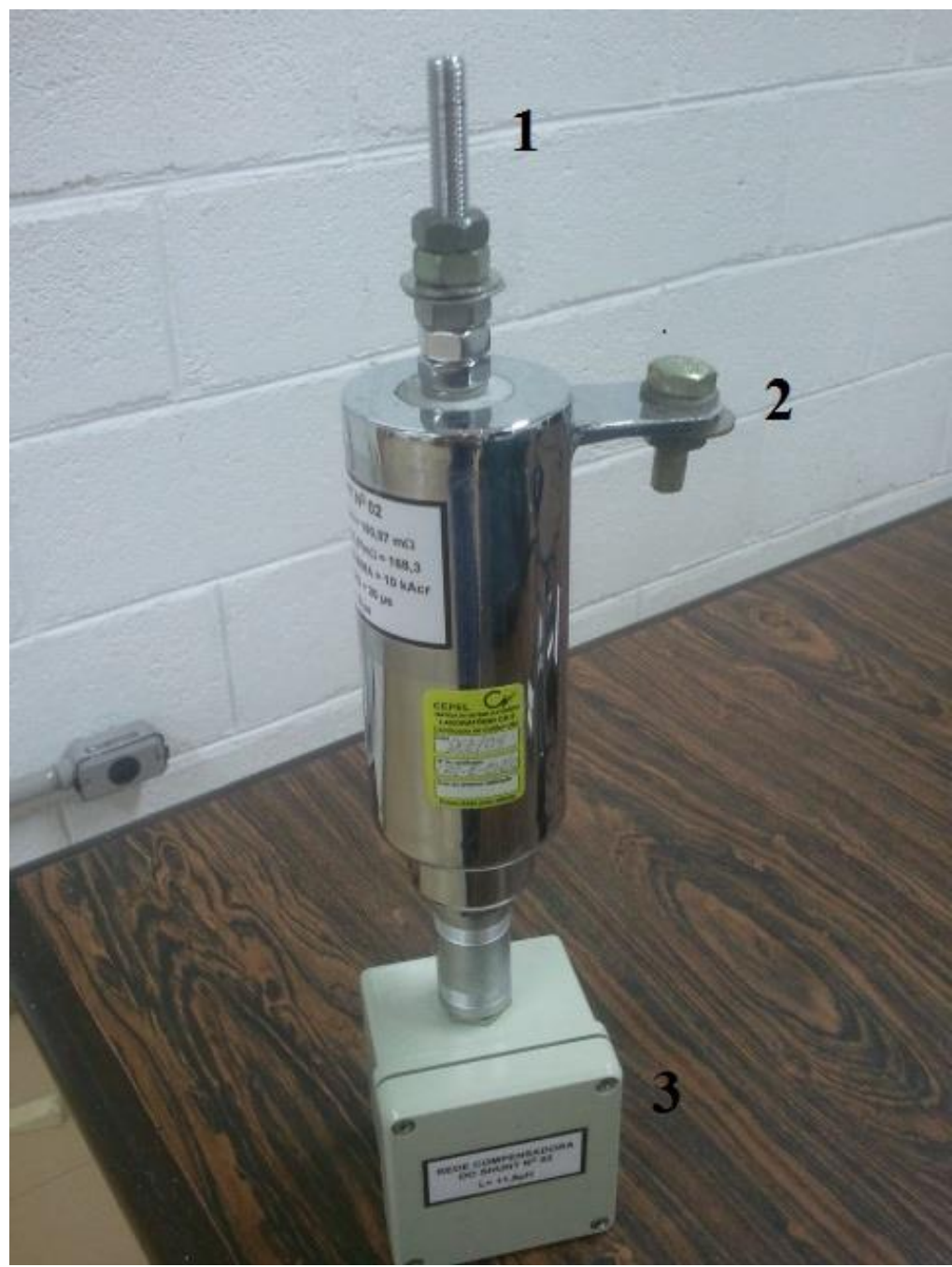

Figura 6: Shunt: (1) Porta de entrada da corrente, (2) Conexão Shunt-Terra e (3) Porta de saída do sinal de tensão

Cada Shunt é desenvolvido para um determinado tipo de ensaio e portanto possui uma configuração específica. A Figura 7 apresenta exemplos de especificações de um Shunt. 


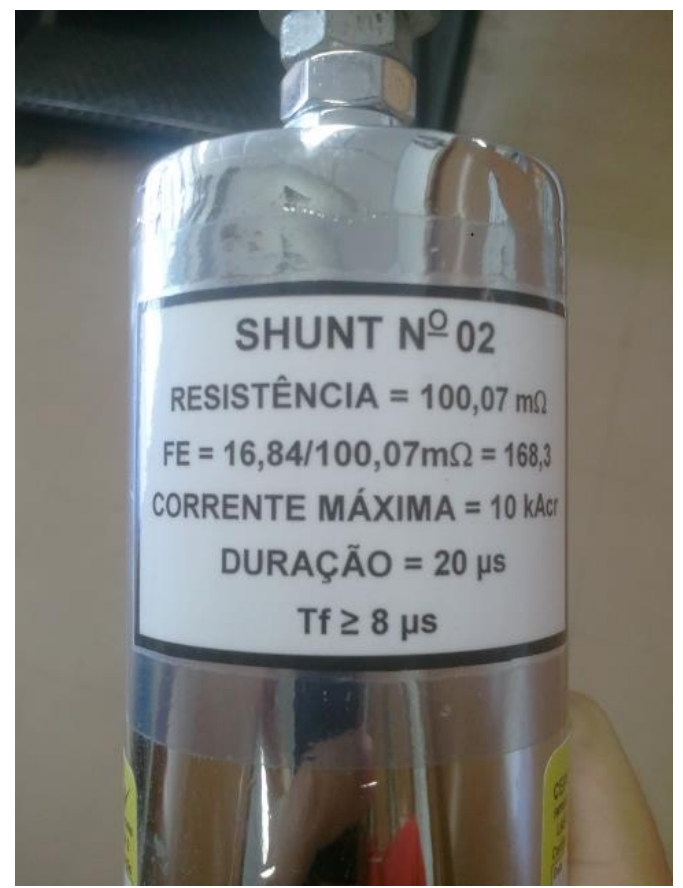

Figura 7: Especificações do Shunt № 02

Na Figura 7 é possível identificar diversas especificações do modelo utilizado nos laboratórios do CEPEL,para o qual tem-se:

- Resistência $(100,07 \mathrm{~m} \Omega)$ : O valor de resistência identificado no shunt está diretamente associado ao valor do fator de escala utilizado o para cálculo dos parâmetros de corrente medidos;

- FE (168,3): O fator de escala é a constante, do modelo de shunt utilizado, que representa a razão entre o valor de tensão medido pelo voltímetro e a corrente em escala real que passa pelo shunt;

- Corrente Máxima (10 kAcr, essa é uma terminologia interna utilizado pelo CEPEL, significa que são $10 \mathrm{kA}$ de "crista", ou seja, $10 \mathrm{kA}$ de pico): O valor de pico ou a amplitude máxima que o modelo suporta;

- Duração (20 $\mu$ s): O tempo de cauda (definido na seção 4,2,1) do ensaio para o qual o shunt foi projetado para medir;

- $T f$ ( $\geq 8 \mu \mathrm{s}$ ): O tempo de frente é o tempo entre $10 \%$ e $90 \%$ do valor de pico do impulso multiplicado pela constante 1,25. Da mesma forma que a duração, o $T f$ é importante para a especificação do tipo de ensaio para o qual o shunt foi projetado.

A Duração e o tempo de frente $(T F)$ são medidas específicas, o ensaio não devendo ser realizado com tempos maiores ou menores que os definidos.

Apresenta-se na Figura 8 a seguir uma tabela com o dimensionamento de alguns modelos de shunt da empresa KDSI, sendo estes modelos para medição de correntes entre 10 A e 5000 A. Esses são exemplos de shunts para CC ou CA. 
Esse tipo de construção não se aplica para medição de impulsos de corrente, pois a frequência é muito maior e o tempo de resposta muito menor no ensaio de impulso em relação ao ensaio com CC ou CA (mais detalhes serão analisados no capítulo 4).

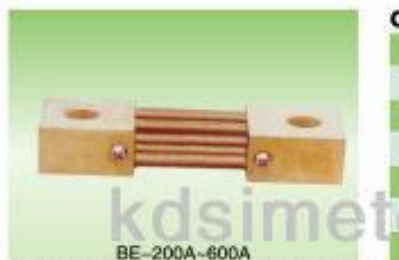

Outline and Fixing Dimensions:(mm)

\begin{tabular}{|c|c|c|c|c|c|c|c|c|c|c|c|c|c|}
\hline \begin{tabular}{c} 
Model \\
\hline BE-10A50-100mV
\end{tabular} & A & B & C & D & E & F & G & H & I & J & K & L & M \\
\hline $\begin{array}{l}\text { BE-150A/50-100mV } \\
\text { BE-200A/50-100mV }\end{array}$ & 31 & 136 & 110 & 73 & 20 & 6 & 12 & 17 & 32 & 13 & 21 & 5 & 17 \\
\hline
\end{tabular}

BE-10A-200A

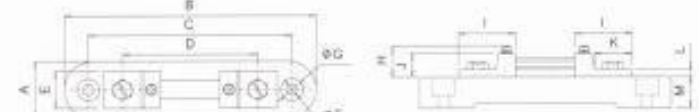

Outline and Fixing Dimensions:(mm)

\begin{tabular}{|l|l|l|l|l|l|l|l|l|l|l|l|l|}
\hline$B E-200 A / 50-100 \mathrm{mV}$ & 31 & 136 & 110 & 67 & 20 & 8 & 12 & 17 & 29 & 15 & - & -17 \\
\hline
\end{tabular}

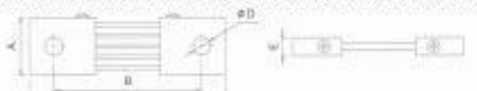

\begin{tabular}{|c|c|c|c|c|c|}
\hline Model & A & 8 & c & D & E \\
\hline BE-200A $50-100 \mathrm{mV}$ & 32 & 89 & 116 & 10 & 10 \\
\hline BE-250A/50-100mV & 41 & 86 & 116 & 10 & 12 \\
\hline BE-300A/50-100mV & 34 & 86 & 118 & 12 & 20 \\
\hline BE-400A/50-100mV & 45 & 86 & 119 & 12 & 20 \\
\hline CEE-50 \& $50-10 \mathrm{mV}$ & $38=$ & 80 & 16 & 2 & 20 \\
\hline BE-600A50-100mV & 55 & 90 & 122 & 12 & 20 \\
\hline
\end{tabular}

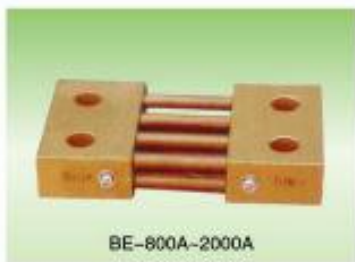

Outline and Fixing Dimensions:(mm)

\begin{tabular}{|c|c|c|c|c|c|c|c|}
\hline Model & A & B & C & D & E & F & G \\
\hline BE-800A/50-100mV & 70 & 122 & 35 & 90 & - & 12 & 20 \\
\hline BE-1000A/50-100mV & 70 & 159 & 35 & 121 & -- & 12 & 21 \\
\hline BE-1500A/50-100mV & 100 & 159 & 49 & 119 & - & 12 & 21 \\
\hline BE-2000A50-100mV & 100 & 190 & 50 & 166 & 38 & 14 & 39 \\
\hline
\end{tabular}

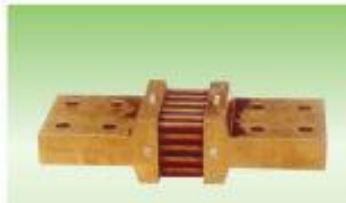

BE-3000A-5000A

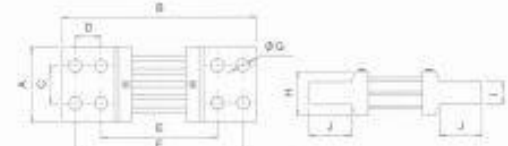

Outline and Fixing Dimensions:(mm)

Figura 8: Tabela de dimensionamento de Shunts da KDSI 
O nível de amplitude ou valor de pico de cada ensaio pode variar de poucos amperes até dezenas de milhares de amperes, sendo por isso necessário empregar o shunt com as especificações corretas para o ensaio a ser realizado.

As desvantagens dos shunts para utilização em ensaios em relação aos transformadores de corrente (TCs) são evidentes: medições por este método demandam que o sistema seja aberto para introdução do shunt, a corrente medida passa inteiramente pelo shunt,; shunts para altas correntes são volumosos, eles dissipam calor e a saída do shunt é galvanizada ao circuito sob medição. Em compensação, sistemas resistivos como esse são uma solução robusta e barata para muitas aplicações. Um sistema coaxial de shunt pode ser facilmente preparado com uma configuração de resistores metálicos em paralelo construídos de forma a minimizar o efeito indutivo.

\section{2. TC - Transformador de Corrente}

O Transformador de Corrente (TC) possui um núcleo de grande seção reta, à base de cobalto ou núcleos de ferrite são utilizados. Para correntes maiores que 50 A o enrolamento primário é normalmente um condutor simples que passa através da abertura central. O enrolamento secundário é conectado ao instrumento de medição e também conectado ao aterramento. O núcleo é enrolado com uma fita de alta permeabilidade (para dispositivos de baixa frequência) ou é feito de ferrite (para sondas de corrente de alta frequência) [7].

A Figura 9 apresenta um exemplo de montagem do TC para monitoramento da corrente. 


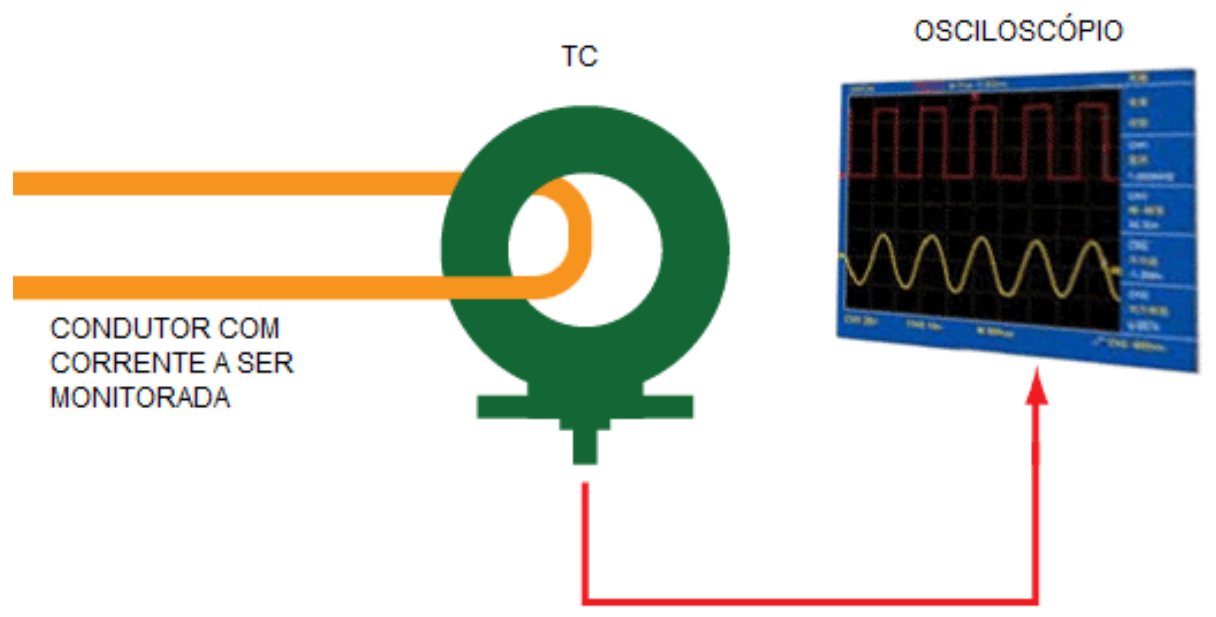

Figura 9: Monitoramento da corrente através de um TC

Os TCs possuem diversas configurações e assim são classificados nos seguintes grupos:

- Enrolado - enrolamento primário constituído de uma ou mais espiras, envolve mecanicamente o núcleo do transformador, ver Figura 10;

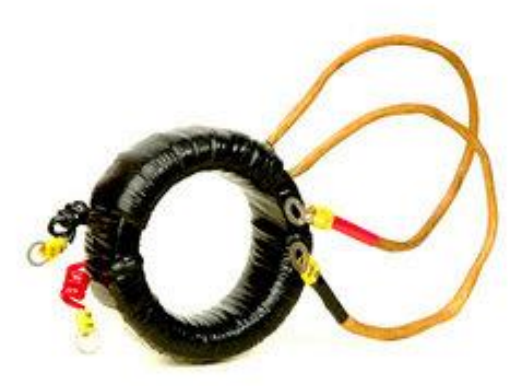

Figura 10: TC - enrolado

- Barra - o primário é composto por uma barra, instalada permanentemente através do núcleo do transformador, ver Figura 11; 


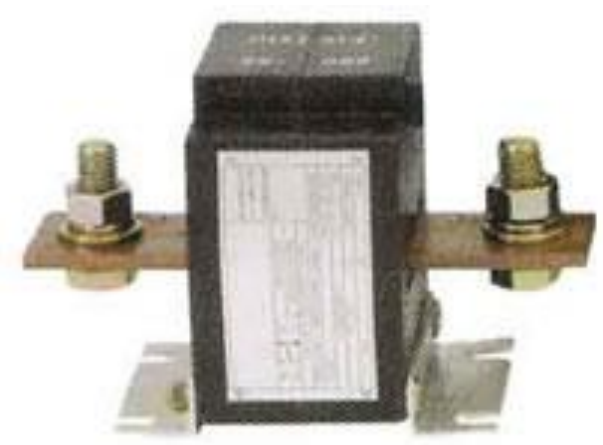

Figura 11: TC - barra

- Janela - Construído com uma abertura através do núcleo, onde passará o primário, formando uma ou mais espiras, ver Figura 12;

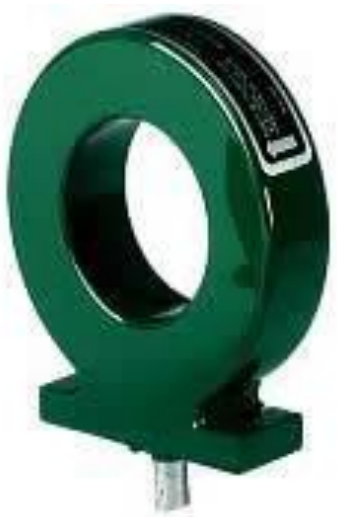

Figura 12: TC - janela

- Bucha - TC do tipo janela, mas especificamente projetado para ser instalado sobre uma bucha, fazendo parte permanente desta, ver Figura 13. 


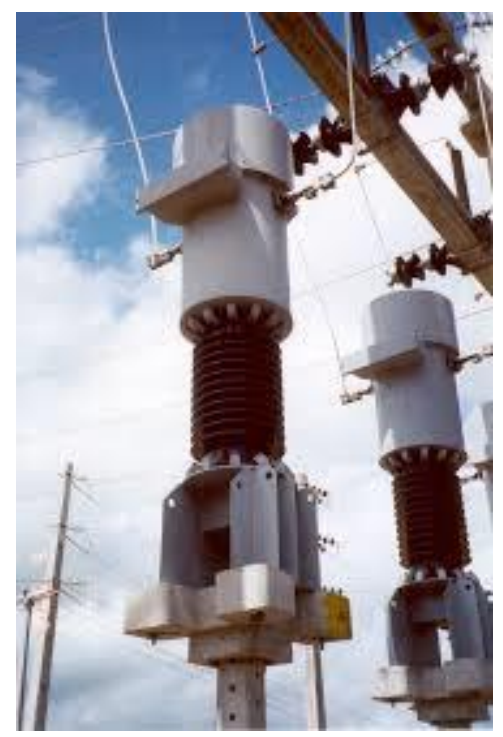

Figura 13: TC - bucha

- Núcleo Dividido ou Separado - TC do tipo janela especialmente construído de forma que parte do núcleo é separável ou basculante, com o objetivo de facilitar o enrolamento do condutor primário. Um exemplo desse tipo de TC é o alicate amperímetro, ver Figura 14.

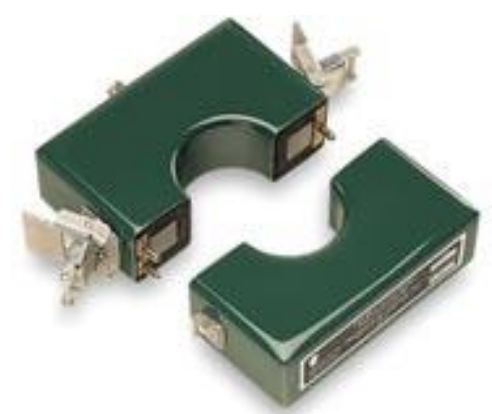

Figura 14: TC - Dividido ou separado

Essas são algumas das razões para os TCs serem tão populares:

- São muito simples e robustos;

- Não precisam de energia externa;

- Têm alto nível de isolamento galvânico;

- São baratos e possuem longa vida útil com parâmetros invariantes.

O TC possui uma teoria de funcionamento similar a outros tipos de transformadores, mas a maior diferença do TC para outros tipos de transformadores, os chamados transformadores de potencial ou de potência (TPs), 
é que nesses é aplicada uma tensão alternada ao enrolamento primário e, no caso do TC, aplica-se uma corrente alternada ao enrolamento primário [8].

A diferença se dá devido ao nível de impedância do enrolamento primário ser desprezível em relação ao circuito externo. Ou seja, enquanto os TPs são tratados como se estivessem ligados a uma fonte de tensão, o TC é tratado como se estivesse ligado a uma fonte de corrente ideal. Para maior esclarecimento, a Figura 15 apresenta o circuito equivalente para baixas e médias frequências de um TC.

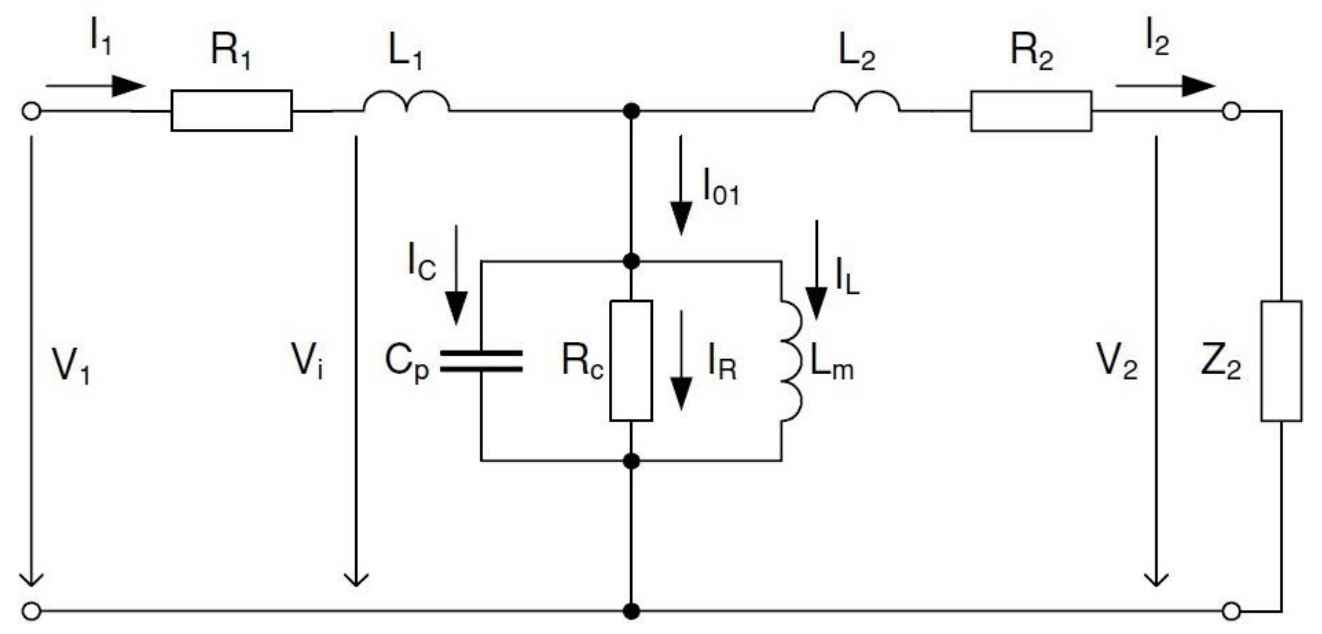

Figura 15: Circuito equivalente de um TC

Na Figura $15, R_{1}, R_{2}, L_{1}$ e $L_{2}$ representam as resistências e indutâncias de fuga dos enrolamentos primário e secundário, respectivamente. $R_{c}$ é a resistência responsável pelas perdas no núcleo ferromagnético, $\mathrm{L}_{\mathrm{m}}$ é a indutância magnética, $\mathrm{C}_{\mathrm{p}}$ representa as capacitâncias parasitas do enrolamento, $Z_{2}$ representa a carga atribuída à impedância do instrumento de medição, e $I_{L}+I_{R}$ é a corrente de magnetização [7].

Em baixas frequências $(50 / 60 \mathrm{~Hz})$ a principal fonte de erro é a corrente de magnetização, que é inversamente proporcional à frequência. Os seguintes procedimentos podem ser aplicados para reduzir essa corrente:

- Usar um material de alta permeabilidade na construção do núcleo;

- Aumentar a área do núcleo;

- Aumentar o números de voltas; 
- Aumentar virtualmente a permeabilidade do núcleo com o auxílio de um amplificador de realimentação (utilizado em comparador de corrente auto balanceável).

Em um transformador de corrente ideal a relação entre a corrente do primário e do secundário é únicamente relacionada ao número de espiras no enrolamento primário e ao número de espiras do secundário, ou seja, o valor de resistência nos enrolamentos é desprezível, chegando-se na relação amperesespiras

$$
N_{1} I_{1}=N_{2} I_{2}
$$

sendo $N_{2} / N_{1}$ a relação de transformação nominal do TC. Além disso, os enrolamentos estão em fases opostas.

Laboratórios de metrologia normalmente calibram transformadores de corrente com a corrente secundária nominal de $1 \mathrm{~A}$ ou $5 \mathrm{~A}$, com pontos de ensaio de $(1 ; 5 ; 20 ; 100 ; 120) \%$ da faixa de corrente primária. Ensaios de rotina são realizados em 50,60 e $400 \mathrm{~Hz}$ com incerteza de $0,01 \%$ do erro relativo e $0,1 \mathrm{mrad}$ no deslocamento da fase de ângulo.

\section{3. \\ Outros Transdutores}

Já foram apresentados nessa dissertação os shunts e os TCs (Transformadores de Corrente) que são os transdutores mais utilizados nos laboratórios e indústrias do setor de elétrico de potência, mas também existem outros instrumentos de medição utilizados que apresentam vantagens e desvantagens em relação aos já apresentados.

\subsection{1.}

\section{Bobinas de Rogowski}

A bobina de Rogowski é uma bobina de núcleo de ar enrolada à volta do condutor da corrente que se deseja medir. O princípio básico de funcionamento é determinado pela indutância mútua $M$ entre o primário (com uma volta) e o secundário (muitas voltas). A tensão de saída $(u)$ é proporcional à derivada da corrente: 


$$
u=M(\mathrm{~d} I / \mathrm{d} t)
$$

A bobina precisa ser fabricada com alto índice de exatidão geométrica para que a densidade e diâmetros sejam constantes durante o enrolamento. Idealmente, uma bobina homogênea possui uma excelente seletividade geométrica, isto é, ela é insensível a campos externos e à posição do condutor de medição, já que ela segue a lei de Ampere ao ar livre.

$$
\oint_{C} \vec{B} \cdot d \vec{l}=\mu_{0} i_{C}
$$

onde C é comprimento do segmento central da bobina, normalmente um círculo.

A bobina de Rogowski não possui material ferromagnético, portanto possui uma excelente linearidade e uma faixa dinâmica extremamente grande em relação aos valores encontrados nos outros transdutores. Os usuários dessa bobina normalmente dependem dessa linearidade e a utilizam para medir correntes que são muito acima da faixa de corrente utilizada para calibração $[7,35]$.

A principal dificuldade inerente ao emprego deste transdutor advém da necessidade de integrar o sinal de saída para obter a estimativa da corrente elétrica, adcionando um fator de erro nos parâmetros de incerteza, mas apesar disso é ideal para a leitura de impulsos em altas corrente e altas frequencias. $\mathrm{Na}$ Figura 16 é apresentado um modelo da bobina de Rogowski.

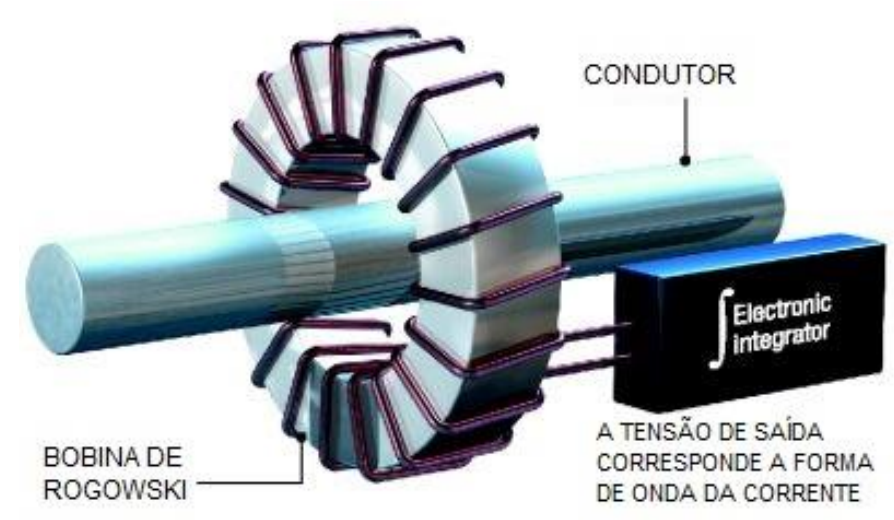

Figura 16: Bobina de Rogowski 


\subsection{2. \\ Efeito Hall}

Muitos transformadores de corrente CC utilizam um sensor Hall acoplado no gap de ar do núcleo magnético, conforme apresentado na Figura 17 [7].

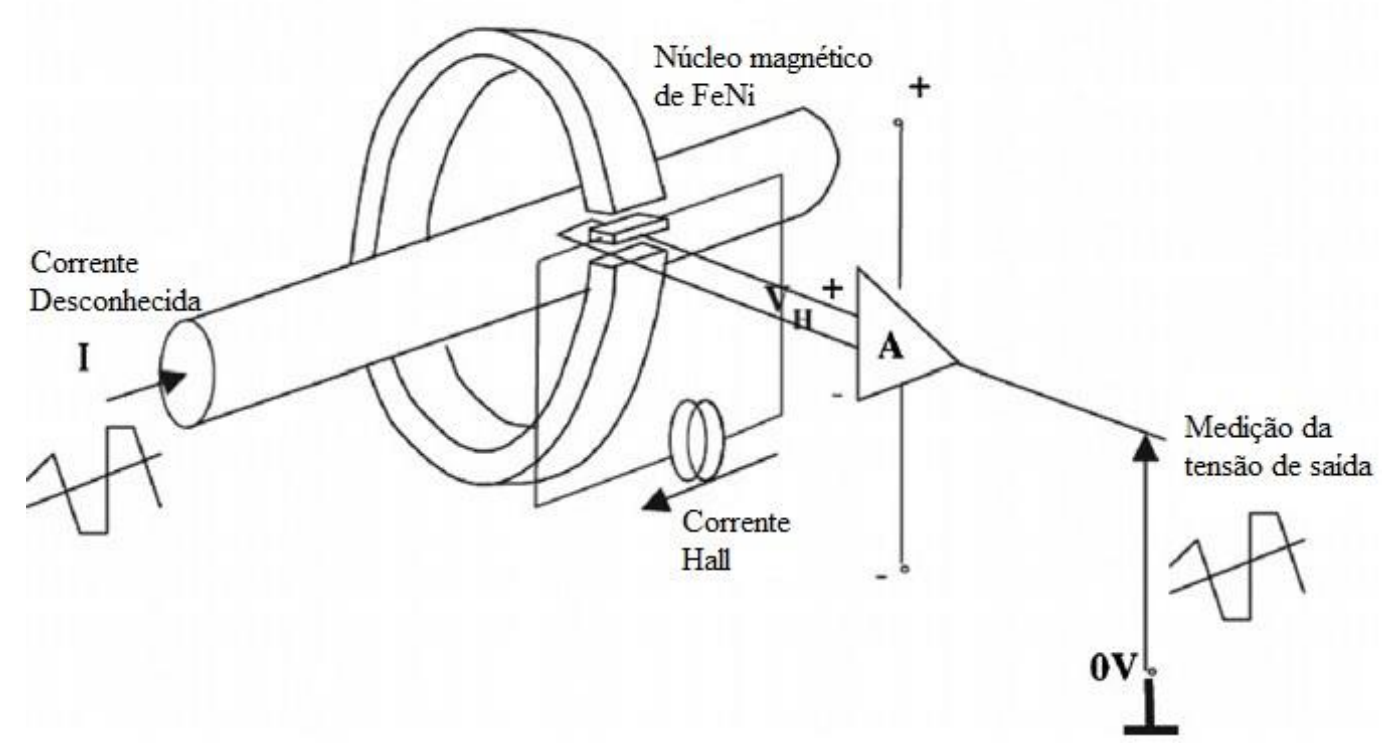

Figura 17: Sensor hall de corrente CC

O Sensor Hall tem seu funcionamento baseado no Efeito Hall, descoberto em 1889 por Edwin Hall, que percebeu que as variações do campo magnético sobre um condutor de corrente contínua provocavam pertubações na trajetória da corrente deste condutor. O efeito Hall pode ser observado em todos os materiais, porém é mais intenso em materiais com alta mobilidade eletrônica, como os semicondutores. Esse desvio da trajetória da corrente permite que uma tensão seja gerada e medida, sendo proporcional ao campo e a corrente desconhecida [36].

A utilização de um cabeçote magnético no Sensor Hall possui dois fatores importantes nas medições: o aumento da sensibilidade e o aumento da seletividade geométrica, isto é, protege-se o sensor de campos externos e se reduz a influência do sentido da corrente medida.

Mesmo utilizando um cabeçote magnético o Sensor Hall é sensível a campos magnéticos externos e a correntes próximas, sendo também sensível à posição do condutor medido, devido à falta de homogeneidade associada com o gap de ar. 
Alguns sensores Hall de corrente utilizam concentradores de campo (Figura 19), o que aumenta o campo medido, mas não cercam completamente a corrente medida. Neste caso, o perigo de saturação é muito mais baixo, mas a posição do condutor de medição deve ser fixa, e a supressão dos campos e correntes externas deve ser alcançada através de outros meios. Um sensor de corrente de baixo custo com base em um sensor de efeito Hall altamente sensível com concentradores simples de fluxo integrados está descrita por Popovic [36] (Figura 18).

Os concentradores de campo transformam um campo lateral localmente para a direção vertical (figura 19). O sensor é fabricado pela Sentron (grupo Melexis) com uma repetibilidade de $1 \%$ na faixa de \pm 12 A. Ele pode ser usado para medir as correntes em condutores de circuito impresso e em condutores de posição livre (figura 20).
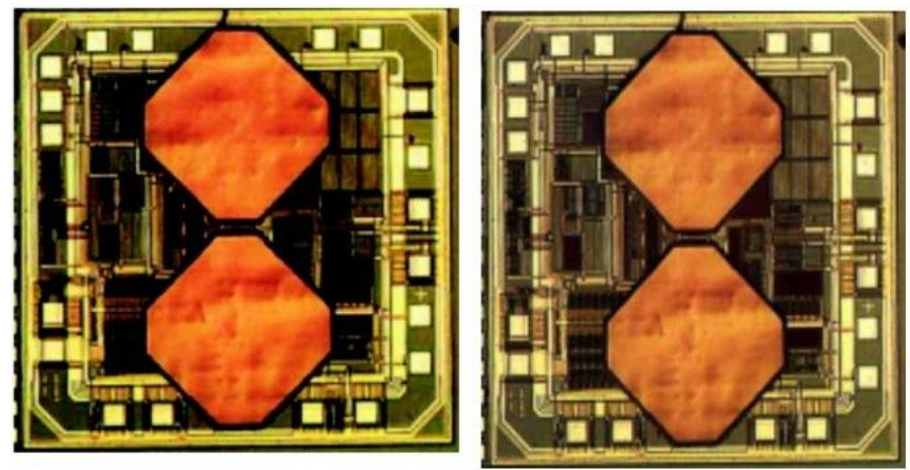

Figura 18: Estrutura interna de um sensor magnético hall integrado, com concentradores magnéticos gêmeos.

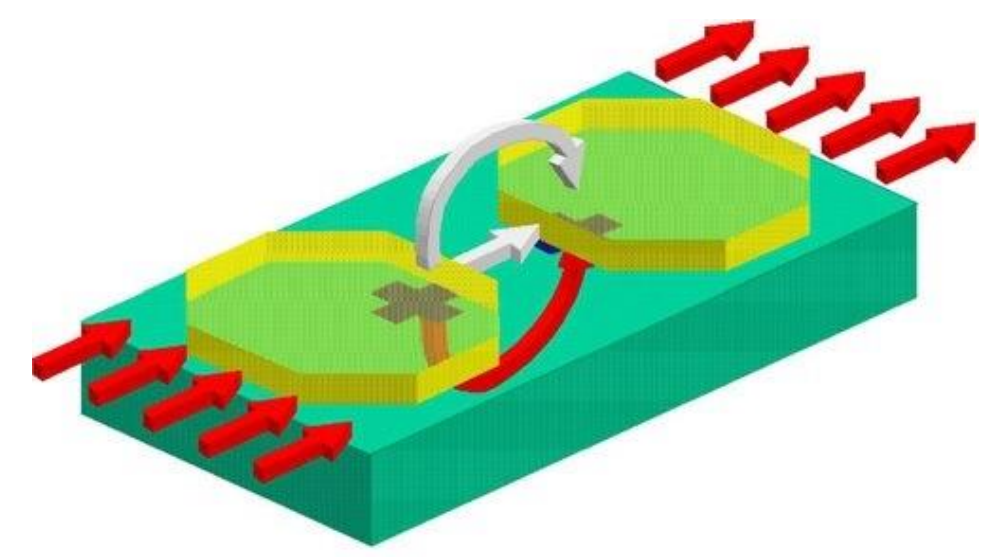

Figura 19: Concentradores de campo refletindo o campo na direção vertical. As duas pequenas cruzes sob os concentradores são sensores hall. 

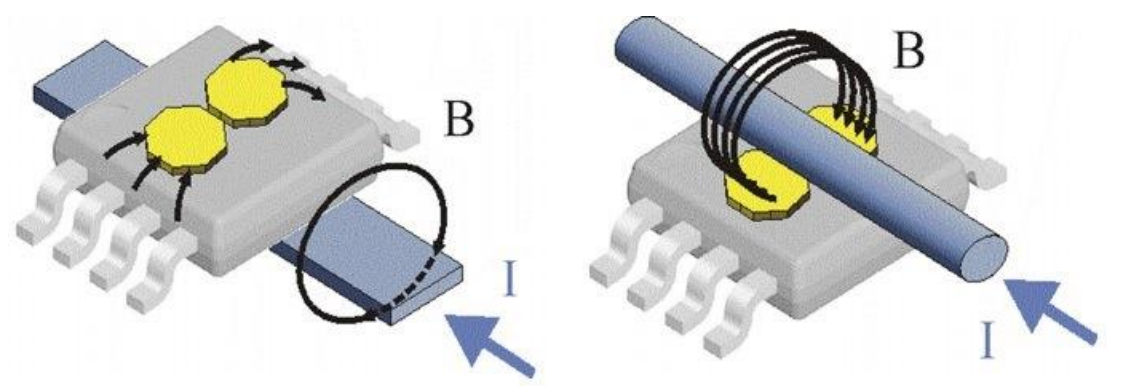

Figura 20: Aplicação de detecção de corrente do sensor magnético hall de corrente integrado por um condutor de circuito impresso (a) e um condutor de posição livre (b).

Alguns sensores de corrente utilizam uma combinação de Sensor Hall (como componente CC e de baixa frequência) e um transformador de corrente (como componente de alta frequência), utilizando um núcleo aberto de ferrite. Desta forma, consegue-se ler frequências de até $30 \mathrm{MHz}$ e correntes de até $40 \mathrm{~A}$ [7]. A conexão entre os dois sensores pode ser feita sem uma estação eletrônica. Para isso o seguinte critério é necessário: um transformador de alta frequência deve ter um número baixo de voltas, o que aumenta a frequência mínima limite. Os sensores Hall são adicionados para cobrir essa faixa de frequência. 


\section{4 \\ Confiabilidade Metrológica de Impulsos de Corrente}

Neste capítulo são apresentadas a IEC (Comissão Eletrotécnica Internacional - International Electrotechnical Commission) e a norma IEC 62475, que é aplicada para avaliação da conformidade de ensaios com impulsos de corrente nas indústrias e laboratórios.

Esse capítulo tem o objetivo de apresentar as diretrizes que um laboratório deve seguir para obter conformidade internacional, ajustando e calibrando seus sistemas de medição respeitando os níveis de incerteza adequados para a finalidade proposta pelo laboratório.

\section{1. IEC - International Electrotechnical Commission}

A IEC (International Electrotechnical Commission) é a Comissão Eletrotécnica Internacional, fundada em 1906, uma organização sem fins lucrativos que desenvolve normas internacionais e opera sistemas de conformidade nas áreas ligadas à eletrotécnica. A IEC é composta por um membro designado pelo Comitê Nacional de cada país, que paga as taxas de adesão e em troca pode participar plenamente dos trabalhos.

Os Comitês Nacionais são responsáveis por nomear peritos e delegados das indústrias, órgãos governamentais, associações e universidades para participar da avaliação técnica e avaliação da conformidade da IEC. São 82 países participantes, sendo 59 membros integrais e 23 membros associados. O Comitê Nacional Brasileiro é composto por 49 membros participantes e 69 membros observadores, com um total de 118 membros. Esse é um número relativamente alto em comparação com outros países da América do Sul como Argentina, com total de 22 membros e Colômbia, com apenas 10 membros, mas bem abaixo de países como Alemanha, China e Japão, que lideram o ranking de número de membros, com 177, 176 e 176 respectivamente [9]. 
A estrutura organizacional da IEC é apresentado no Quadro 1.

Quadro 1: Estrutura Organizacional da IEC em maio de 2014

\begin{tabular}{|l|c|}
\hline Comitês e Subcomitês Técnicos da IEC (TC/SC) & 176 \\
\hline Grupos de Trabalho & 469 \\
\hline Equipe de Projeto & 262 \\
\hline Manutenção & 555 \\
\hline Especialistas da IEC & 13179 \\
\hline
\end{tabular}

Dentre os 176 Comitês e Subcomitês Técnicos da IEC, o Quadro 2 a seguir aponta alguns que estão mais diretamente ligados aos ensaios com impulsos de corrente e níveis de tensão estudados por esta dissertação.

Quadro 2: Comitês e Subcomitês da IEC

\begin{tabular}{|l|l|}
\hline $\begin{array}{l}\text { Comitê e Subcomitês } \\
\text { técnicos - IEC }\end{array}$ & \multicolumn{1}{c|}{ Descrição } \\
\hline TC 42 & High-voltage and high-current techniques \\
\hline TC 13 & $\begin{array}{l}\text { Electrical energy measurement and control } \\
\text { voltages above } 100 \mathrm{kV}\end{array}$ \\
\hline TC 115 & $\begin{array}{l}\text { Measuring equipment for electrical and electromagnetic } \\
\text { quantities }\end{array}$ \\
\hline TC 85 & High-voltage switchgear and controlgear \\
\hline SC 17A & High-voltage switchgear and controlgear assemblies \\
\hline SC 17C & $\begin{array}{l}\text { Power electronics for electrical transmission and } \\
\text { distribution systems }\end{array}$ \\
\hline SC 22F &
\end{tabular}

Os comitês e subcomitês da IEC geram, como resultado de suas pesquisas, produtos normativos e informativos. Os produtos normativos são as normas internacionais como as detalhadas e estudadas nessa dissertação, especificações técnicas, especificações disponíveis publicamente e acordos técnicos industriais. Já os produtos informativos são relatórios técnicos, avaliações de tendências tecnológicas e guias. Os resultados das pesquisas desses comitês são usadas como referência e afetam diretamente as barreiras técnicas no comércio entre nações.

Algumas das normas produzidas pela IEC estão diretamente ligadas aos sistemas de medição que realizam ensaios utilizando o impulso de medição, notadamente as seguintes: 
- IEC 60060:2010 High-voltage test techniques - ed. 3. Essa norma define o sistema de medição para ensaio com impulso de tensão e as técnicas aplicadas para análise dos parâmetros avaliados no ensaio. Essa norma é utilizada ainda hoje como referência nos laboratórios do PTB e MIKES que atualmente são os únicos que possuem SMRs - Sistemas de Medição de Referência para ensaio em alta tensão com impulso de corrente, conforme será descrito no Capítulo 6. Até 2010 essa era a única norma utilizada como parâmetro de caracterização dos ensaios com sistemas de medição para impulsos de corrente.

- IEC 61083-1:2001 Instruments and software used for measurement in highvoltage impulse tests - Part 1: Requirements for instruments - ed. 2.0. Esta norma é aplicada para avaliação da conformidade dos instrumentos de medição, focalizando nas especificações do hardware, utilizados nos ensaios com impulso em alta tensão [26].

- IEC 61083-2:2013 Instruments and software used for measurement in highvoltage impulse tests - Part 2: Requirements for software for test with impulse voltage and currents - ed. 2.0. Diferentemente da parte 1, esta norma é aplicada para a avaliação da conformidade do software utilizado para adquirir os dados do ensaio e calcular os parâmetros dos ensaios com impulso em alta tensão e alta corrente [27].

- IEC 62475:2010-09 High-current test techniques - Definitions and requirements for test currents and measuring systems - ed. 1.0. Esta é a principal norma relacionada aos ensaios com impulso de corrente. Publicada em 2010, ainda está sendo adaptada nos laboratórios internacionais que certificavam seus sistemas de medição de ensaios com impulso de corrente com base na norma para sistemas de medição em alta tensão IEC 60060 [4].

A norma IEC 62475, publicada em 2010, trouxe características singulares dos sistemas de medição para ensaio com impulso de corrente, que os diferenciam dos sistemas de medição com impulso de tensão. Estas especificações serão detalhadas na próxima seção.

A norma IEC 61083-1 apresenta a especificação e características do hardware utilizado. Um aspecto que deve ser ressaltado é que o hardware utilizado por um SMR deve possui resolução maior e incerteza menor que um hardware utilizado por um SMA. Na Tabela 1 é possível ver a diferença do nível de incertezas entre um SMA e um SMR. 
Tabela 1: Incerteza do digitalizador

\begin{tabular}{ccc}
\hline & $\begin{array}{c}\text { Incerteza do SMA } \\
(u)\end{array}$ & $\begin{array}{c}\text { Incerteza do SMR } \\
(u)\end{array}$ \\
\hline Valor de pico $\left(U_{\max }\right)$ & $u_{m} \leq 2 \%$ & $u_{m} \leq 0,7 \%$ \\
Parâmetros de tempo & $u_{t} \leq 4 \%$ & $u_{t} \leq 3 \%$ \\
$\left(T_{1}, T_{2}\right)$ & $u^{2}$ & \\
\hline
\end{tabular}

A taxa de amostragem para o digitalizador não deve ser menor que $30 / T_{x}$, onde $T_{x}$ é o intervalo de tempo a ser mensurado, sendo esta taxa de amostragem aceita para SMAs e SMRs.

A resolução do digitalizador é outro ponto que deve ser observado no momento de se adquirir um osciloscópio ou outro digitalizador para o sistema de medição. A resolução de $2^{-8}(0,4 \%$ da escala total), ou melhor, é requisito para ensaios nos quais os parâmetros de impulso estejam sendo avaliados. Para ensaios que envolvam processamento de sinal além da avaliação dos parâmetros de impulso é recomendada a resolução de $2^{-9}(0,2 \%$ da escala total) ou melhor. Para osciloscópios analógicos a melhor resolução é de $0,3 \%$ da escala total.

Um sistema de medição é formado especificamente por 3 partes: instrumento de medição, transmissão do sinal e interface de leitura, todos os quais devem ser avaliados para determinar a incerteza de medição, que por sua vez determina o tipo de sistema, existindo os seguintes tipos de sistemas definidos pela norma IEC 62475:

- SMR (Sistema de Medição de Referência) - Um sistema de medição de referência deve ter o nível de incerteza de medição suficientemente baixo para garantir que o nível de incertezas exigido nos sistemas de medição aprovados esteja adequado. Este também deve ter rastreabilidade de um padrão de medição nacional ou internacional através de uma cadeia de rastreabilidade de medições comparativas, todas tendo o nível de incerteza de medição estabelecido.

- SMA (Sistema de Medição Aprovado) - Um sistema de medição que é preparado para respeitar um ou mais conjuntos de requisitos estabelecidos na norma IEC 62475 para ensaios de impulso de corrente. A conformidade de um SMA é comprovada por meio de um ensaio de calibração utilizando um SMR como padrão.

A Figura 21 é um exemplo de sistema de medição utilizado no laboratório CA2 do CEPEL. Esse sistema de medição foi montado com a finalidade de calibrar TCs (Transformadores de Corrente), ou seja, esse sistema de medição é considerado um sistema de medição de referência para outros laboratórios do 
CEPEL que utilizam os seus TCs em ensaios de dispositivos, como para-raios e transformadores.

Contudo, o TC padrão do CA2 deve ser periodicamente calibrado em um laboratório de nível de incerteza inferior, ou seja, o CA2 é um sistema de medição aprovado (SMA) em relação a um laboratório internacional como o MIKES ou PTB, que possuem os TCs de referência (SMRs) com menor nível de incerteza em conformidade com a IEC. Essa relação do CEPEL como SMR ou SMA é apresentada na Figura 22.

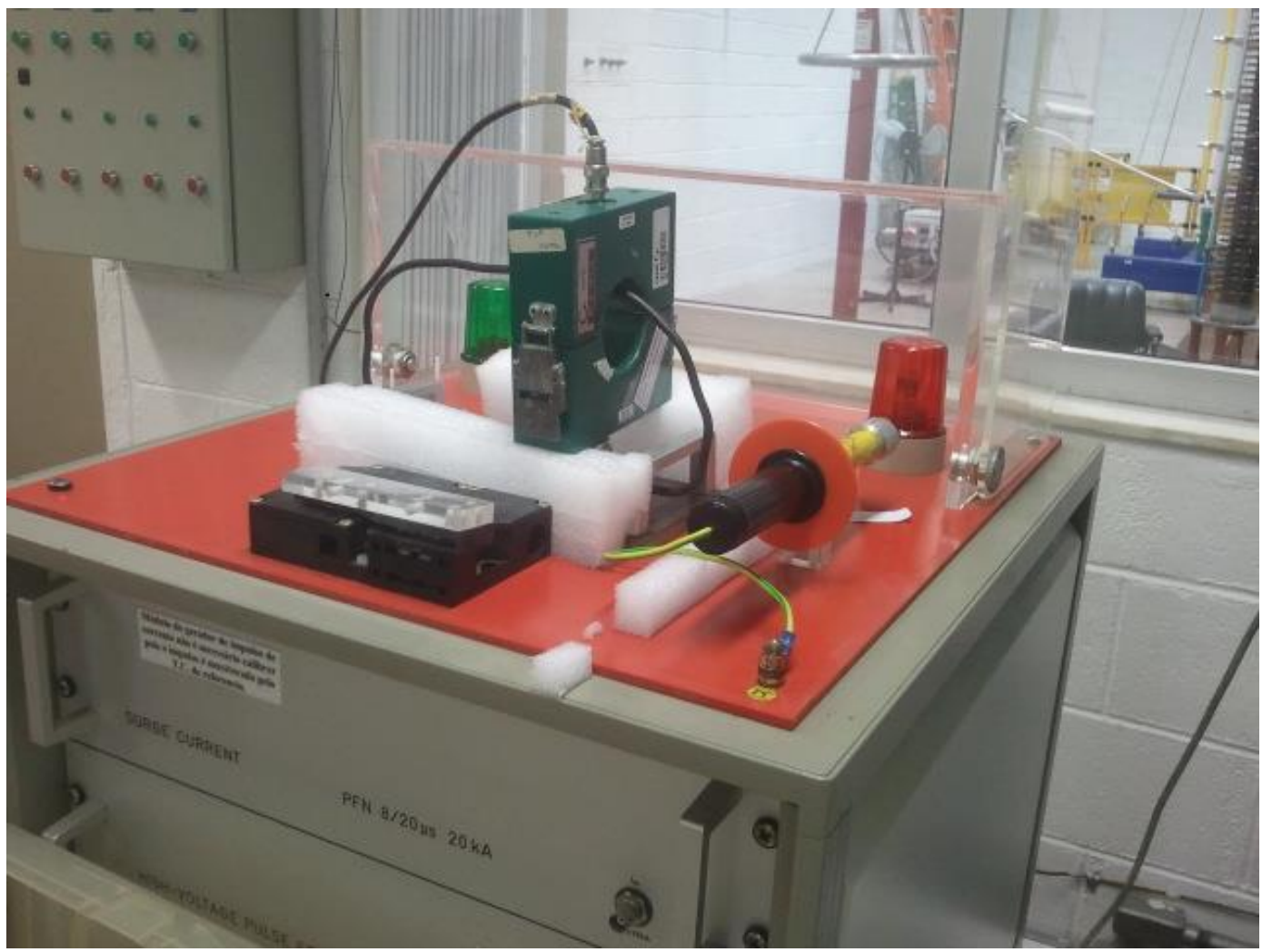

Figura 21: Sistema de medição do CA2 


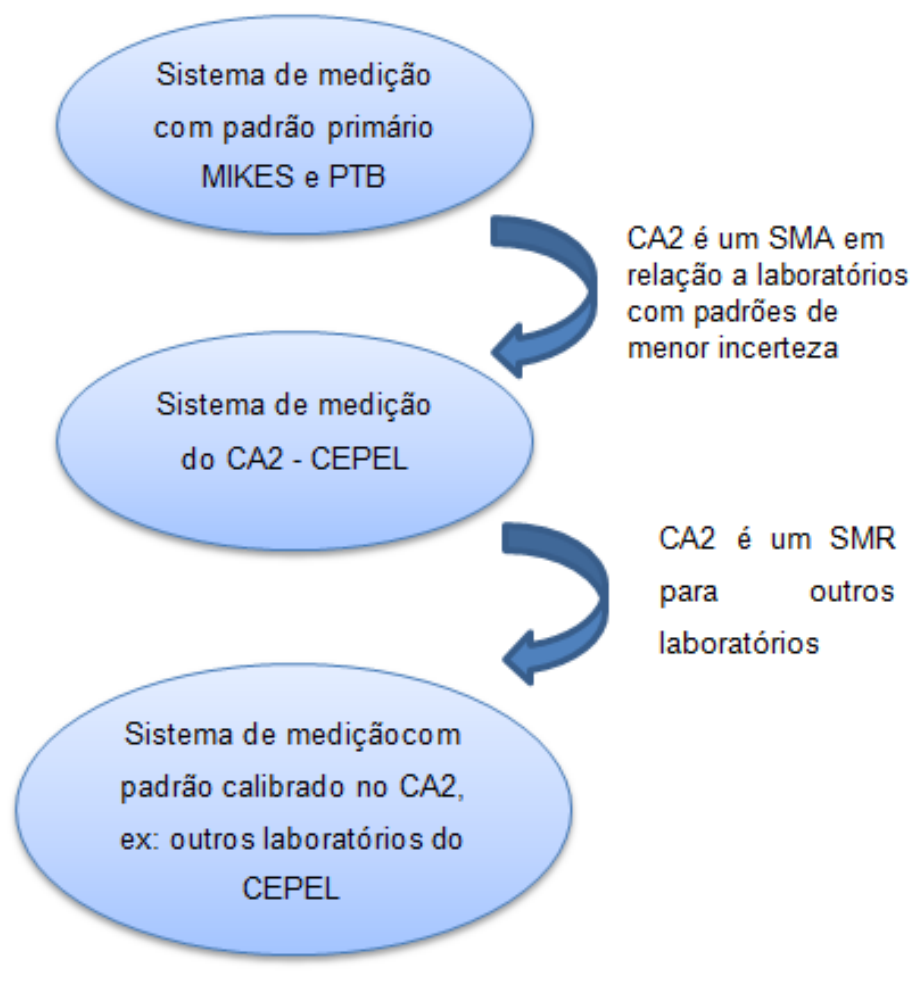

Figura 22: CEPEL como SMR e SMA

\section{2. \\ Ensaios de Impulso de Corrente}

Os ensaios de impulso são aplicáveis para ensaios de resistência a impulsos de corrente, por exemplo, ensaios de para-raios e testes de resistência a grandes descargas elétricas.

Os procedimentos da norma IEC 62475 [4] para ensaios de impulso servem tanto para medição quanto para calibração de instrumentos de medição.

Há basicamente dois tipos de impulsos de corrente, os exponenciais e os retangulares, conforme descrito nas seções a seguir.

\subsection{1. Impulso de Corrente Exponencial Exponential Impulse Current}

Este tipo de impulso é caracterizado por um crescimento de zero ao valor de pico em um curto intervalo de tempo, seguido de uma redução a zero de duas formas possíveis: aproximadamente exponencial (Figura 23) ou na forma de uma curva senoidal fortemente amortecida (Figura 24). Os parâmetros principais que 
definem o impulso são o tempo de frente $\boldsymbol{T}_{\mathbf{1}}$ e o tempo de cauda $\boldsymbol{T}_{2}$, conforme descrito a seguir. Os dois valores são geralmente empregados em conjunto para denotar a forma de onda como impulso de corrente $T_{1} / T_{2}$.

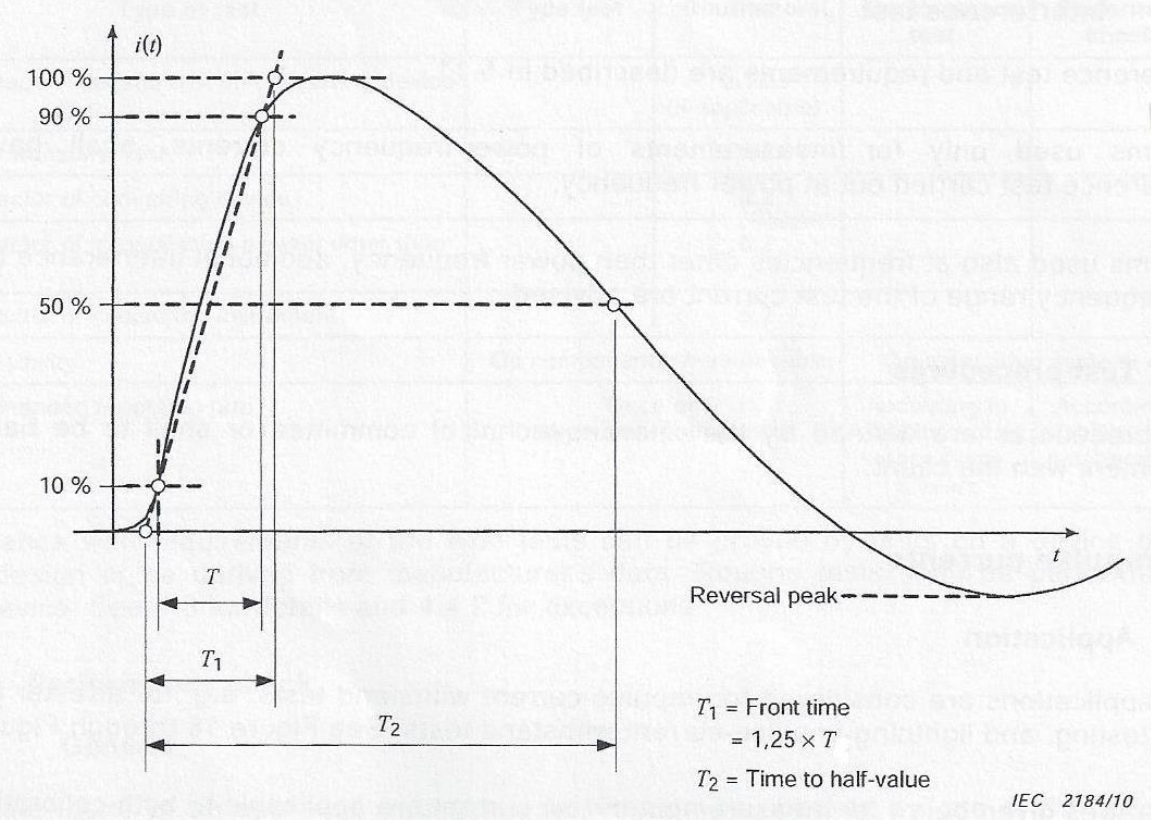

Figura 23: Forma de onda do impulso de corrente exponencial

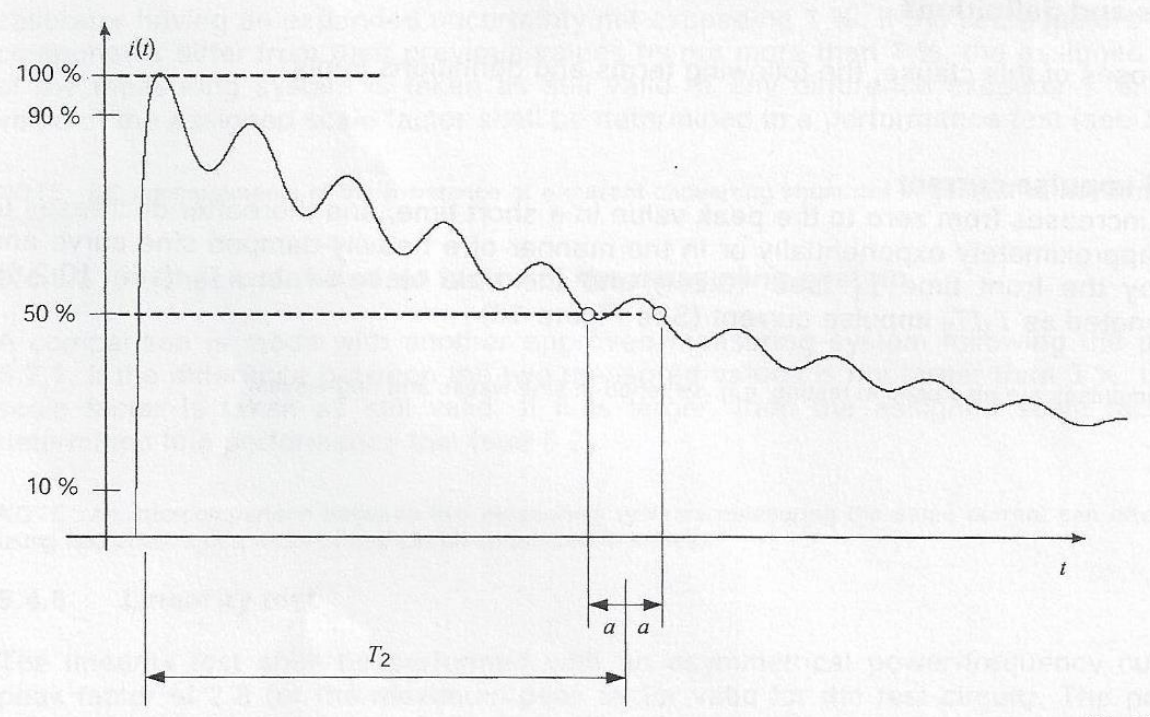

IEC $\quad 2185 / 10$

Figura 24: Forma de onda do impulso de corrente exponencial - oscilação na cauda

Os parâmetros de Interesse do Impulso de Corrente Exponencial são:

a) Valor do Impulso de Corrente (value of the impulse current) 
O valor de pico do ensaio geralmente é determinado pelo valor mais alto de corrente atingido no ensaio, com a exceção de ensaios nos quais o comitê técnico responsável tenha especificado algum procedimento diferente.

b) Tempo de frente $-T_{1}$ (front time)

É um parâmetro virtual definido como 1,25 vezes o valor de $T$, que é o período compreendido entre os instantes nos quais o impulso atinge $10 \%$ e $90 \%$ do valor de pico.

c) Origem Virtual - $O_{1}$ (virtual origin)

A origem virtual é representada pelo ponto de intercessão entre o eixo do tempo e a reta traçada pelos pontos de $10 \%$ e $90 \%$ do valor de pico.

d) Tempo de cauda $-\boldsymbol{T}_{\mathbf{2}}$ (time to half-value)

É um parâmetro de tempo virtual definido como o intervalo entre o ponto $O_{1}$ e o instante no qual a corrente decresceu até $50 \%$ do valor de pico. Caso haja oscilação presente na cauda, calcula-se a média entre os instantes de tempo referentes ao primeiro e ao último cruzamento pelo nível de $50 \%$ do pico.

\subsection{2. Impulso de Corrente Retangular Rectangular impulse current}

A corrente nesse tipo de impulso tem uma forma de onda aproximadamente retangular (Figura 25) e é definida pela duração do pico $T_{\mathrm{d}}$ e pela duração total $T_{\mathrm{t}}$, sendo geralmente denominada como impulso de corrente $T_{\mathrm{d}} / T_{\mathrm{t}}$. O Impulso retangular também pode ser realizado com oscilação, como apresentado na Figura 26. 


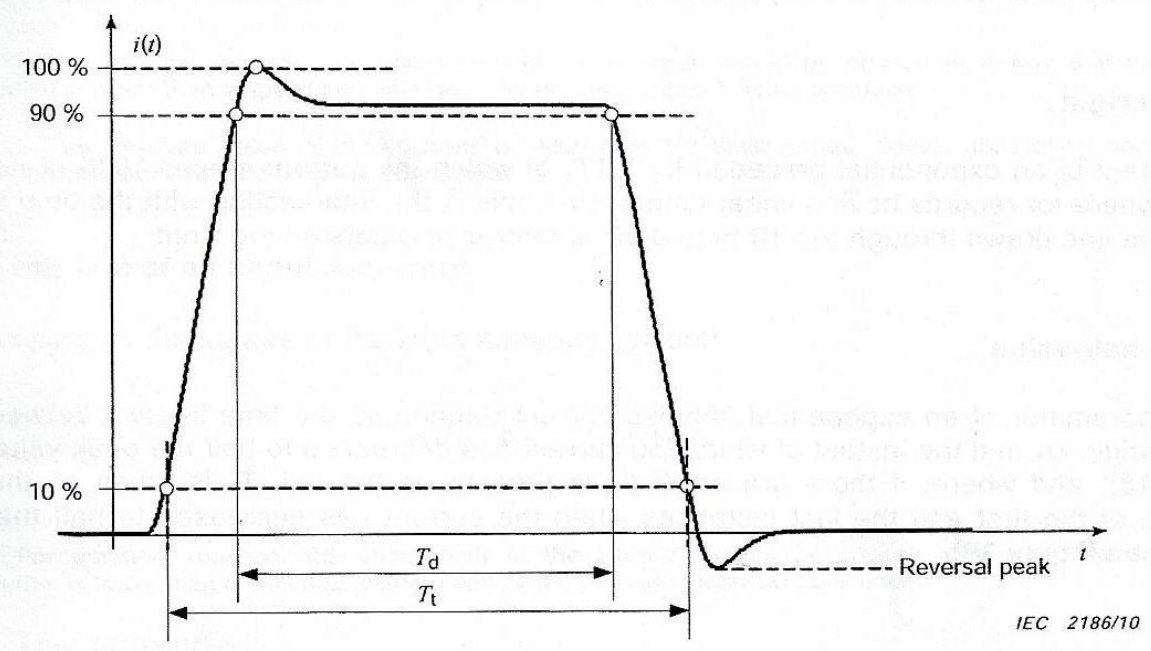

Figura 25: Forma de onda do impulso de corrente - retangular, suave

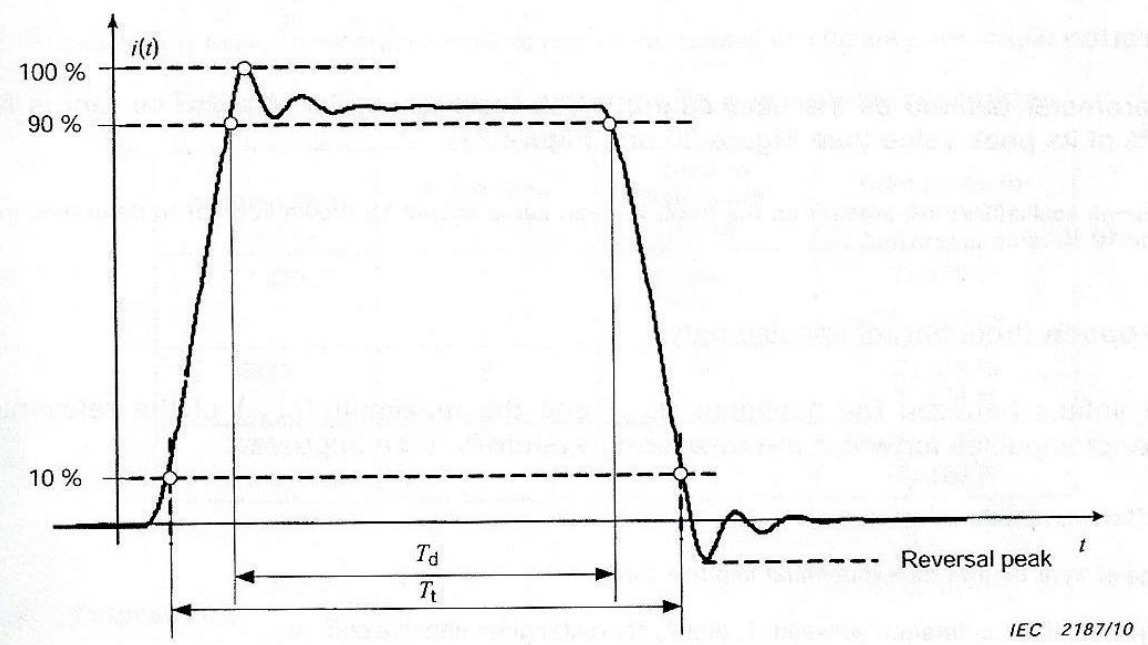

Figura 26: Forma de onda do impulso de corrente - retangular com oscilação

Os parâmetros de Interesse do Impulso de Corrente Retangular são:

a) Valor do Impulso de Corrente (value of impulse current)

$O$ valor de pico do ensaio geralmente é determinado pelo valor mais alto de corrente atingido no ensaio, com a exceção de ensaios nos quais o comitê técnico responsável tenha especificado algum procedimento diferente.

b) Duração - $\boldsymbol{T}_{\boldsymbol{d}}$ (duration)

Mede quanto tempo o impulso de corrente retangular permanece acima de $90 \%$ do valor de pico. Se houver oscilações presentes, $T_{\mathrm{d}}$ é determinado pelo 
período mais longo durante o qual a corrente fica consistentemente acima de $90 \%$ do valor de pico.

c) Duração Total - $\boldsymbol{T}_{\boldsymbol{t}}$ (total duration)

É um parâmetro virtual definido como o tempo durante o qual o impulso de corrente retangular é maior do que $10 \%$ do valor de pico.

\subsection{3.}

\section{Outros Parâmetros de Interesse dos Impulsos de Corrente}

a) Faixa Nominal $-\mathbf{T}_{\mathbf{N}}$ (nominal epoch - front part of impulse only)

Faixa de valores entre o mínimo $\left(t_{\min }\right)$ e o máximo $\left(t_{\max }\right)$ dos parâmetros de tempo relevantes do impulso para o qual o sistema de medição foi aprovado.

Para o impulso de corrente retangular a faixa nominal deve ser calculada como

$$
t_{\min }=\min \left(\frac{T_{\mathrm{t}}-T_{\mathrm{d}}}{2}\right) \text { e } t_{\max }=\max \left(\frac{T_{\mathrm{t}}-T_{\mathrm{d}}}{2}\right) .
$$

b) Carga de um impulso de corrente $-\mathbf{Q}$ (charge of an impulse current)

É a integral no tempo do valor absoluto da corrente instantânea:

$$
Q=\int_{0}^{\infty}|i(t)| d t
$$

c) Integral de Joule de um impulso de corrente - $\mathbf{I}^{2} \mathbf{t}$ (Joule integral of an impulse current)

É a integral no tempo do quadrado da corrente instantânea:

$$
\boldsymbol{I}^{2} \boldsymbol{t}=\int_{0}^{\infty}\left|i^{2}(t)\right| d t
$$

\subsection{4.}

\section{Impulsos de Corrente Padronizados}

Durante os ensaios, diferentes impulsos de corrente padronizados são utilizados, dependendo da aplicação. A Tabela 2 apresenta exemplos de impulsos de corrente exponencial, e mais alguns exemplos são apresentados no Anexo $\mathrm{H}$ da norma IEC 62475. 
Tabela 2: Lista dos ensaios específicos com impulso de corrente exponencial [4]

\begin{tabular}{|c|c|c|c|}
\hline $\begin{array}{c}\text { Tipo de equipamento sob } \\
\text { ensaio }\end{array}$ & $\begin{array}{l}\text { Referência das } \\
\text { normas do IEC }\end{array}$ & $\begin{array}{l}\text { Tipo de } \\
\text { Impulso }\end{array}$ & $\begin{array}{c}\text { Tolerâncias para } \\
\text { parâmetros de } \\
\text { tempo }\end{array}$ \\
\hline $\begin{array}{l}\text { Ensaio de para-raios sem } \\
\text { lacunas (gaps) }\end{array}$ & IEC 60099-4 & $1 / \leq 20$ & $\begin{array}{c}T_{1} \pm 10 \% \\
T_{2} \leq 20 \mu \mathrm{s}\end{array}$ \\
\hline $\begin{array}{l}\text { Ensaio de para-raios sem } \\
\text { lacunas (gaps) }\end{array}$ & IEC 60099-4 & $4 / 10$ & $\begin{array}{c}\left(3,5<\mathrm{T}_{1}<4,5\right) \mu \mathrm{s} \\
T_{2} \pm 10 \%\end{array}$ \\
\hline $\begin{array}{l}\text { Ensaio de para-raios sem } \\
\text { lacunas (gaps) }\end{array}$ & IEC 60099-4 & $8 / 20$ & $\begin{array}{c}\left(7<\mathrm{T}_{1}<9\right) \mu \mathrm{s} \\
\left(18<\mathrm{T}_{2}<22\right) \mu \mathrm{s}\end{array}$ \\
\hline Ensaio de para-raios & Future IEC 61643-11 & & $\begin{array}{l}T_{1} \pm 10 \% \\
T_{2} \pm 10 \%\end{array}$ \\
\hline Dispositivos eletrônicos & IEC 61000-4-5 & & $\begin{array}{l}T_{1} \pm 20 \% \\
T_{2} \pm 20 \%\end{array}$ \\
\hline $\begin{array}{l}\text { Dispositivos de proteção contra } \\
\text { surtos conectados à rede de } \\
\text { telecomunicação e sinalização }\end{array}$ & IEC 61643-21 & & $\begin{array}{l}T_{1} \pm 20 \% \\
T_{2} \pm 20 \%\end{array}$ \\
\hline $\begin{array}{l}\text { Dispositivos de proteção contra } \\
\text { surtos (SPD) conectados a } \\
\text { sistemas de distribuição de } \\
\text { energia em baixa tensão }\end{array}$ & & & \\
\hline $\begin{array}{l}\text { Ensaio de para-raios sem } \\
\text { lacunas (gaps) }\end{array}$ & IEC 60099-4 & $30 / 80$ & $\begin{array}{l}\left(25<\mathrm{T}_{1}<35\right) \mu \mathrm{s} \\
\left(70<\mathrm{T}_{2}<90\right) \mu \mathrm{s}\end{array}$ \\
\hline $\begin{array}{l}\text { Ensaio de para-raios sem } \\
\text { lacunas (gaps) }\end{array}$ & IEC 60099-4 & $30-100 /(60-200)$ & \\
\hline $\begin{array}{l}\text { Ensaio de para-raios sem } \\
\text { lacunas (gaps) }\end{array}$ & $\begin{array}{l}\text { IEC 60099-4:2004, } \\
\text { Tabelas } 5 \text { e } 6\end{array}$ & $\begin{array}{c}T_{\mathrm{d}} \text { de } 500 \mu \mathrm{s} \text {, } \\
1000 \mu \mathrm{s} \mathrm{ou} \\
2000 \mu \mathrm{s} \mathrm{ou} \\
\text { entre } 2000 \mu \mathrm{s} \text { e } \\
3200 \mu \mathrm{s}\end{array}$ & $\begin{array}{l}T_{1} \pm 20 \% \\
T_{2} \pm 20 \%\end{array}$ \\
\hline $\begin{array}{l}\text { Dispositivos de proteção contra } \\
\text { surtos conectados à rede de } \\
\text { telecomunicação e sinalização }\end{array}$ & IEC 61643-21 & $5 / 300$ & $\begin{array}{l}T_{1} \pm 30 \% \\
T_{2} \pm 20 \%\end{array}$ \\
\hline $\begin{array}{l}\text { Ensaio de para-raios sem } \\
\text { lacunas (gaps) }\end{array}$ & IEC 62305-1 & $10 / 350$ & Não definida \\
\hline $\begin{array}{l}\text { Dispositivos de proteção contra } \\
\text { surtos conectados à rede de } \\
\text { telecomunicação e sinalização }\end{array}$ & IEC 61643-21 & $\begin{array}{l}10 / 350 \\
10 / 250\end{array}$ & $\begin{array}{l}\text { T1 } \pm 30 \% \\
\text { T2 } \pm 20 \%\end{array}$ \\
\hline
\end{tabular}

\subsection{5.}

Tolerâncias

Tolerances

Os parâmetros calculados para os ensaios de impulso de corrente possuem tolerâncias específicas para seus resultados. 


\section{a) Tolerância do impulso de corrente exponencial}

- Carga

$0 \%$, limite superior especificado pela comissão técnica de relevância;

- Integral de Joule $\quad 0 \%$, limite superior especificado pela comissão técnica de relevância;

- Valor da corrente de ensaio $\pm 10 \%$;

- Tempo de frente $T_{1} \quad \pm 20 \%$;

- Tempo de cauda $T_{2} \quad \pm 20 \%$.

Qualquer pico de polaridade invertida após a corrente no ensaio ter passado de zero não deve ser maior que $30 \%$ do valor do impulso de corrente, isto é, do valor de pico, a menos que a comissão técnica responsável tenha especificado alguma mudança.

\section{b) Tolerância do impulso de corrente retangular}

- Carga $0 \%$, limite superior especificado pela comissão técnica de relevância;

- Integral de Joule $\quad 0 \%$, limite superior especificado pela comissão técnica de relevância;

- Valor de pico $\quad 0 \%,+20 \%$;

- Duração $T_{\mathrm{d}}$ do pico $\quad 0 \%,+20 \%$;

- Tempo de cauda $T_{\mathrm{t}} \quad<1,5 T_{\mathrm{d}}$.

O pico de polaridade invertida, após a corrente do ensaio ter cruzado o zero não deve ser maior que $10 \%$ do valor do impulso de corrente, isto é, do valor de pico.

\subsection{6.}

Medição do Impulso de Corrente

Measurement of the test current

\subsubsection{1.}

Requisitos Gerais de um SMA

Requirements for an approved measuring system

Um sistema de medição aprovado para realizar ensaios de impulso de corrente precisa atender aos seguintes requisitos: 
- Medir o valor do impulso de corrente, isto é, o valor de pico, com uma incerteza expandida $U_{\text {mes }}$ (com intervalo de confiança de 95\%) de não mais que $3 \%$;

- Medir os parâmetros de tempo (que definem a forma de onda) com uma incerteza expandida (com intervalo de confiança de 95\%) de não mais que $10 \%$;

- Exibir um erro sistemático de saída suficientemente baixo para permitir o cálculo da carga do impulso de corrente e da Integral de Joule.

\subsubsection{2.}

\section{Contribuições de Incerteza} Uncertainty contributions

Para um sistema de medição de impulso de corrente, a incerteza expandida deve ser avaliada de acordo com o item 5.10.3 e os anexos A e B da norma IEC 62475, as orientações para o cálculo da incerteza dos anexos da norma são com base no Guia ISO/IEC 98-3. A informação é dada aqui somente para orientação; outras contribuições podem ser importantes em alguns casos e devem ser consideradas também.

\subsubsection{3. \\ Comportamento Dinâmico Dynamic behaviour}

O comportamento dinâmico de um sistema de medição é adequado para sua faixa de formas de onda especificadas no registro de desempenho se:

- o fator de escala é constante dentro de $1 \%$ sobre cada faixa de forma de onda;

- a incerteza expandida dos parâmetros de tempo medidos mais os seus erros não é mais que $10 \%$.

O comportamento dinâmico de um sistema de medição deve ser determinado para uma faixa nomial usando impulsos com duas formas de onda diferentes de modo que:

- $t_{\min }$ seja igual ao menor parâmetro de tempo dentro da faixa nominal;

- $t_{\max }$ seja igual ao maior parâmetro de tempo dentro da faixa nominal;

O tempo de cauda ( duração total se a forma de onda é retangular) deve se aproximar do maior tempo para que o sistema de medição possa ser aprovado. 
A contribuição de incerteza $u_{\text {dyn }}$ devido a variação do fator de escala ao longo da faixa nominal deve ser avaliado de acordo com o item 5.4 da IEC 62475.

Os mesmos registros com os dados do ensaio 5.2.1 da IEC 62475 para fator de escala podem ser usados, com os parâmetros relevantes de tempo dos impulsos medidos sendo avaliados para cada sistema. Os erros dos parâmetros de tempo medidos pelo sistema sob calibração devem ser avaliados. A incerteza também deve ser avaliada, considerando ambas as incertezas, do sistema de medição de referência e do processo de calibração.

\subsubsection{4.}

\section{Calibração e ensaios em um sistema de medição aprovado}

A conformidade com os requisitos dos tipos de ensaio pode ser aprovada por ensaios em um dispositivo do mesmo projeto ou ser derivado de dados do fabricante. Ensaios de rotina devem ser realizados em cada dispositivo. O item 4.6 da IEC 62475 possui mais detalhes e o item 4.4.2 da norma possui uma lista de exceções. 
Tabela 3: Ensaios aplicáveis em um SMA

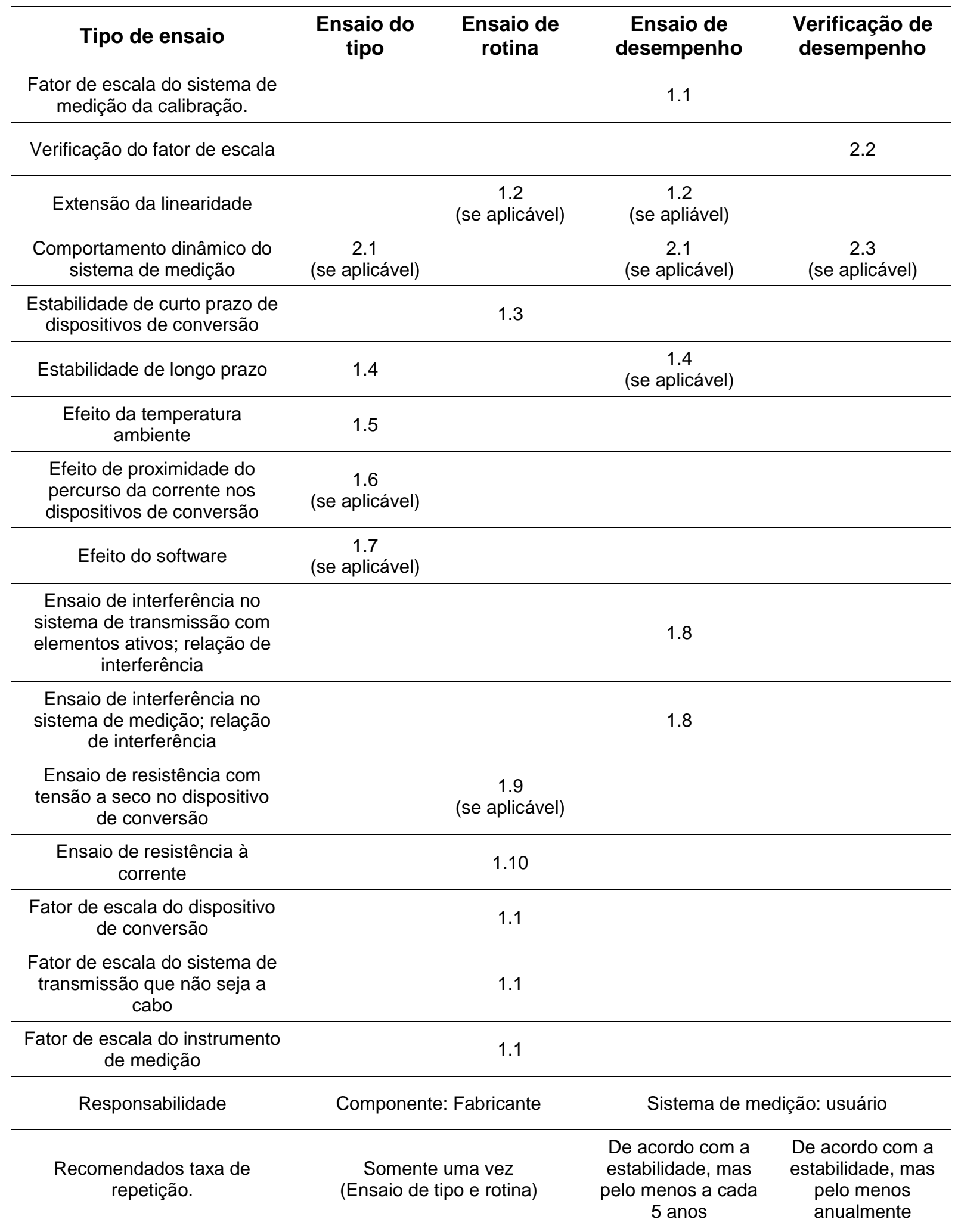

Legenda:

1.1 Calibração do Fator de escala, item 5.2 da IEC 62475;

1.2 Ensaio de linearidade, item 5.3 da IEC 62475;

1.3 Estabilidade de curto prazo, item 5.5 da IEC 62475;

1.4 Estabilidade de longo prazo, item 5.6 da IEC 62475; 
1.5 Efeito da temperatura ambiente, item 5.7 da IEC 62475;

1.6 Efeito de proximidade do percurso da corrente, item 5.8 da IEC 62475;

1.7 Efeito do software, item 5.9 da IEC 62475;

1.8 Ensaio de interferência, item 5.12 da IEC 62475;

1.9 Ensaio de resistência à tensão, item 5.13.1 da IEC 62475;

1.10 Ensaio de resistência à corrente, item 5.13.2 da IEC 62475;

2.1 Comportamento Dinâmico, item 10.4.3 da IEC 62475;

2.2 Verificação de desempenho, item 10.4.5 da IEC 62475;

2.3 Verificação do comportamento dinâmico, item 10.4.5.4 da IEC 62475.

\subsubsection{5.}

\section{Verificação de Desempenho}

No sistema de medição aprovado de impulso de corrente é necessária uma verificação de desempenho periódico. O fator de escala de um sistema de medição aprovado pode ser verificado a partir dos seguintes métodos:

\section{a) Verificação do fator de escala do sistema de medição}

A comparação deve ser realizada com outro sistema de medição aprovado de acordo com o procedimento 5.2.1 da IEC 62475. Se a diferença entre os dois valores de corrente medidos não é maior que $3 \%$, o fator de escala designado é considerado ainda válido. Se este for maior, então o fator de escala designado deve ser determinado em um ensaio de desempenho.

\section{b) Verificação do fator de escala dos componentes}

$\mathrm{O}(\mathrm{s})$ fator(es) de escala de cada componente pode ser verificado usando um calibrador interno ou externo que possua uma incerteza expandida que não exceda 1\%. Um calibrador de impulso para calibração de instrumentos de medição de impulso deve ter uma incerteza expandida de não mais do que $1,5 \%$, se o fator de escala dos componentes individualmente diferem dos seus valores anteriores por não mais que $1 \%$, o fator de escala do sistema de medição é considerado ainda válido. Se qualquer diferença excede $1 \%$, então um novo valor do fator de escala designado deve ser determinado em um ensaio de desemepenho.

\section{c) Verificação do comportamento dinâmico}

O comportamento dinâmico deve ser verificado por comparação com outro sistema de medição aprovado ( ou por um sistema de medição de referência) usando o procedimento do item 10.4.3.2 da IEC 62475. 
Alternativamente, pode ser realizada uma verificação a partir da medição da resposta ao degrau (Anexo C da IEC 62475), onde, em cada verificação, a resposta ao degrau deve ser registrada do mesmo modo e no mesmo circuito que foram usados para obter o registro de referência. O registro da resposta ao degrau deve ser comparado com os registros de verificações anteriores. Pequenas variações podem ser esperadas no decorrer das verificações e o número de variações aceitáveis deve estabilizar após as verificações iniciais. Qualquer grande diferença deve ser investigada e um ensaio de desempenho deve ser realizado. 

Corrente

A demanda por este tipo de ensaio é cada vez maior em todo o sistema elétrico nacional. Subestações de energia e linhas de transmissão necessitam do para-raios para proteger seus equipamentos, e principalmente o transformador de potência, que é o ativo de maior valor na subestação, o que faz do para-raios o equipamento de proteção mais importante. Da mesma forma, este ensaio com impulso de corrente é aplicado para testes em aeronaves, principalmente nas asas do avião, região onde se localiza o combustível do avião [11].

Desta forma, este capítulo apresenta detalhadamente estas duas principais aplicações de ensaios com impulso de corrente.

\section{1. \\ Para-raios}

As sobretensões são variações de tensão que ocorrem entre fase e terra ou entre as fases de um sistema elétrico, cujo valor de pico é superior ao valor máximo de tensão de operação do sistema. Constituem um dos principais problemas dos sistemas elétricos de potência e podem ser de origem externa, por motivo de descargas atmosféricas, ou interna, devido a operações de manobra ou falhas nos sistemas.

O para-raios mostrou ser o equipamento mais eficaz na proteção ou redução do efeito proveniente das sobretensões sobre os equipamentos instalados nas redes elétricas. O para-raios tem como função limitar os sobreníveis de tensão transitórias nos terminais dos equipamentos por ele protegidos a níveis préestabelecidos, de forma que o isolamento dos equipamentos não tenham suas características afetadas após a ocorrência de uma sobretensão [10].

Para se garantir a eficiência e a confiabilidade de um determinado projeto de para-raios, em relação às características de proteção e operação requeridas para o bom desempenho desse equipamento nos sistemas elétricos, são realizados, 
inicialmente, ensaios de tipo em protótipos do projeto desenvolvido. Uma vez aprovado o projeto, todas as unidades de para-raios produzidas são submetidas aos ensaios de rotina, definidos em normas da NBR e da IEC. Durante a fase de aquisição de lotes de fornecimento, algumas unidades de para-raios são submetidas a ensaios de aceitação ou recebimento, normalizados ou não. Estes ensaios têm por finalidade avaliar as características de proteção e de operação do lote de para-raios novos produzidos, em relação às características de projeto obtidas nos ensaios de tipo.

Os ensaios de tipo, rotina e recebimento em para-raios, com e sem centelhadores, são prescritos pelas normas técnicas. Entre as diversas normas existentes as mais utilizadas no Brasil são:

- IEC 99-1/1991 - Surge Arresters - Part 1: "Non-linear resistor type gapped surge arresters for a.c. systems";

- IEC 99-4/2006 - Surge Arresters - Part 4: "Metal-Oxide surge arresters without gaps for a.c. systems";

- ANSI C62.1/1984 - "IEEE Standard for surge arresters for AC power circuits";

- ANSI C62.11/1987 - "IEEE Standard for Metal-Oxide surge arresters for AC power circuits";

- NBR 5287/88 - "Pára-raios de resistor não-linear a Carboneto de Silício (SiC) para circuitos de potência de corrente alternada" - Especificação;

- NBR 5309/91 - "Pára-raios de resistor não-linear a Carboneto de Silício (SiC) para circuitos de potência de corrente alternada" - Método de ensaio.

No mercado internacional e nacional existem três tipos de para-raios:

- Para-raios de carboneto de silício ( $\mathrm{SiC}$ ) com centelhadores série e invólucro de porcelana;

- Para-raios de óxido de zinco $(\mathrm{ZnO})$ sem centelhadores série e com invólucro de porcelana ou de material polimérico;

- Para-raios de óxido de zinco com centelhadores série e invólucro de porcelana.

A seguir, descreve-se brevemente cada tipo de para-raios. 


\subsection{1. Para-raios de Carbeto ou Carboneto de Silício (SiC)}

Também conhecido como para-raios convencional, Figura 27, formado basicamente por resistores não-lineares à base de Carboneto de Silício em série com um conjunto de centelhadores e limitadores de corrente.

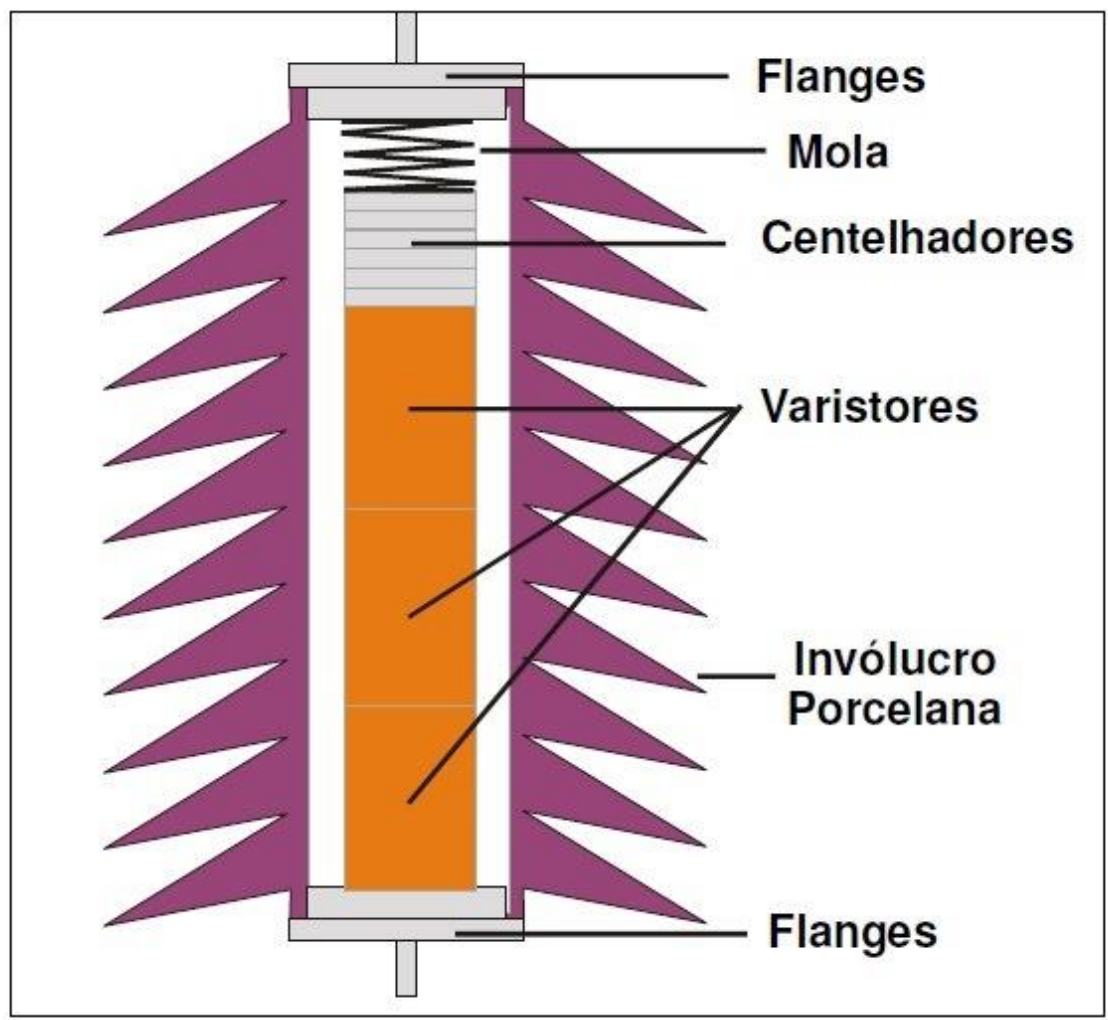

Figura 27: Para-raios de carboneto de silício (SiC)

Neste tipo de para-raios, os centelhadores têm duas funções principais: a primeira é a de "isolar" o para-raios do sistema sob condições de regime permanente, uma vez que, sem estes centelhadores ter-se-ia, para condições normais de operação, uma grande amplitude de corrente de frequência industrial, provocando um aquecimento excessivo nos resistores não-lineares de $\mathrm{SiC}$ levando à destruição dos mesmos em poucos ciclos; a segunda função é auxiliar a extinção da corrente subsequiente que flui através dos resistores não-lineares quando da passagem da mesma pelo zero [10].

Projetos mais modernos aplicados a para-raios da classe de distribuição utilizam centelhadores parcialmente ativos, formados por resistores equalizadores, utilizados para minimizar o efeito de distribuição não uniforme de tensão ao longo 
dos centelhadores, especialmente em ambientes poluídos. Projetos de centelhadores mais complexos são aplicados a para-raios da classe estação. Este tipo de para-raios ainda apresenta um bom mercado em sistemas de distribuição, tendo uma penetração limitada em sistemas de transmissão.

\subsection{2. \\ Para-raios de Óxido de zinco (ZnO)}

A tecnologia dos varistores de $\mathrm{SiC}$ perdurou sem concorrência até o final da década de 60, quando um novo tipo de dispositivo utilizado para a proteção contra sobretensões foi desenvolvido pela Matsushita Electrical Co. Ltd. [10].

Este dispositivo, formado por elementos cerâmicos à base de Óxido de Zinco $(\mathrm{ZnO})$ e pequenas quantidades de outros óxidos metálicos adicionados ao $\mathrm{ZnO}$, apresenta um elevado grau de não linearidade na sua característica de tensão $\mathrm{x}$ corrente, proporcionando aos elementos de $\mathrm{ZnO}$ baixos valores de corrente na região de operação, associado a uma boa estabilidade quando continuamente solicitados pela tensão normal de operação.

Esses elementos não-lineares à base de $\mathrm{ZnO}$ começaram a ser produzidos em escala industrial a partir de 1968, sendo inicialmente destinados à proteção de circuitos eletrônicos, caracterizados por baixos valores de tensão e de energia. A partir desse desenvolvimento, diversas empresas, sob a licença da Matsushita, iniciaram estudos visando ao desenvolvimento de resistores não-lineares de alta capacidade de absorção de energia que pudessem ser utilizados em sistemas elétricos de potência.

Os primeiros para-raios de $\mathrm{ZnO}$ desenvolvidos para sistemas de potência foram apresentados ao mercado no final de década de 70 pela Meidensha Electric Manufacturing Company Ltda [10]. Na década de 80 diversas empresas japonesas, europeias e americanas desenvolveram e produziram para-raios de $\mathrm{ZnO}$ para aplicação em redes de distribuição, subestações e linhas de transmissão.

Este tipo de para-raios é constituído por resistores não-lineares à base de $\mathrm{ZnO}$, conforme ilustrado na Figura 28. A grande não-linearidade na característica tensão x corrente deste tipo de resistor faz com que este tipo de para-raios dispense a utilização dos centelhadores, tornando o projeto mais simplificado em 
relação à montagem dos para-raios, além de oferecer ao sistema inúmeras vantagens de aspectos protetivos e operativos.

No entanto, pelo fato do mesmo não apresentar centelhadores série, este tipo de para-raios, além de atuar para solicitações transitórias, se mantém continuamente solicitado pela tensão de operação do sistema, fato este que propicia uma degradação ou deterioração mais rápida dos resistores não-lineares de $\mathrm{ZnO}$ ao longo do tempo.

Este tipo de para-raios vem sendo largamente utilizado para proteção dos sistemas de transmissão. Em alguns países como, por exemplo, o Japão, quase a totalidade dos para-raios instalados em suas redes de transmissão são à base de ZnO. No Brasil, as empresas concessionárias e grandes indústrias vêm adquirindo para-raios de $\mathrm{ZnO}$ em substituição aos para-raios de SiC. No entanto, para redes de distribuição, em face do custo ainda elevado deste tipo de para-raios em relação aos para-raios com centelhadores, a sua utilização ainda é pequena [10].

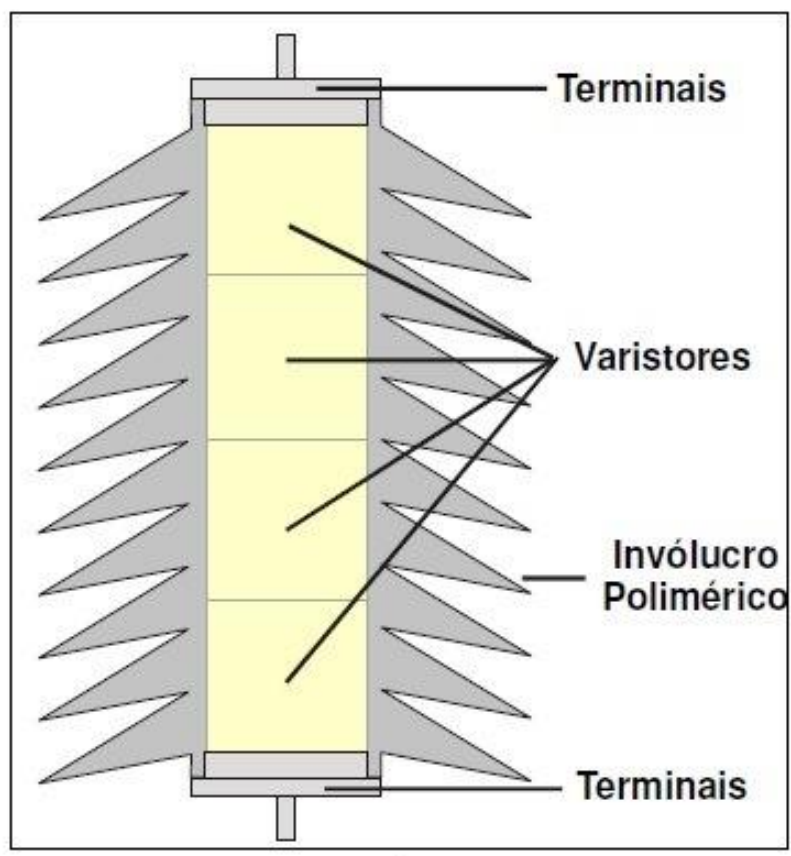

Figura 28: Para-raios de óxido de zinco $(\mathrm{ZnO})$

\subsection{3.}

\section{Para-raios de Óxido de zinco (ZnO) com Centelhador}

Esse tipo de para-raios é aplicado basicamente a redes de distribuição. Neste tipo de projeto de para-raios, adicionalmente aos resistores não-lineares de $\mathrm{ZnO}$, 
são introduzidos em série centelhadores, que têm como função principal, para este tipo de projeto, "isolar" o para-raios do sistema sob condições de regime permanente, reduzindo a degradação dos resistores não-lineares de $\mathrm{ZnO}$ que são geralmente de características inferiores aos utilizados na montagem dos para-raios sem centelhadores. Os centelhadores utilizados neste tipo de projeto podem ser de construção simplificada, quando comparados aos utilizados na montagem dos para-raios de $\mathrm{SiC}$.

Alguns fabricantes nacionais e internacionais apontam para o futuro deste tipo de para-raios como o mais adequado, sob o ponto de vista técnico-econômico, para a utilização em redes de distribuição, pois o mesmo apresenta uma maior não-linearidade na característica tensão x corrente dos resistores não-lineares de ZnO. Também apresentam menores valores de tensão residual e valores muito baixos de corrente subseqüente comparados aos para-raios de SiC. A utilização dos centelhadores propicia um aumento na vida útil dos para-raios, além de reduzir o custo de aquisição, quando comparado aos para-raios de $\mathrm{ZnO}$ tradicionais (sem centelhadores). No Brasil, a utilização deste tipo de para-raios está limitada pelas normas técnicas (ainda em fase de projeto de norma) à tensão nominal de $39 \mathrm{kV}$.

\subsection{4. \\ Resumo das Diferenças Entre Tecnologias}

Cada um dos três tipos de para-raios apresentados possui características específicas e tecnologias distintas, sendo apresentadas tais informações de forma sucinta no Quadro 3. 
Quadro 3: Diferenças entre tecnologias dos tipos de para-raios

\begin{tabular}{|c|c|c|}
\hline \multicolumn{3}{|c|}{ Tipo de Para-raios } \\
\hline Carboneto de Silício(SiC) & $\begin{array}{l}\text { Oxido de Zinco ( } \mathrm{ZnO}) \\
\text { sem centelhador }\end{array}$ & $\begin{array}{l}\text { Oxido de Zinco }(\mathrm{ZnO}) \\
\text { com centelhador }\end{array}$ \\
\hline Necessita centelhador série & $\begin{array}{c}\text { Alta não-linearidade da } \\
\text { curva "Vxl" }\end{array}$ & Necessita centelhador série \\
\hline $\begin{array}{l}\text { Problema de distribuição } \\
\text { de tensão no centelhador }\end{array}$ & $\begin{array}{l}\text { Conectado diretamente à } \\
\text { rede }\end{array}$ & Basicamente distribuição \\
\hline \multirow[t]{5}{*}{ Distribuição e Estação } & $\begin{array}{l}\text { Baixa tensão, distribuição, } \\
\text { estação e transmissão }\end{array}$ & $\begin{array}{c}\text { Características VxI } \\
\text { inferiores ao ZnO sem } \\
\text { centelhador }\end{array}$ \\
\hline & Menor tensão residual & $\begin{array}{l}\text { Menor custo que } \mathrm{ZnO} \text { sem } \\
\text { centelhador }\end{array}$ \\
\hline & Não tem tensão disruptiva & $\begin{array}{c}\text { Centelhador com } \\
\text { montagem simplificada em } \\
\text { comparação aos de SiC }\end{array}$ \\
\hline & & $\begin{array}{c}\text { Menor tensão residual que } \\
\text { os de SiC }\end{array}$ \\
\hline & & $\begin{array}{l}\text { Menor corrente } \\
\text { subsequente }\end{array}$ \\
\hline
\end{tabular}

\subsection{5. \\ Ensaios de Verificação das Características de Proteção dos Para- raios}

As características de proteção dos para-raios dependem basicamente do tipo de para-raios utilizado, de forma que os parâmetros resultantes nos ensaios de verificação do para-raios atendam aos valores normalizados. Uma vez que estas características e o nível de isolamento dos equipamentos a serem protegidos indicam o grau de proteção oferecido pelo para-raios, esses ensaios tornam-se extremamente importantes para que sejam estabelecidos os critérios gerais de proteção [10].

Estes ensaios visam estabelecer as características de proteção dos para-raios, cobrindo os ensaios de tensão disruptiva de frequências industrial e de impulso, no caso de para-raios com centelhadores, e as tensões residuais provenientes de impulso de corrente. 


\subsubsection{1}

\section{Para-raios com centelhador}

As características de proteção dos para-raios com centelhadores são definidas pela IEC 99.1/91 e NBR 5287/88 e pelo Projeto de norma da NBR para $\mathrm{ZnO}$ com centelhadores como a combinação das seguintes curvas características:

- Tensão disruptiva de impulso atmosférico $x$ tempo para disrupção

Curva que relaciona a tensão disruptiva de impulso atmosférico ao tempo para disrupção, obtida a partir de ensaio de tipo para determinada forma de impulso e determinada polaridade, porém variando-se as amplitudes.

- Tensão residual $x$ corrente de descarga $8 / 20 \mu s$

Curva que relaciona a tensão residual do para-raios à corrente de descarga com forma de impulso $8 / 20 \mu$ s e amplitudes definidas em norma.

\section{- Tensão disruptiva de impulso de manobra $x$ tempo para disrupção (*)}

Curva que relaciona a tensão disruptiva de impulso de manobra ao tempo para disrupção, obtida a partir de ensaio de tipo em para-raios de $10 \mathrm{kA}$, com tensão nominal superior a $100 \mathrm{kV}$, e para-raios de $15 \mathrm{kA}\left(^{* *}\right)$ e $20 \mathrm{kA}$ $(* *)$.

(*) não aplicado ao projeto de norma da NBR referente ao para-raios de $\mathrm{ZnO}$ com centelhadores.

(**) valores utilizados somente na NBR 5287/88, aplicável a para-raios de SiC.

\subsubsection{2}

\section{Para-raios sem centelhador}

No caso de para-raios sem centelhadores as características de proteção são definidas pela IEC 99-4/06, pela combinação dos seguintes ensaios:

- Tensão residual para impulso de corrente com frente íngreme de $1 \mu \mathrm{s}$;

- Curva característica de tensão residual x corrente de descarga 8/20 $\mu \mathrm{s}$;

- Tensão residual para impulso de manobra.

O nível de proteção para impulso atmosférico e impulso de manobra é definido como o maior valor de tensão residual obtido nas amostras de ensaio, durante o ensaio de tipo, para a corrente de descarga nominal e o impulso de manobra especificado, respectivamente. 


\subsection{6. Ensaios de Verificação das Características de Operação}

Os ensaios de verificação das características de operação dos para-raios visam estabelecer as características operativas dos para-raios, cobrindo os seguintes ensaios: corrente elevada, corrente de longa duração (retangular e de descarga de linha de transmissão), alívio de sobrepressão, ciclo de operação convencional, ciclo de operação combinado com corrente elevada ou impulso de manobra, poluição artificial, tensão de ionização interna, descargas parciais, envelhecimento e ensaio em desligador automático (quando aplicável).

\section{2.}

\section{Aeronaves}

Um dos objetos alvos de ensaio com impulso de corrente são as aeronaves, frequentemente afetadas por descargas atmosféricas durante o voo, sendo seu sistema de proteção altamente relevante para a segurança da tripulação e dos passageiros.

As aeronaves cada vez mais possuem estruturas de materiais compósitos, geralmente de baixa condutividade elétrica, criando dificuldades para o sistema de proteção atmosférica nas aeronaves. Por este motivo é necessário pesquisar os efeitos destas descargas elétricas em tais materiais e desenvolver novas técnicas para o projeto e avaliação da proteção atmosférica das aeronaves.

Novos projetos de aeronaves utilizando inovações tecnológicas, sob cada vez mais severas regulamentações, requerem especialistas e exaustivas simulações e ensaios para atingir um alto grau de confiança no sistema de proteção contra raios.

A avaliação dos efeitos de um raio na aeronave é baseada em zonas de diferentes probabilidades de ocorrência de descargas atmosféricas. As zonas de raios definem a forma de onda e amplitude da descarga a ser aplicada durante os estudos de eficácia de novas tecnologias de proteção contra raios ou requalificação de soluções já em uso, bem como para indicar possíveis melhorias. Laboratórios de ensaios especializados são muito úteis nessas pesquisas de simulação de efeitos de impacto de raios, considerando as zonas de fixação e diferentes formas de onda das tensões e correntes. 
A Embraer S.A. até recentemente contratava laboratórios no exterior, principalmente nos Estados Unidos, para a realização de todos os ensaios de efeito direto de raios, devido à inexistência no Brasil de laboratórios preparados e qualificados para realizar estes tipos de ensaios para a indústria aeroespacial.

Uma parceria da Embraer com o CEPEL tornou possível a realização deste tipo de ensaio em solo brasileiro, desenvolvendo laboratórios e profissionais do CEPEL com o conhecimento e as técnicas necessárias para atingir a incerteza desejada para os resultados dos parâmetros sob ensaio. Esta parceria é de grande importância para ambas as empresas, pois o CEPEL se qualificou para a realização de ensaio de efeito direto de raios para a indústria aeroespacial e a Embraer reduziu consideravelmente os gastos e os prazos normalmente necessários para a realização de ensaios de efeitos diretos de raios [11].

\subsection{1.}

Normas

A MIL-STD-1757 A [38] desenvolvida em 1980, com última revisão em 1996, apresenta as formas de onda e técnicas do padrão de ensaio para ensaios de qualificação atmosférica de veículos aeroespaciais. As formas de onda deste documento destinam-se reproduzir os efeitos significativos do ambiente natural e são, portanto, independentes do tipo ou configuração do veículo. Os ensaios descritos incluem ensaios de dano físico ao tanque de combustível e equipamentos elétricos, bem como efeitos indiretos associados com descargas elétricas nos equipamentos montados externamente, envolvendo aplicações de alta tensão e alta corrente.

\subsection{2.}

\section{Zonas de Fixação}

Três zonas de fixação de raios são caracterizadas na superfície de veículos aeroespaciais [11]:

- Zona 1: Superfícies dos veículos para as quais há uma alta probabilidade de ocorrer o início do raio (entrada ou saída).

- Zona 2: Superfícies dos veículos para as quais existe uma alta probabilidade de serem alcançadas por um raio através do fluxo de ar, a partir de um ponto inicial (Zona 1). 
- Zona 3: Inclui todas as outras áreas dos veículos que não estejam abrangidos pelas regiões das Zonas 1 e 2. Na Zona 3, há uma baixa probabilidade de qualquer conexão direta com o arco elétrico do raio. As áreas da Zona 3 podem transportar quantidades substanciais de corrente elétrica por condução entre alguns pares de pontos de fixação iniciais ou varridos.

\subsection{3.}

\section{Formas de Onda}

Existem três formas de onda de tensão: A, B e D, que representam os campos elétricos associados a uma descarga elétrica. As formas de onda de tensão A e D são utilizadas para testar possíveis perfurações dielétricas e outros potenciais pontos de fixação. A forma de onda de tensão B é utilizada para testar os efeitos de arcos voltaicos. Existe também uma forma de onda $\mathrm{C}$, que é usada para dimensionar ensaios modelo, que não está coberta pela MIL-STD-1757A (ver Figura 29 e 30).

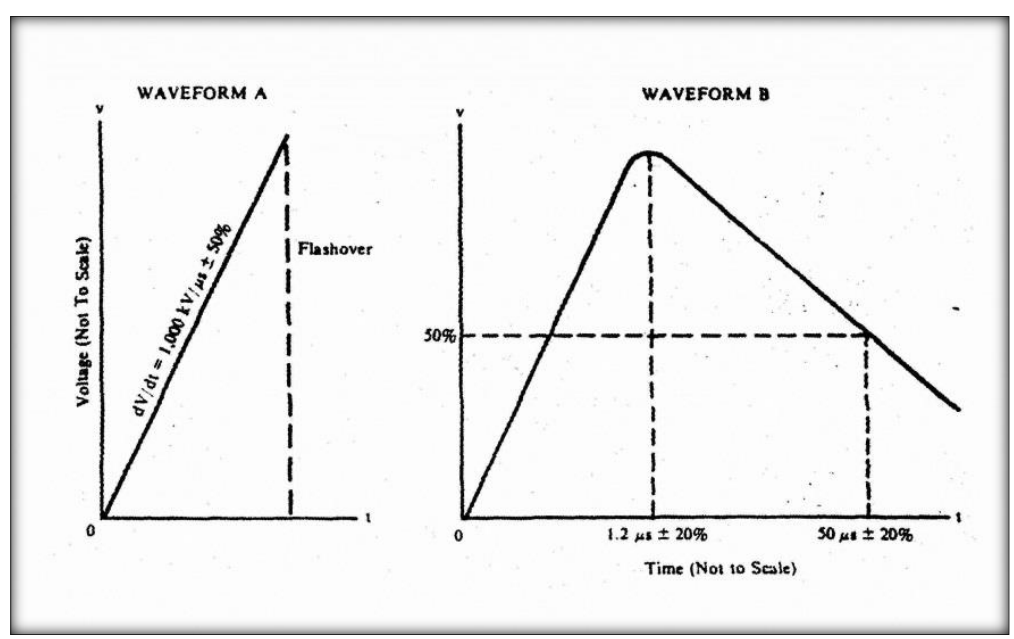

Figura 29: Formas de onda idealizadas A e B 


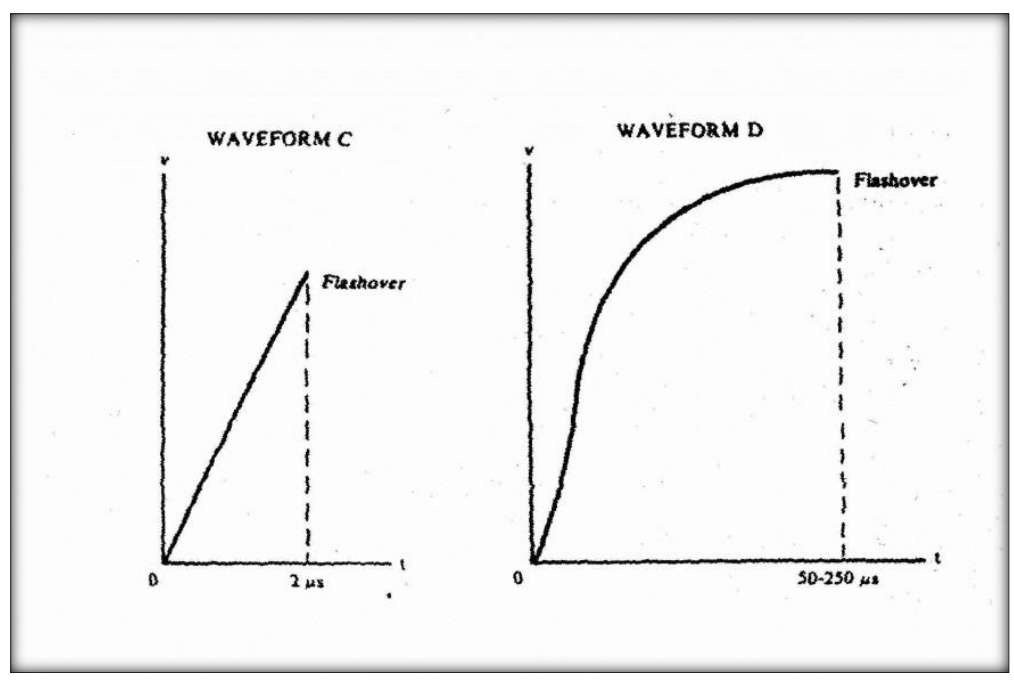

Figura 30: Formas de onda idealizadas C e D

Existem 4 componentes de corrente, A, B, C e D, que são utilizados para determinar os efeitos diretos (ver Figura 31). Cada componente tem a intenção de simular uma diferente característica da corrente proviniente de um raio em ambiente natural. Eles são aplicados individualmente, com dois ou mais componentes em um mesmo ensaio. Na norma MIL-STD-1757A existe também uma forma de onda $\mathrm{E}$, que é usada para determinar efeitos indiretos em um ensaio de descarga elétrica, com nível de crescimento rápido, no equipamento de tamanho real.

A Figura 31 apresenta as 4 formas de onda da corrente, as quais não estão em escala de amplitude ou tempo, mas a figura permite visualizar a variação da corrente em cada componente.

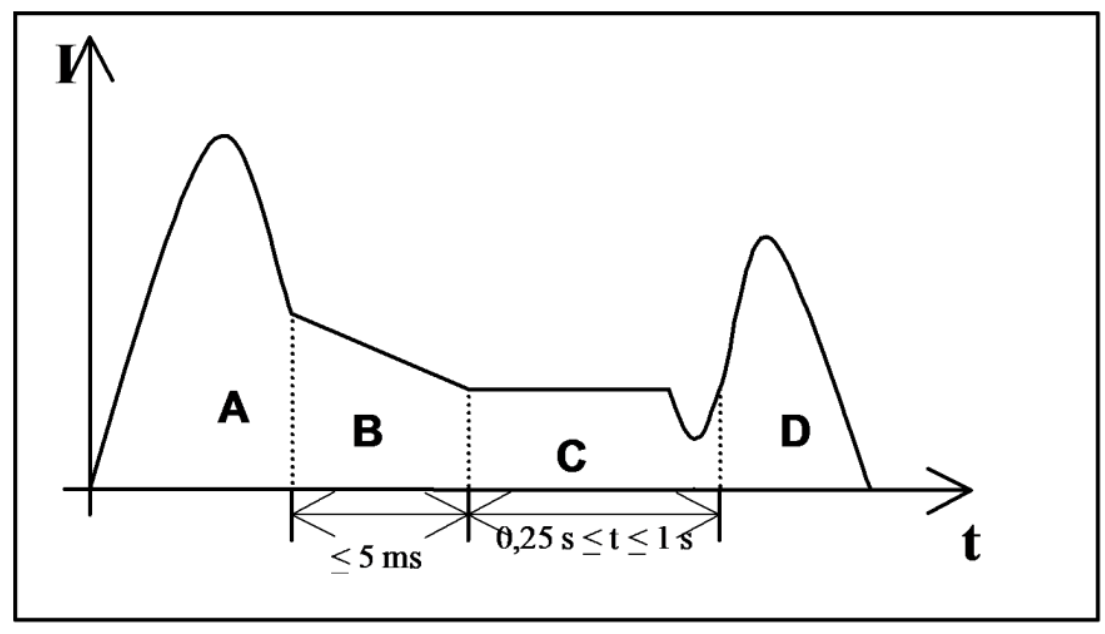

Figura 31: Forma de onda de corrente 


\subsection{4.}

\section{Valores dos Parâmetros das Formas de Onda}

A seguir detalham-se os principais parâmetros das formas de onda da tensão:

- Forma de onda A - Forma de onda atmosférica básica: Taxa média de crescimento de $1000 \mathrm{kV} / \mu \mathrm{s} \pm 50 \%$ até o seu crescimento ser interrompido por perfuração, ou é intermitente, do objeto sob ensaio. Neste momento a tensão decai para zero, ver Figura 29;

- Forma de onda $\mathbf{B}$ - Onda completa: Tempo de frente $\mathrm{T}_{1}=1,2 \mu \mathrm{s} \pm 20 \% \mathrm{e}$ tempo de cauda $\mathrm{T}_{2}=50 \mu \mathrm{s} \pm 20 \%$, ver Figura 29;

- Forma de onda D - Caracterizada pelo crescimento lento do tempo de frente da forma de onda, tipicamente entre 50 e $250 \mu \mathrm{s}$, para dar tempo dos arcos voltaicos se estabelecem no objeto sob ensaio, ver Figura 30.

A seguir detalham-se os principais parâmetros das formas de onda da corrente:

- Componente de corrente A - Descarga inicial: Pode ser unidirecional ou oscilatória. Amplitude de pico $200 \mathrm{kA} \pm 10 \%$, integral de ação $2 \times 10^{6} \mathrm{~A}^{2} . \mathrm{s} \pm$ $20 \%$, tempo de duração de $\leq 500 \mu$ s.

A integral de ação é definida por:

$$
\text { Integral de ação }=\int_{0}^{t} i(t)^{2} d t\left(\mathrm{~A}^{2} . \mathrm{s}\right)
$$

- Componente de corrente B - Corrente intermédia: Deve ser unidirecional, por exemplo, retangular, exponencial ou com decaimento linear. Tem amplitude média de $2 \mathrm{kA} \pm 10 \%$, tempo de duração $\leq 5 \mathrm{~ms}$ e uma carga de transferência $\leq 10$ A.s.

A carga de transferência é definida por:

$$
\mathrm{Q}=\int_{0}^{t} i(t) d t(\text { As ou Colombs) }
$$

- Componente de corrente C - Corrente contínua: Deve ser unidirecional, por exemplo, retangular, exponencial ou com decaimento linear. Carga de transferência de 200 A.s $\pm 20 \%$ e tempo de duração entre 0,25 e 1 s.

- Componente de corrente D - Corrente de re-descarga: Pode ser unidirecional ou oscilatória. Amplitude de pico $100 \mathrm{kA} \pm 10 \%$, integral de ação $0,25 \times 10^{6} \mathrm{~A}^{2} . \mathrm{s} \pm 20 \%$, tempo de duração de $\leq 500 \mu \mathrm{s}$. 


\subsection{5.}

\section{Proposta de Cada Ensaio}

Existem 5 diferentes tipos de ensaio que devem ser realizados no veículo [10]:

- T01 Ponto de fixação do hardware em tamanho completo - Zona 1: Realizado na estrutura em tamanho completo, incluindo superfícies não metálicas para determinar a possibilidade de perfuração e qualquer outro caminho percorrido pela corrente atmosférica atingindo algum elemento condutor ou para determinar posições específicas onde o ponto de fixação inicial do raio pode ser possível.

- T02 Efeitos diretos - Estruturas: Para determinar os efeitos diretos que resultam da interação de correntes atmosféricas com veículos e hardware aeroespaciais.

- T03 Efeitos diretos - Ignição do vapor do combustível: Para determinar a possibilidade de ignição do vapor do combustível como resultado de perfuração do componente, pontos quentes, faíscas ou arcos dentro ou próximos do sistema de respiro do combustível ou outra região onde possa existir vapor de combustível.

- T04 Efeitos diretos - Descarga de Corona e Arcos Voltaicos: Para determinar se arcos voltaicos ou descargas de coronas elétricas, que são pequenas faíscas, podem ser produzidas em aberturas ou próximas de aberturas ou em outros pontos onde arcos voltaicos ou descargas de coronas possam ser motivo de preocupação.

- T05 Efeitos indiretos - Equipamentos elétricos externos: Para determinar a amplitude dos efeitos indiretos quando descargas elétricas atigem equipamentos elétricos externos. Por ser realizado no objeto por completo, ou seja, em uma aeronave inteira, o ensaio é de difícil realização.

Nos métodos de ensaio são aplicados as formas de onda dos ensaios de tensão e os componentes de corrente específicados para cada tipo de métodos a ser utilizado e zona de fixação determinada, conforme descrito no Quadro 4.

Quadro 4: Aplicação de forma de onda por métodos de ensaio

\begin{tabular}{|c|c|c|c|}
\hline Método & Zona & Tensão & Corrente \\
\hline T01 & 1A,B & A, D & \\
\hline & 1A & & A, B \\
\cline { 2 - 4 } & 1B & & A, B, C, D \\
\cline { 2 - 4 } & 2A & & B, C, D \\
\cline { 2 - 4 } & 2B & & B, C, D \\
\cline { 2 - 4 } & 3 & & A, C \\
\hline T04 & & B & \\
\hline T05 & & & E \\
\hline
\end{tabular}




\subsection{6.}

\section{Estrutura do CEPEL para Ensaios em Aeronaves}

Ensaios atmosféricos são realizados em 2 laboratórios de ensaio do CEPEL. O primeiro é o laboratório de alta tensão (AT1), que possui gerador de impulso de tensão de até $1 \mathrm{MV}, 50 \mathrm{~kJ}$, disponível para os métodos de ensaios do tipo T01 e T04, ver Figura 32 e 33.

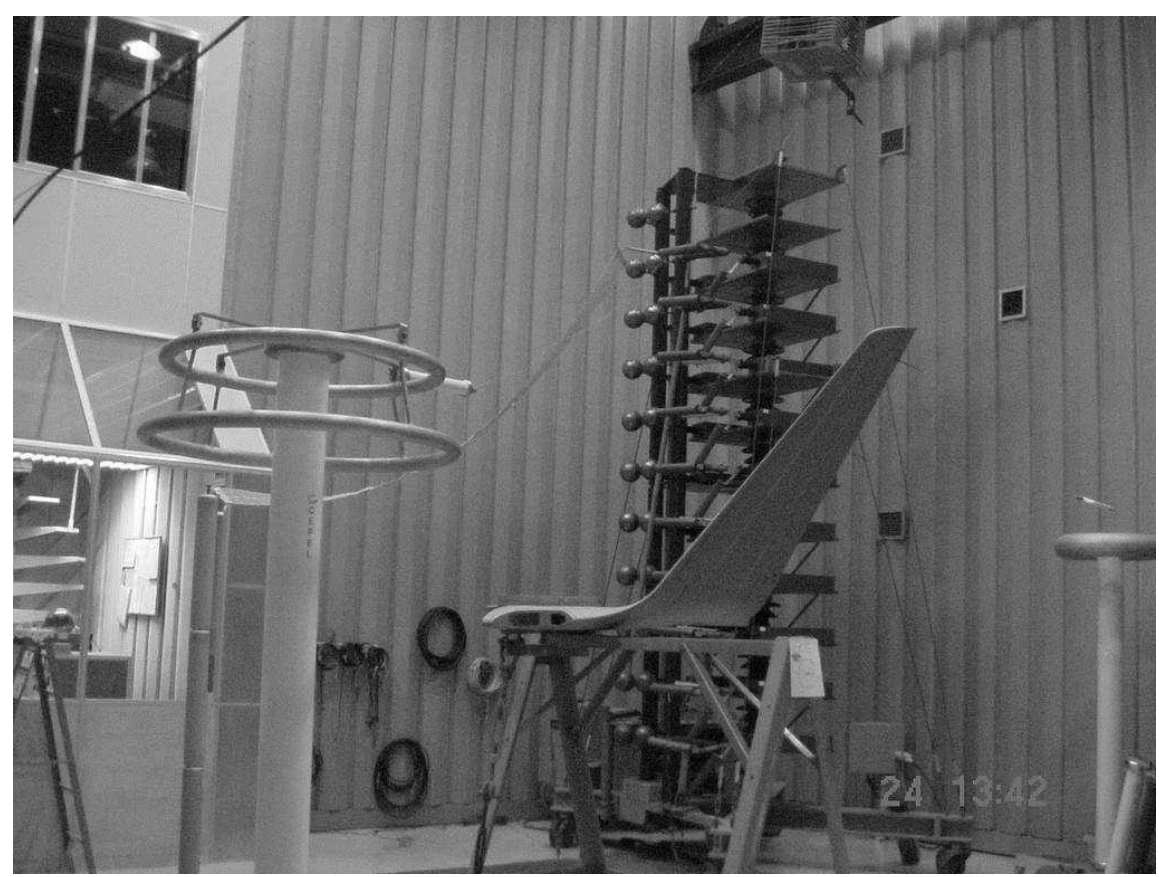

Figura 32: Ensaio T01 no lab. Alta Tensão do CEPEL 


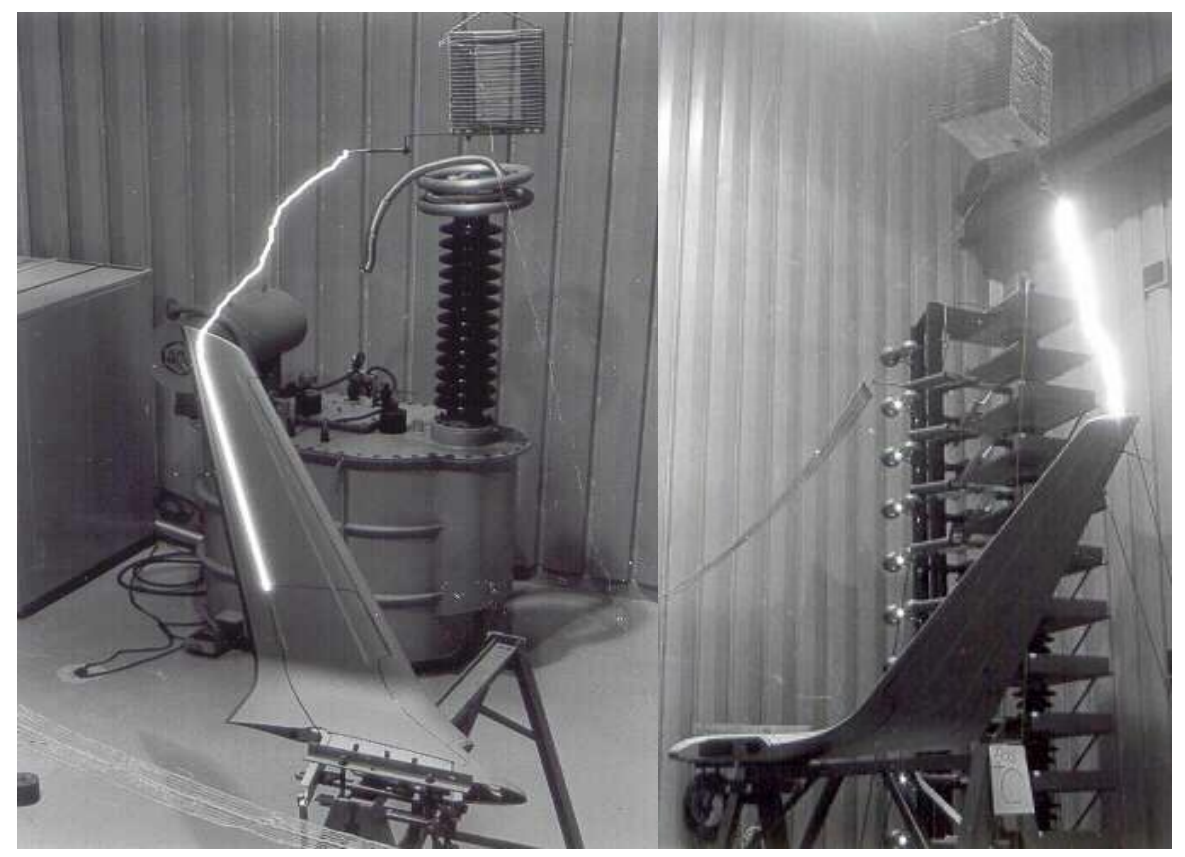

Figura 33: Ensaio T01 no lab. Alta Tensão do CEPEL

O segundo é o laboratório de para-raios (AT4), com capacidade de geração de impulsos de corrente, possuindo estrutura para gerar impulsos de corrente de até $200 \mathrm{kA}, 150 \mathrm{~kJ}$, disponível para os métodos de ensaios do tipo T02 e T03, ver Figura 34.

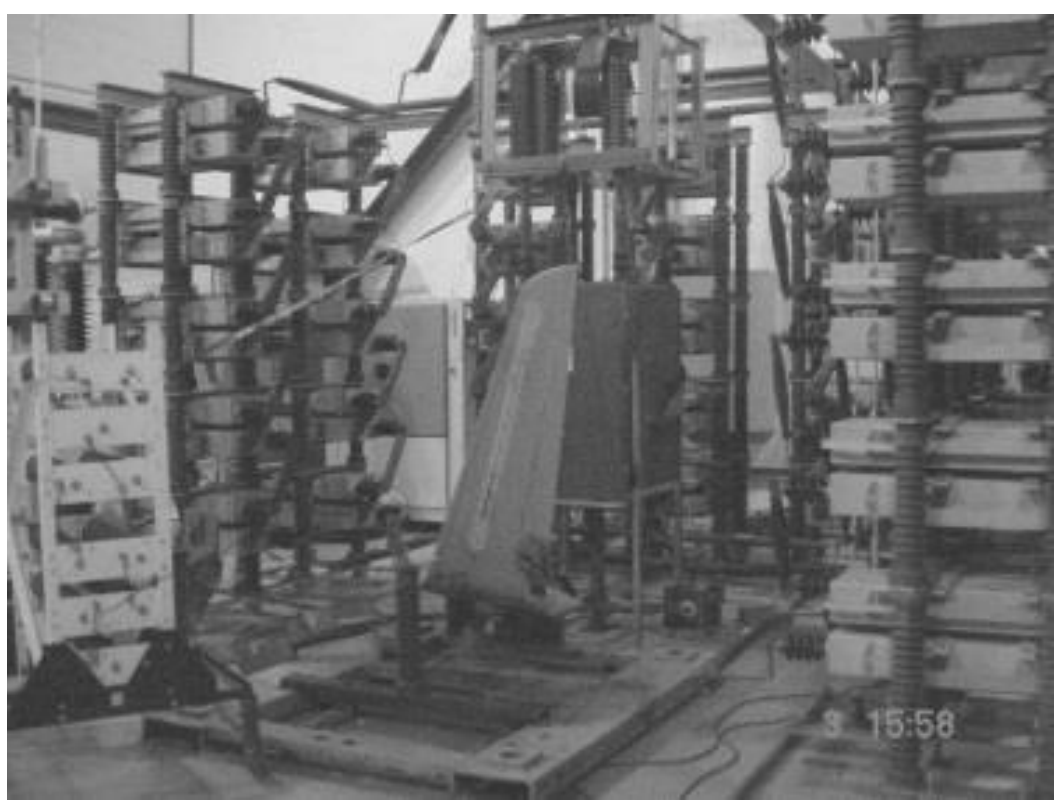

Figura 34: Ensaio T02 no lab. de para-raios do CEPEL

Os ensaios do tipo T02 de efeitos diretos da descarga elétrica atmosférica na estrutura da aeronave são realizados no AT4 e nas Figuras 35 e 36 é possível 
observar os efeitos do impacto de descargas elétricas. Em alguns destes ensaios a corrente é elevada ao nível de perfuração da estrutura externa da aeronave.

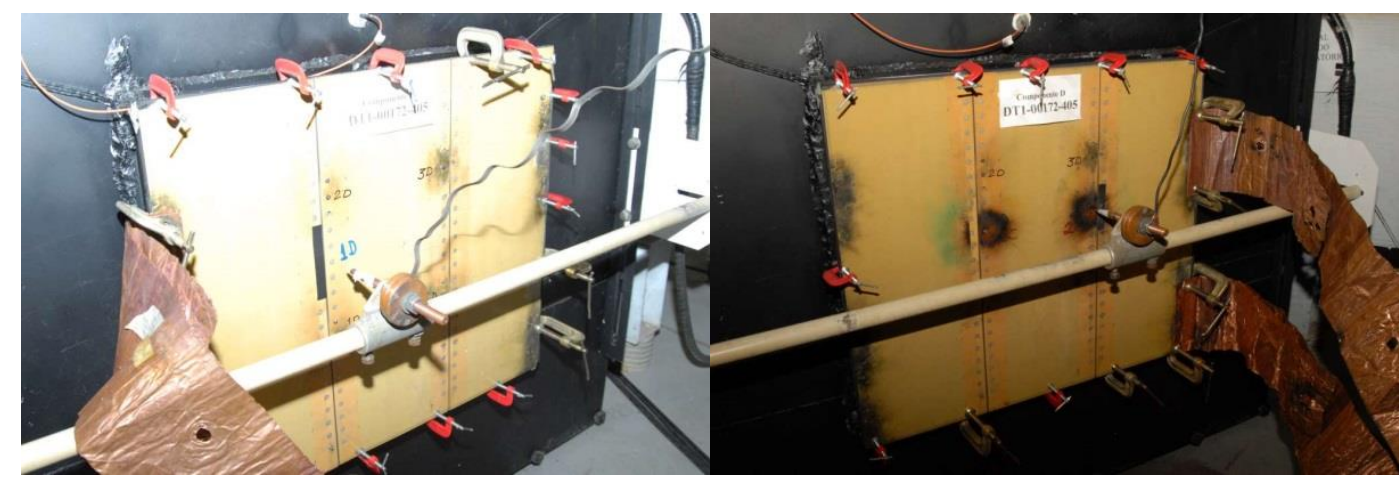

Figura 35: Ensaio T02 no CEPEL

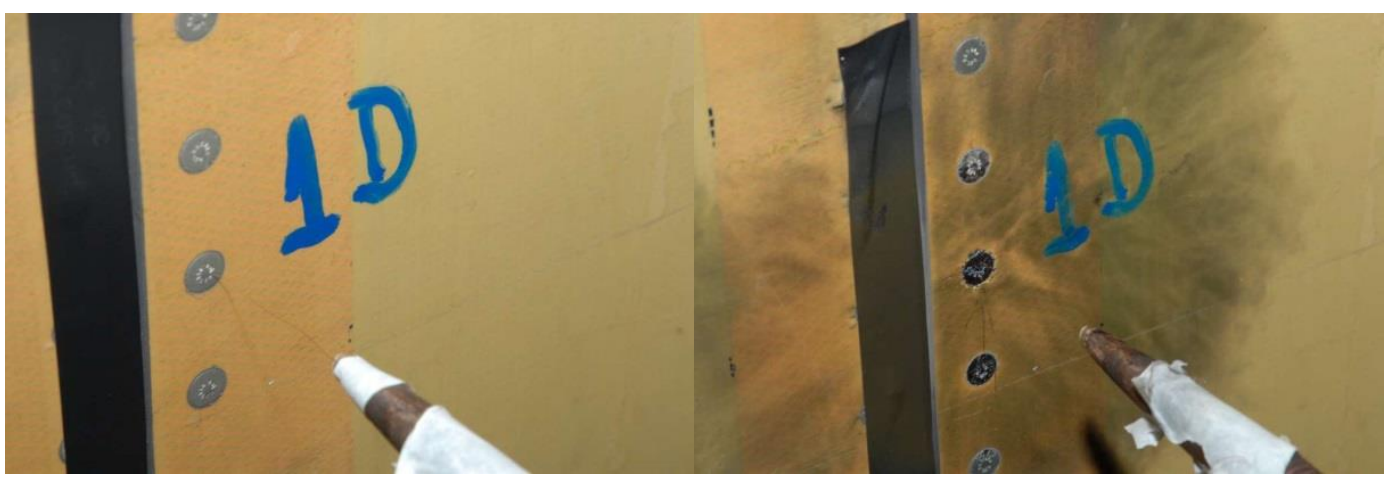

Figura 36: Ensaio T02 no CEPEL

A realização do ensaio T03 possui elevado nível de atenção e seus resultados devem ser precisos, pois a estrutura da asa da aeronave não pode permitir que o raio ou os efeitos do campo elétrico criado no momento da descarga atmosférica crie uma faísca nos reservatórios de combustível, ver Figura 37. 


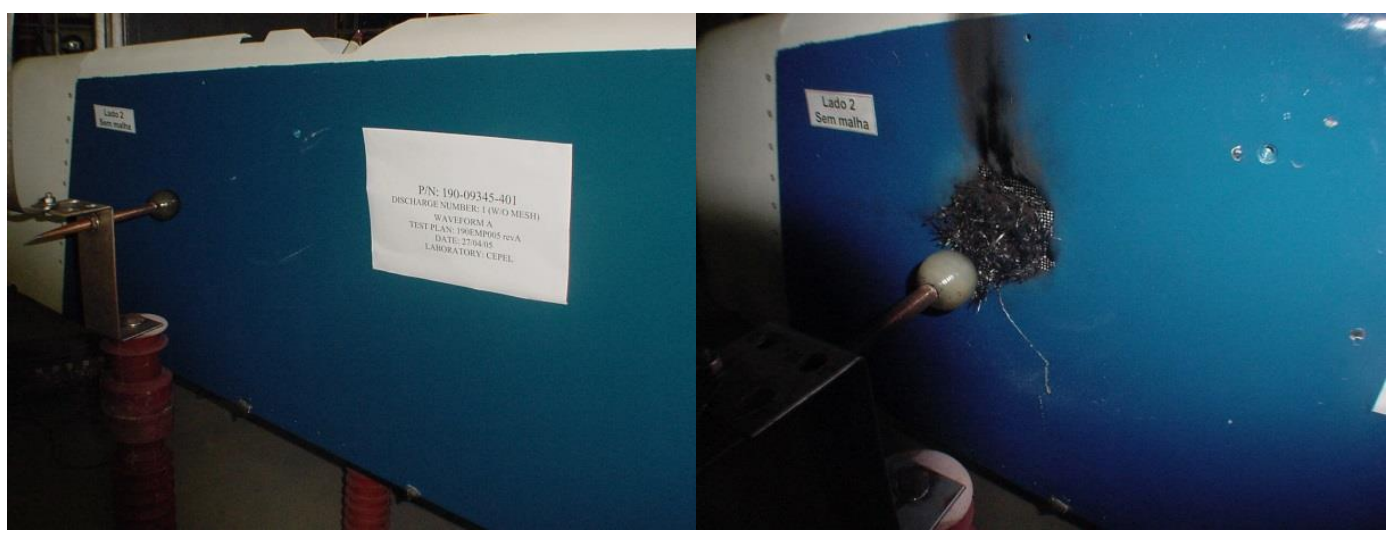

Figura 37: Ensaio T03

Em ambos os laboratórios existe uma estrutura adequada de sistema de medição, incluindo divisores de tensão, transformador de corrente de alta frequência e instrumentos de gravação. Alguns dispositivos especiais foram construídos, tais como eletrodos de injeção e um tanque padronizado para o método de ensaio T03. 


\section{6 Infraestrutura para Calibração e Rastreabilidade de Impulsos de Corrente}

Este capítulo apresenta a infraestrutura de laboratórios que fazem parte da cadeia metrológica do impulso de corrente, apresentando os Sistemas de Medição de Referência (SMR) e os Sistemas de Medição Aprovados (SMA) que são responsáveis pela calibração dos padrões de referência utilizados na indústria e em laboratórios de testes de equipamentos elétricos com impulso de corrente.

Além disso, caracteriza-se um SMR nacional que teria, como principal função, gerar conformidade e confiabilidade para os padrões nacionais, conectando os laboratórios nacionais com as referências internacionais do BIPM, completando assim a pirâmide de rastreabilidade do impulso de corrente.

O desenvolvimento tecnológico e a garantia da qualidade estão diretamente conectados ao avanço da metrologia. Sendo assim, países que possuem o setor metrológico pouco desenvolvido ficam vulneráveis na disputa comercial internacional e sua indústria nacional fica enfraquecida e desacreditada.

\section{1. \\ SMRs}

Um Sistema de Medição de Referência (SMR), segundo a norma IEC 62475o é definido como um sistema responsável por calibrar e se tornar um organismo acreditador para outros sistemas de medição que sejam capazes de realizar calibrações de padrões de medição a níveis de incerteza dentro da faixa aceitável. Estes sistemas de medição, que são calibrados pelos SMRs, são reconhecidos como Sistemas de Medição Aprovados (SMAs).

Atualmente, apenas 2 institutos metrológicos apresentam CMC declarada no BIPM para realizar calibrações como SMR em ensaios com impulso de corrente: o PTB da Alemanha e o MIKES da Finlândia. Nesta seção será apresentada a estrutura dos SMRs internacionais e possíveis SMRs nacionais [6]. 


\subsection{1. \\ Mikes}

O MIKES (Mittatekniikan keskus - Centre for Metrology and Accreditation), é um instituto de pesquisa com especialização na ciência e tecnologia da medição e, por ser o Instituto Nacional de Metrologia (INM) da Finlândia, é o responsável pelas pesquisas e desenvolvimento dos padrões de medição e pela implementação do SI na Finlândia.

A sede do MIKES se encontra na cidade de Espoo, próxima a Helsinque, e possui uma filial na cidade de Kajaani, que é o Laboratório Nacional de Metrologia mais ao Norte do mundo. Os seus laboratórios fornecem calibrações e medições com alta exatidão e precisão gerando mais de 1600 certificados por ano na Finlândia [12].

O MIKES é signatário do CIPM MRA (Acordo de Reconhecimento Mútuo do Comitê Internacional de Pesos e Medidas - International Committee for Weights and Measures, Mutual Recognition Arrangement) e membro da EURAMET (Associação Europeia dos Institutos Nacionais de Metrologia European Association of National Metrology Institutes). Com a colaboração internacional o MIKES está ligado diretamente às pesquisas do sistema internacional de medidas e às investigações metrológicas na comunidade europeia e internacional.

A procura pelos certificados de calibração emitidos pelo MIKES é de escala global, inclusive de laboratórios brasileiros, devido ao mesmo ser formado por uma equipe de alto nível de qualificação e possuir laboratórios modernos. Seus laboratórios são referência e procurados constantemente para realização de ensaios de calibração em alta tensão.

Apresentam-se abaixo algumas das áreas da eletricidade nas quais o MIKES é acreditado para realização de ensaios de calibração:

- Calibração de tensão e corrente contínua;

- Calibração de tensão e corrente alternada;

- Calibração de padrões de indutância e capacitância;

- Calibração de resistores;

- Alta tensão e alta corrente; 
O MIKES possui um dos 2 laboratórios no mundo que são acreditados pelo BIPM para realização de ensaios de calibração em alta tensão com impulso de currente. Seus padrões de medição realizam ensaios na faixa de 1 A a 10000 A com incerteza expandida relativa de $30 \mathrm{~mA} / \mathrm{A}$. Seus padrões de medição foram aprovados em abril de 2009 pelo BIPM e, como a norma IEC 62475 específica para ensaios com impulso de corrente só foi publicada em 2010, seus padrões ainda não foram aprovados na nova norma.

Como o tema desta dissertação envolve ensaios em alta tensão e alta corrente, apresentam-se abaixo na Tabela 4 mais detalhes sobre a capacitação do MIKES nestas áreas.

Tabela 4: Serviços de calibração em alta tensão, fonte MIKES

\begin{tabular}{|c|c|c|}
\hline Grandeza & Faixa de medição & Incerteza $(\mathrm{k}=2,95 \%)$ \\
\hline Tensão contínua & $1 \mathrm{kV}-200 \mathrm{kV}$ & $0,005-0,05 \%$ \\
\hline $\begin{array}{l}\text { Tensão alternada, relação de } \\
\text { tensão }\end{array}$ & $1 \mathrm{kV}-200 \mathrm{kV}$ & $0,002-0,01 \%$ \\
\hline - Erro de fase & $0-100 \mathrm{mrad}$ & $0,02 \mathrm{mrad}$ \\
\hline $\begin{array}{c}\text { Corrente alternada, relação de } \\
\text { corrente }\end{array}$ & $0,2 \mathrm{kA}-3 \mathrm{kA}$ & $0,02-0,06 \%$ \\
\hline - Erro de fase & $0-100 \mathrm{mrad}$ & $0,2-0,4 \mathrm{mrad}$ \\
\hline Capacitância & $1-100 \mathrm{kV} / 10 \mathrm{pF}-200 \mu \mathrm{F}$ & $0,002-0,05 \%$ \\
\hline Perda do coeficiente da $\tan \delta$ & $1.10^{-5}-2$ & $1 \%\left(1.10^{-5} \mathrm{abs}\right)$ \\
\hline Indutância / perdas & $1 \mu \mathrm{H}-10 \mathrm{H}$ & $0,03 \% / 0,2 \mathrm{mrad}$ \\
\hline Impulso atmosférico & $50 \mathrm{mV}-400 \mathrm{kV}$ & $0,1-0,5 \%$ \\
\hline Impulso de manobra & $1 \mathrm{~V}-200 \mathrm{kV}$ & $0,1-0,2 \%$ \\
\hline $\begin{array}{l}\text { Outros impulsos de tensão (ex. } \\
\text { Oscilatório) }\end{array}$ & $1 \mathrm{~V}-400 \mathrm{kV}$ & $0,1-0,5 \%$ \\
\hline Impulso de corrente & $1 \mathbf{A}-10 \mathbf{k A}$ & $3 \%$ \\
\hline
\end{tabular}

Em alguns casos o cliente solicita a calibração do sistema de medição completo e não apenas do instrumento de medição. O MIKES realiza calibrações nas instalações do cliente se assim solicitado, mas as melhores incertezas são alcançadas em seus próprios laboratórios.

Os dispositivos que são calibrados pelo Mike incluem os seguintes:

- Divisores de tensão;

- Transformadores de tensão e corrente; 
- Pontas de prova, sensores de tensão e corrente, e shunts de corrente;

- Capacitores e indutores de alta tensão;

- Gravadores de fenômenos transitórios e medidores de valores de pico;

\subsection{2. PTB}

O PTB (Physikalisch-Technische Bundesanstalt) é o Instituto Nacional de Metrologia da Alemanha e é o outro instituto metrológico que assim como o MIKES possui laboratório com um Sistema de Medição de Referência (SMR) aprovado pelo BIPM [13].

A sede do PTB na Alemanha fica na cidade de Braunschweig desde 1947, com 8 das 10 divisões de trabalho e ocupa uma área de aproximadamente $1 \mathrm{~km}^{2}$. A sede mais tradicional do PTB fica em Berlin- Charlottenburg (desde 1887), e uma terceira base de laboratórios fica em Berlin-Adlershof com estudos focados em radiação síncrotron ou radiação eletromagnética, como UV e raios X.

O Instituto subdivide-se em 10 divisões com 60 departamentos aproximadamente. A divisão de interesse para o presente estudo é a divisão 2 Eletricidade, que concentra suas pesquisas nas 3 unidades base da eletricidade, ampere, volt e ohm, utilizando tecnologias de medição em alta-frequência e medição de energia com eletrônica quântica.

A divisão de Eletricidade oferece vários serviços de calibração e aconselha as autoridades governamentais, organizações de normalização e da indústria sobre questões relativas medições elétricas. Além disso, também são oferecidos programas de transferência de conhecimento, de suporte a inovação e crescimento econômico.

Os departamentos que constituem a divisão Eletricidade são:

- Corrente Contínua e Baixa frequência;

- Alta frequência e Campos Eletromagnéticos;

- Técnicas de Medição de Energia Elétrica;

- Eletrônica Quântica;

- Física dos Semicondutores e Magnetismo;

- Metrologia da Eletricidade Quântica. 
Dentre os departamentos de Eletrica o que estuda técnicas de medição de energia em alta tensão e alta corrente é o 2.3 Técnicas de Medição de Energia Elétrica, que é formado por 4 grupos de trabalho:

- Transformadores e Sensores;

- Metrologia de Alta-Tensão;

- Potência, Energia e Suporte para Centros de Testes Aprovados;

- Conjunto de Medição e Sistemas de Medição de Energia Elétrica.

Esses grupos de trabalho possuem muitas áreas de pesquisa que estão diretamente relacionadas com o ensaio de sistemas de medição com impulso de corrente, mas o grupo de trabalho que pesquisa técnicas de calibração de equipamentos em alta-tensão é o 2.3.2 Metrologia de Alta-Tensão que tem como objetivo "Calibração de equipamentos para medição em alta tensão/corrente CA,CC e impulso de tensão, para impulso de corrente, descargas parciais, capacitância e fator de perda", dentre outros objetivos.

O PTB possui aprovação pelo BIPM para realizar ensaio de calibração com impulso de corrente em duas faixas de medição, diferenciadas pelo nível de incerteza entre eles.

Tabela 5: Faixas de operação do PTB aprovadas pelo BIPM em 2013

\begin{tabular}{cc}
\hline Faixas de corrente de medição & Incerteza relativa \\
\hline $50 \mathrm{~A}-5000 \mathrm{~A}$ & $5 \times 10^{-3}$ \\
$5001 \mathrm{~A}-20000 \mathrm{~A}$ & $6 \times 10^{-3}$ \\
\hline
\end{tabular}

O PTB possui seus sitemas medição com selo de aprovação mais recente que o MIKES (MIKES 2009 e PTB 2013) [6], mas ambos foram aprovados de acordo com a norma IEC 60060 Técnicas de Ensaio em Alta Tensão específica para ensaios em Alta Tensão. Os laboratórios devem atualizar-se, em breve, para adequação à nova norma para ensaio de impulso de corrente. 


\subsection{3.}

Inmetro

Em 1973 o Brasil criou o Instituto Nacional de Metrologia, Normalização e Qualidade Industrial, o Inmetro, atualmente chamado Instituto Nacional de Metrologia, Qualidade e Tecnologia.

O Inmetro é dividido em 9 divisões, cada uma possuindo um laboratório metrológico no campus do Inmetro que se localiza em Xerém, RJ, sendo estes os laboratórios [14]:

- Laboratórios de Metrologia Acústica e de Vibrações;

- Laboratórios de Metrologia Mecânica;

- Laboratórios de Metrologia Química;

- Laboratórios de Metrologia Térmica;

- Laboratórios de Metrologia Óptica;

- Laboratórios de Metrologia Elétrica;

- Laboratório de Metrologia em Telecomunicações;

- Laboratórios de Metrologia de Materiais;

- Laboratório de Metrologia em Dinâmica de Fluidos.

Além desses laboratórios, o Inmetro conta ainda com laboratórios que operam por delegação supervisionada, que são:

- Laboratório da Hora do Observatório Nacional (DSHO/ON);

- Laboratório Nacional de Metrologia das Radiações Ionizantes (LNMRI) do Instituto de Radioproteção e Dosimetria (IRD/CNEN).

A Divisão da Metrologia Elétrica (Diele) é composta por 6 laboratórios de referência, responsáveis pela manutenção, realização e disseminação das unidades elétricas, e por guardar e primar pela conservação e rastreabilidade dos padrões nacionais de dez grandezas elétricas. São os seguintes laboratórios:

- Laboratório de Calibração em Metrologia Elétrica (Lacel),

- Laboratório de Metrologia em Alta Tensão (Lamat),

- Laboratório de Metrologia de Campo Elétrico e Magnético (Lamce),

- Laboratório de Metrologia em Energia Elétrica (Lamel),

- Laboratório de Metrologia em Padronização Elétrica (Lampe),

- Laboratório de Metrologia Elétrica Quântica (Lameq). 
Dos laboratórios de elétrica, o que se identifica mais com o tema desta dissertação é o Lamat, que possui a missão de proporcionar a rastreabilidade para medições em alta tensão alternada (CA) e contínua (CC), alta corrente alternada (CA) e capacitância em alta tensão. Possui padrões de relação de tensão (CA/CC), padrões de relação de corrente (CA), capacitância em alta tensão e pontes de medição e comparações em corrente e capacitância. Também oferece serviços de calibração de instrumentos de alta tensão e alta corrente, tais como fontes, divisores, transformadores de potencial e de corrente, kilovoltímetros, bobinas de corrente, amperímetros de alicate, capacitores de alta tensão e fatores de dissipação. Na Figura 38 é apresentada uma das estruturas disponíveis no Lamat.

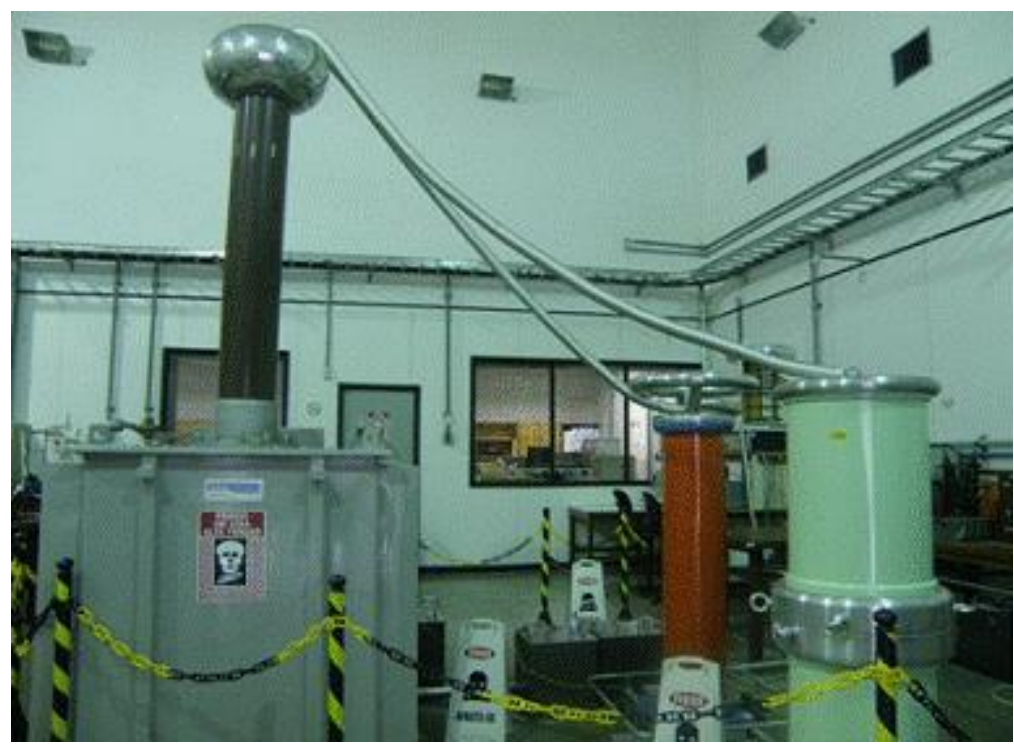

Figura 38: Sistema de medição de referência de alta tensão alternada e corrente alternada no Lamat

O Lamat mantém a unidade de corrente CA por meio de seu sistema de referência em alta corrente. O Sistema de Referência em Alta Corrente CA é composto por uma ponte comparadora de medição de erros de relação e defasagem angular, além de transformadores de corrente padrão, todos do fabricante Tettex. Este Sistema de Referência em Alta Corrente tem seus componentes calibrados individualmente pelo PTB e é utilizado para calibrar, por comparação, transformadores de corrente, amperímetros de alicate, além de caracterizar bobinas de corrente.

A necessidade levantada por esta dissertação é a lacuna existente na área de medição de alta corrente relacionada ao ensaio de impulso. Este ensaio é regido 
pela norma internacional IEC 62475 de forma separada dos ensaios com corrente alternada (CA) ou corrente contínua (CC). O ensaio com impulso só pode ser realizado com transformadores apropriados para leitura de corrente em alta frequência e, da mesma forma, o sistema de medição deve ser apropriado para a realização e reprodução do ensaio.

Assim, atualmente, os transformadores de corrente, TCs utilizados em ensaios de tipo, verificação e rotina dos para-raios nacionais não possuem rastreabilidade e confiabilidade, já que os mesmos não são fiscalizados e regulamentados pelo Inmetro.

\subsection{4.}

\section{CEPEL}

O CEPEL, Centro de Pesquisas de Energia Elétrica, foi fundado, em 1974, pela Eletrobras e suas subsidiárias Furnas, Chesf, Eletronorte e Eletrosul, com a missão de conceber e fornecer soluções tecnológicas voltadas à geração, transmissão e distribuição de energia elétrica. Desde sua criação, desenvolve projetos de Pesquisa, Desenvolvimento e Inovação (P\&D+I) e presta serviços tecnológicos e laboratoriais para as empresas Eletrobras e todo o setor elétrico brasileiro.

Como principal fonte de fomento a pesquisa em energia elétrica para o setor elétrico Brasileiro, o CEPEL possui no seu organograma uma Diretoria Geral DG, uma Diretoria Administrativa - DA, uma Diretoria de Pesquisa experimental - DL, responsável pelos laboratórios de ensaios e calibração e uma Diretoria de Pesquisa, Desenvolvimento e Inovação - DP.

\subsubsection{1.}

\section{Áreas de conhecimento}

As áreas de conhecimento estão principalmente localizadas nas Diretorias DL e DP. Essas Diretorias são subdivididas em departamentos de acordo com a área de conhecimento específico. De forma simplificada são apresentadas a seguir algumas das principais atividades dos Departamentos da DL e DP.

- Automação de sistemas (DAS) - Tem como base a análise de perturbações nas redes; automação pontual de instalações e inteligência artificial voltada para 
operações em sistemas elétricos; tecnologias com o intuito de operar sistemas elétricos em tempo real.

O principal produto desenvolvido nesta área é o software responsável pelo gerenciamento da malha nacional de transmissão de energia elétrica de alta tensão, denominado SAGE (Sistema Aberto de Gerenciamento de Energia). Tal software é utilizado pela maioria das concessionárias de transmissão e distribuição do país, isso inclui as empresas Eletrobrás, possuindo cerca de 600 instalações no sistema elétrico [31].

- Linhas e Estações (DLE) - Consistem em novas concepções e otimização de projetos de linhas de transmissão; tecnologias, modelagens, medições e estudos de linhas de transmissão e equipamentos; monitoramento e diagnóstico de equipamentos e instalações; interações entre linhas de transmissão e meio ambiente; desempenho elétrico e mecânico de linhas de transmissão.

- Laboratórios (DLA) - Unidade Adrianópolis - O CEPEL possui um complexo de 31 laboratórios, sendo 24 deles instalados em sua sede, na Unidade Ilha do Fundão, no Rio de Janeiro; e 7 na unidade de Adrianópolis, em Nova Iguaçu (RJ). Vários desses laboratórios são pioneiros em suas atividades no Brasil, e por vezes únicos na América do Sul. As principais especialidades envolvidas são: alta tensão e potência, materiais; eficiência energética; medição; calibração; supervisão e controle e computação intensiva.

Os laboratórios atuam basicamente em desenvolvimento de técnicas de ensaios de medição, certificação de serviços e produtos, ensaio de equipamentos e materiais de grandezas elétricas, ensaios especiais em rede e desenvolvem pesquisa experimental.

- Otimização energética e Meio Ambiente (DEA) - Consiste em metodologias e programas computacionais para o planejamento da expansão e operação de sistemas hidrotérmicos interligados para incorporação da dimensão ambiental no planejamento da expansão e da transmissão; hidrologia estocástica, recursos hídricos e ventos; inventário de bacias hidrográficas; análise de projetos e tarifas e técnicas computacionais aplicadas à área energética.

- Redes elétricas (DRE) - Consiste em metodologias e programas computacionais para planejamento, operação e análise de redes elétricas. Atua a fim de promover confiabilidade de geração e transmissão; planejamento da 
expansão da transmissão e estudos de sistemas elétricos, amplamente utilizados por todo o setor elétrico do país.

- Tecnologia de distribuição (DTD) - Consistem em sistemas de medição e de gerenciamento da demanda e redução de perdas técnicas e comerciais; soluções tecnológicas para redes elétricas inteligentes (smart grids); tecnologias para automação de processos associados à distribuição e medição; análise e diagnóstico para a garantia da qualidade de energia elétrica.

- Tecnologias especiais (DTE) - Consiste em eficiência energética; novas fontes renováveis e geração distribuída; células a combustível e geração de hidrogênio; metalurgia e materiais; supercondutividade e nanotecnologias.

\subsubsection{2. Áreas de atuação}

Além dos diversos ensaios realizados para pesquisa em diversas áreas da engenharia elétrica, o CEPEL também é conhecido como referência no campo da calibração de instrumentos de medição e sistemas de medição. O laboratório de calibração do CEPEL é localizado no campus de Adrianópolis (DLA), possuindo capacidade para atuar na calibração de inúmeras grandezas elétricas, como: medições de capacitância (capacitor, década capacitiva, medidor de capacitância), medições de corrente CA (fonte de corrente CA e medidor de corrente CA), medições de corrente CC (fonte de corrente CC e medidor de corrente CC), medições de potência CA (medidor de potência ativa), medições de resistência (década resistiva, medidor de resistência e resistor padrão), medições de tensão CA (fonte de tensão CA e medidor de tensão CA), medições de tensão CC (fonte de tensão $\mathrm{CC}$ e medidor de tensão $\mathrm{CC}$ ). Outra categoria de medições realizadas pelo CEPEL é a de impulso de tensão $(100 \mathrm{kV}$ a $500 \mathrm{kV}$, com tempo de frente $=$ $0,9 \mu \mathrm{s}$, tempo de frente $=1,5 \mu$ s e tempo de corte $=0,5 \mu \mathrm{s}$ ).

Outra categoria de calibração que o CEPEL realiza é a calibração de sistemas de medição, utilizados em ensaios de alta tensão para CA, CC, impulso atmosférico, impulso cortado e impulso de manobra, com certificados de calibração para os sistemas de medição aprovados.

Os pesquisadores do laboratório de calibração realizam trabalhos de consultoria e palestras de instrução em medição para as empresas que contratam 
os seus serviços, além de viajarem para realizar calibrações nas instalações do cliente.

O CEPEL tem como projeto montar uma infraestrutura para ensaios de calibração de sistemas de medição com impulso de corrente. Os transformadores de corrente (TCs) utilizados nos laboratórios internos já são calibrados internamente mas, devido ao fato do Inmetro ainda não oferecer rastreabilidade para esse tipo de ensaio, os padrões de referência de TC têm que ser enviados ao exterior, para o MIKES ou PTB, para serem calibrados, o que gera um custo alto para um ensaio de calibração que não é rastreável nacionalmente.

\section{2.}

\section{Sistemas de Medição Aprovados - SMAs}

Os SMAs são sistemas de medição estruturados para exercerem a mesma função que os SMRs, mas o nível de incerteza é um pouco maior e os requisitos para ensaio são menores segundo a norma, ou seja, um SMA é um sistema de medição que foi aprovado por um SMR, pelo método da comparação de resultados ou por calibração individual dos equipamentos.

Essa seção apresenta os SMAs internacionalmente conhecidos e possíveis SMAs nacionais para ensaios de impulsos de corrente. Estes SMAs nacionais seriam clientes de futuras calibrações dos seus padrões e sistemas de medição pelo SMR nacional proposto nesta dissertação.

\subsection{1.}

\section{CESI/Itália}

O CESI possui um posicionamento único em consultoria e serviços de engenharia destinados ao setor elétrico. De acordo com a família de normas ISO 9000 e ISO/IEC 17025, a calibração periódica de equipamentos de medição é obrigatória e os certificados de calibração são a prova da rastreabilidade. Os laboratórios de calibração do CESI emitem certificados e são acreditados desde 1995 [15].

Estes são os equipamentos diretamente ligados à grandeza corrente elétrica que atualmente são calibrados pelo CESI:

- Transformadores de corrente, 
- Instrumentos de medição e bobina de Rogowski,

- Shunts,

Utilizando estes equipamentos, o CESI é capaz de realizar ensaios de alta corrente segundo a IEC 62475, podendo medir impulsos de corrente até 8 kA 8/20 $\mu \mathrm{s}$.

\subsection{2. HIGHVOLT}

A HIGHVOLT (Prüftechnik Dresden $G m b H$ ) é líder mundial em sistemas de ensaio e medição de alta tensão com percentagem de exportações de aprox. 90\%. Em Dresden, Alemanha, são desenvolvidos e fabricados sistemas para ensaios de dispositivos de transmissão e distribuição de energia elétrica, tais como transformadores, cabos e mecanismos de comutação. Além disso, equipa instituições de pesquisa e ensino com os seus sistemas [16].

A empresa está no mercado de sistemas de ensaio e medição de alta tensão há mais de 100 anos. A HIGHVOLT surgiu em 1995 como uma continuidade da Koch \& Sterzel, fundada em 1904 que, nessa altura, foi o fabricante líder alemão no setor de transformadores, transformadores de medição e sistemas de ensaio de alta tensão. Após a Segunda Guerra Mundial, a empresa foi renomeada para Transformatoren- und Röntgenwerk (TuR). Depois da unificação da Alemanha em 1991, a TuR foi comprada pela Siemens AG. Em 1995, a Siemens separou o setor técnicas de teste de alta tensão do restante de suas atividades. Em consequência, a HIGHVOLT foi estabelecida como uma empresa independente. Desde 2002 a HIGHVOLT é membro do grupo Reinhausen Group.

Em 18 de julho de 2014 a HIGHVOLT não só renovou a sua acreditação na DIN EN ISO/IEC 17025:2005, como também expandiu significativamente o escopo de acreditações de seus laboratórios de calibração. Com efeitos imediatos, o laboratório de calibração da HIGHVOLT ampliou seus serviços de calibração, incluindo sistemas de medição de impulso de corrente e energia CA. O parâmetro de energia CA é utilizado para avaliar eficiência energética de equipamentos de engenharia elétrica. No caso da calibração com impulso de corrente, capacitou-se de modo a calibrar com impulsos de até $200 \mathrm{kA}$ e formas de onda 8/20 $\mu$ s, dependendo dos sistemas individuais de medição. 


\subsection{3.}

CPRI

O Central Power Research Institute (CPRI) é o centro de pesquisas em energia da indústria de energia elétrica da Índia, criado em 1960 pelo governo e funcionando como um centro de pesquisa aplicada em engenharia elétrica, auxiliando a indústria elétrica no desenvolvimento de produtos e na garantia da qualidade. O CPRI também funciona como uma autoridade independente para testes e certificações de equipamentos elétricos. O CPRI emprega mais de 300 engenheiros e cientistas e pessoal de apoio [17].

O Laboratório de Impulso de Corrente foi criado em 1996 como uma instalação de ensaio em elementos de Óxido de Zinco $(\mathrm{ZnO})$ e para-raios de $\mathrm{ZnO}$ com seções de suporte até $11 \mathrm{kV}$, avaliados de acordo com a norma IEC 60099-4, considerando a importância do para-raios de $\mathrm{ZnO}$ que está sendo cada vez mais utilizado. O diferencial do laboratório de impulso de corrente do CPRI está no fato do mesmo possuir um gerador de impulso de corrente controlado por computador na faixa de até $100 \mathrm{kA}$, com capacidade de $150 \mathrm{~kJ}$. Na Tabela 6 são apresentados alguns tipos de ensaio com impulso de corrente realizados no CPRI.

Tabela 6: Formas de onda do CPRI

\begin{tabular}{ccc}
\hline Tipo de onda & Forma de Onda & Amplitude \\
\hline Impulso de corrente atmosférico & $8 / 20 \mu \mathrm{s}$ & $50 \mathrm{kA}$ \\
Impulso de alta corrente & $4 / 10 \mu \mathrm{s}$ & $120 \mathrm{kA}$ \\
Impulso de corrente acentuado & $1 / 20 \mu \mathrm{s}$ & $20 \mathrm{kA}$ \\
Impulso de corrente de manobra & $36 / 90 \mu \mathrm{s}$ & $2 \mathrm{kA}$ \\
Impulso de corrente retangular & Máximo de $4000 \mu \mathrm{s}$ & $1 \mathrm{kA}$ \\
\hline
\end{tabular}

O gerador possui acessorios separados, como resistores separados, para realizar as medições de cada um dos tipos de ensaio referidos, com indutores e resistores moldando as formas de onda. São 12 estágios no total, com um capacitor de 2,5 $\mu \mathrm{F}$ em cada estágio.

O CPRI realiza todos os tipos de ensaio em para-raios de $\mathrm{ZnO}$ com blocos de até $6 \mathrm{kV}$ nos padrões nacionais e internacionais. Destacam-se os ensaios de: 
tensão residual, tensão de referência, perda de energia, e medições de corrente de fuga em para-raios montados.

\subsection{4.}

\section{CEPEL - AT4}

O CEPEL executa diversos ensaios em alta tensão e alta corrente diariamente. Dentre os seus laboratórios, existe o laboratório de calibração CA2 e o laboratório de alta tensão AT4, ambos com estrutura para ensaios de impulso de corrente, mas com finalidades diferentes [18].

O laboratório de calibração CA2 tem o objetivo de realizar ensaios de medição e calibração de padrões de medição e calibração de sistemas de medição. Ou seja, o sistema de medição do CA2 serviria, se acreditado, como um SMR, e seus padrões de medição seriam aprovados pelo MIKES ou PTB, ou pelo INMETRO quando houver um SMR nacional disponível.

O laboratório de ensaios de alta tensão e alta corrente - AT4 - tem o objetivo de realizar ensaios de impulso de corrente em equipamentos e dispositivos que necessitam passar por simulações de descargas atmosféricas ou impulsos de manobra, definidos na norma IEC 60060, de modo a testar o nível de qualidade dos equipamentos.

O AT4 possui estrutura para realização de ensaios com impulso de corrente com as seguintes características:

- Corrente suportável até 100 kA (elevada, retangular e descarga de linha de transmissão),

- Pastilhas do para-raios de até $12 \mathrm{kV}$,

- Levantamento de curva tempo x corrente em desligador automático,

- Alívio de sobrepressão interna,

- Corrente de fuga,

- Impulso de corrente de curta duração em cabos de para-raios contendo no seu interior vias para comunicação em fibra ótica (OPGW - optical ground wires),

- Impulso de corrente em protetores de baixa tensão;

- Susceptibilidade a danos provocados por descargas atmosféricas em cabos ópticos com proteção metálica. 
Os ensaios de para-raios realizados no AT4 são:

- Ionização interna de para-raios,

- Características operativas e protetivas em para-raios ( $\mathrm{SiC}$ ou $\mathrm{ZnO})$ de acordo com as normas ABNT, IEC e ANSI,

- Tensão de referência, corrente de longa duração, levantamento da característica tensão de frequência industrial x tempo, estabilidade térmica, distribuição de corrente em para-raios multi-colunas, verificação da equivalência térmica entre o para-raios completo e o modelo térmico equivalente em para-raios $\mathrm{ZnO}$,

- Simulação de operação de para-raios em religador automático,

- Alívio de sobrepressão em para-raios.

Dentre os ensaios já realizados pelo AT4, destaca-se a simulação de impacto direto de raios em parte estrutural de aeronaves, sendo possível verificar nas Figuras 34, 35 e 36 do capítulo 5 alguns resultados dos ensaios de dano causados após a simulação de descarga atmosférica em aeronaves.

\subsection{5.}

\section{LAT-EFEI}

O LAT-EFEI é um laboratório de alta tensão da Universidade Federal de Itajubá e realiza pesquisas para empresas do setor elétrico na área de desempenho de equipamentos e componentes para redes de média e alta tensão, mantendo pesquisas de mestrado e doutorado em áreas correlatas à alta tensão [19].

O LAT-EFEI possui laboratório com estrutura de ensaio de para-raios ( $\mathrm{SiC}$ e $\mathrm{ZnO}$ ) e realiza os seguintes ensaios:

- Resistência do isolamento;

- Corrente de fuga;

- Tensão disruptiva a frequência industrial (seco e sob chuva);

- Tensão disruptiva a impulso atmosférico;

- Tensão residual X corrente de descarga;

- Correntes suportáveis a impulso (até $50 \mathrm{kA}$ );

- Corrente suportável de longa duração;

- Suportabilidade do invólucro;

- Ensaio do desligador automático; 
- Característica de Tensão disruptiva X tempo;

- Tensão de rádio-interferência;

- Ciclo de operação;

- Tensão residual de impulso íngreme;

- Descargas parciais.

\subsection{6.}

\section{LAT-FEE Unicamp}

O laboratório de alta tensão LAT da Unicamp realiza ensaios de pesquisa com impulsos atmosféricos, manobra e corrente, além de ensaios com corrente CA e CC. Na Tabela 7 são apresentados alguns tipos de ensaio realizados no LAT-FEE [20].

Tabela 7: Ensaios realizados no LAT - Unicamp

\begin{tabular}{ccc}
\hline \multicolumn{2}{c}{ Ensaios } & Valores máximos \\
\hline \multirow{3}{*}{ Impulsos } & Atmosférico & $1000 \mathrm{kV}, 30 \mathrm{~kJ}$ \\
\cline { 2 - 3 } & Manobra & $500 \mathrm{kV}, 30 \mathrm{~kJ}$ \\
\cline { 2 - 3 } & Corrente & $100 \mathrm{kA}(4 / 10 \mu \mathrm{s}), 60 \mathrm{~kJ}$ \\
\cline { 2 - 3 } & & $40 \mathrm{kA}(8 / 20 \mu \mathrm{s}), 60 \mathrm{~kJ}$ \\
\hline \multirow{2}{*}{ CA } & Seco & $350 \mathrm{kVrms}-60 \mathrm{~Hz}$ \\
\cline { 2 - 3 } & Chuva & $350 \mathrm{kVrms}-60 \mathrm{~Hz}$ \\
\hline \multirow{2}{*}{ CC } & Seco & $200 \mathrm{kV}$ \\
\cline { 2 - 3 } & Chus \\
\hline
\end{tabular}

O laboratório atua em ensaios de confiabilidade de para-raios, realizando os seguintes ensaios:

- Ensaio de impulso;

- Ensaio de tensão aplicada;

- Análise de transitórios;

- Medição da tensão residual;

- Medição da tensão de referência;

- Medição da corrente de fuga.

Na Figura 39 é possível observar parte da estrutura do LAT. 


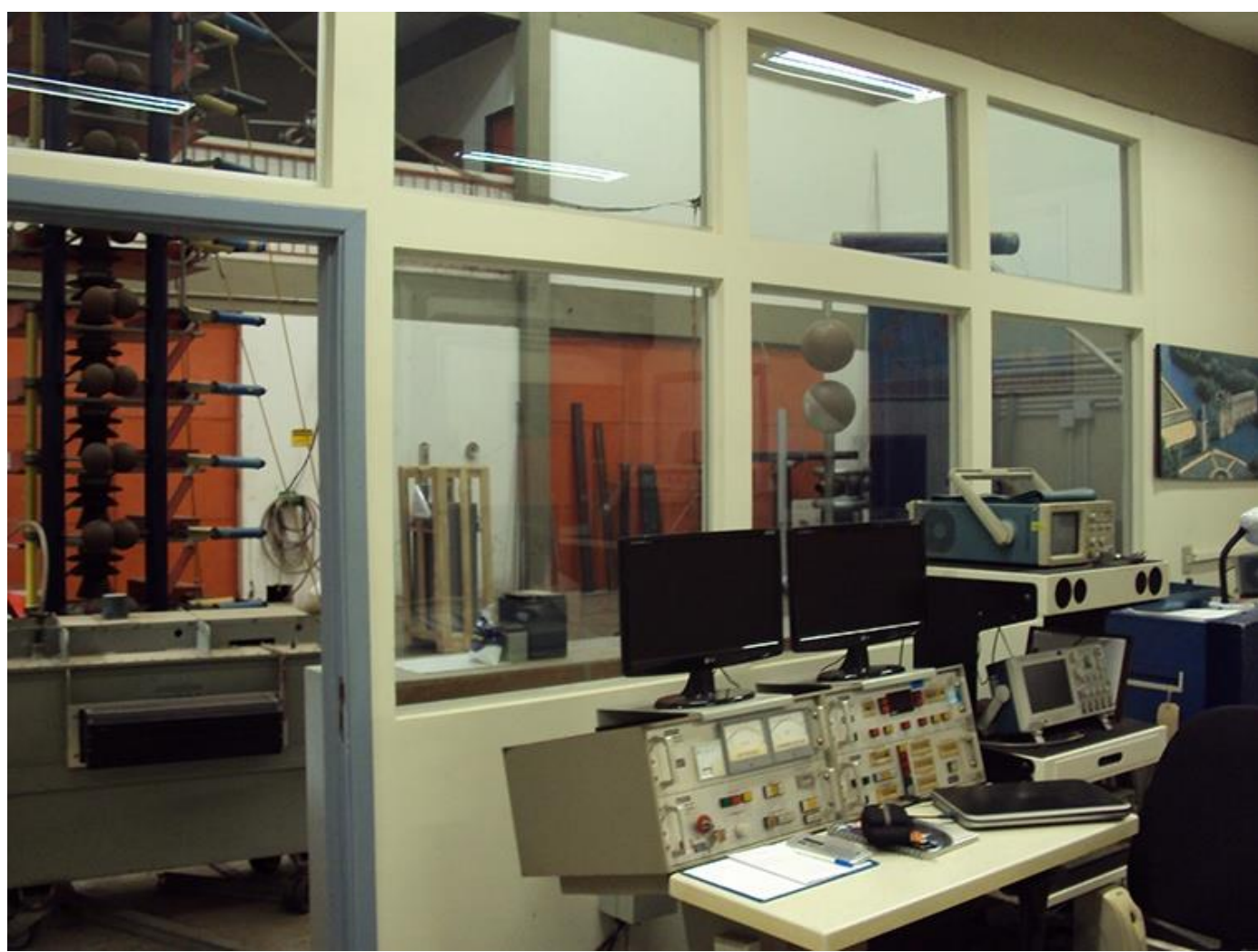

Figura 39: LAT - Unicamp

\subsection{7.}

IEE - Instituto de Energia e Ambiente da USP

O laboratório de para-raios da divisão científica de tecnologia de sistemas elétricos conta com instalações para realizar ensaios e avaliações resultantes da aplicação de impulsos de corrente em para-raios de média e alta tensão, em dispositivos de proteção contra surtos de baixa tensão e em equipamentos eletroeletrônicos.

A capacidade máxima de geração de impulsos de correntes por meio de geradores de corrente fixos é de até $50 \mathrm{kA}$ (com forma de onda 8/20 $\mu$ s) e de até $100 \mathrm{kA}$ (com forma de onda 4/10 $\mu$ s), ver gerador na Figura 40 [21]. 


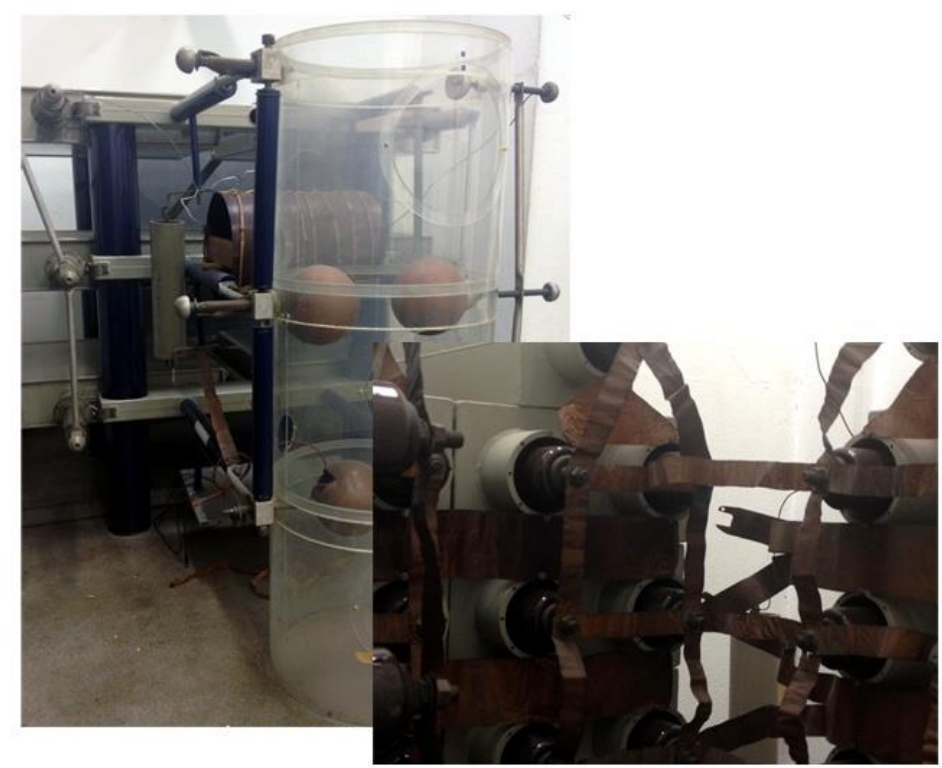

Figura 40: Sistema gerador de impulsos de corrente da USP

No escopo do laboratório estão as seguintes tarefas:

- calibração e/ou comparação de sistemas de medição de impulsos de corrente;

- medição da tensão de radiointerferência;

- medição da intensidade de descargas parciais;

- medição da corrente de fuga;

- ensaio de tensão residual;

- suportabilidade e desempenho de equipamentos.

\section{3.}

Caracterização de um SMR Nacional para Calibração de Sistemas de Medição para Impulsos de Corrente

Após a realização do estudo completo que levou a esta disertação, é possível agregar as informações necessárias para esboçar a caracterização de um sistema de medição de referência nacional, rastreável a padrões internacionais e desta forma fornecendo rastreabilidade e confiabilidade aos SMAs que possivelmente venham a ser calibrados.

Conforme citado no Capítulo 5, o equipamento mais importante a ser submetido periodicamente aos ensaios de impulso de corrente é o para-raios, por ser componente fundamental de proteção de todo o sistema elétrico, estando 
instalado em todo o sistema elétrico de potência, nas linhas de transmissão e nos terminais de entrada próximos aos transformadores de potência. Assim, a confiabilidade de seu funcionamento é imprescindível para garantir a não interrupção do fornecimento de energia elétrica.

O primeiro item necessário a se considerar para esta caracterização é a atualização de como está a estrutura metrológica relacionada a esta área atualmente no Brasil. Quais são os personagens da cadeia metrológica e integrantes da pirâmide de rastreabilidade dos para-raios no Brasil?

A estrutura com a hierarquia da pirâmide metrológica é apresentada na Figura 41.

\section{HIERARQUIA DO SISTEMA METROLÓGICO}

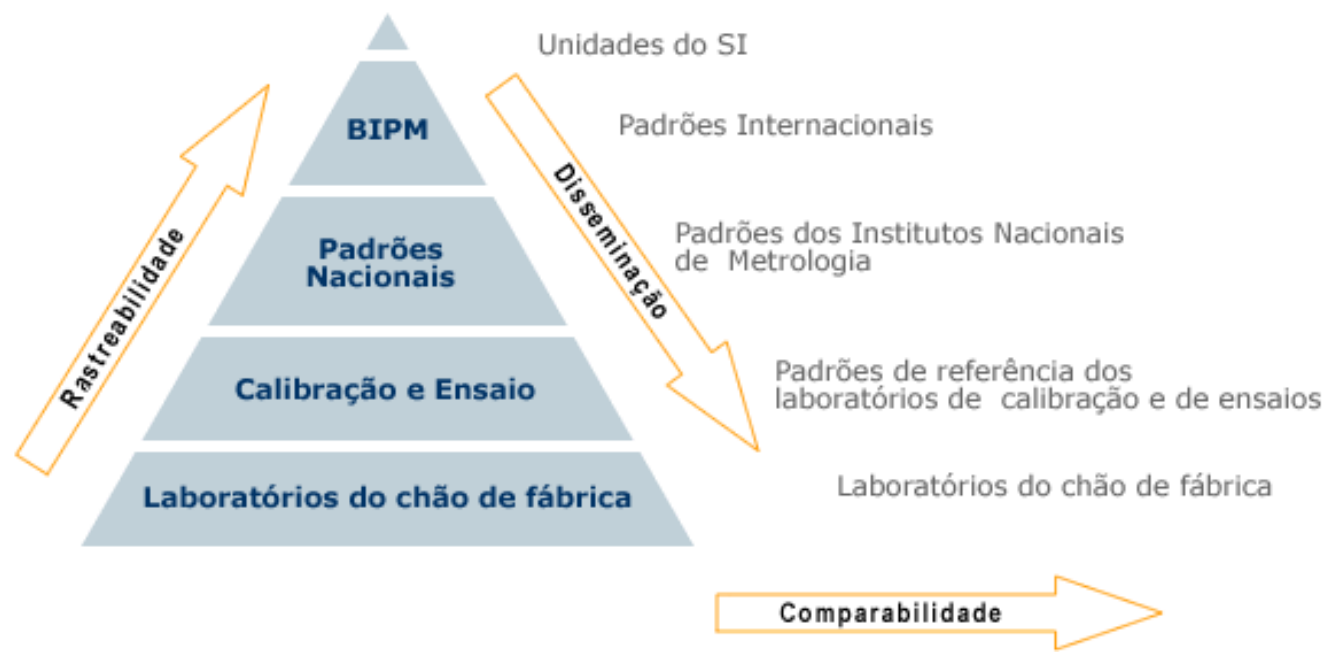

Figura 41: Hierarquia do sistema metrológico

Os elementos da pirâmide metrológica em ordem decrescente de hierarquia são o BIPM contendo os padrões internacionais do SI, os institutos metrológicos nacionais, contendo os padrões nacionais, os laboratórios de calibração e ensaio, contendo padrões de medição acreditados e os laboratórios de chão de fábrica.

Usando essa pirâmide como referência, é possível determinar quais seriam os elementos da pirâmide metrológica para o impulso de corrente. 
Na base da pirâmide estão os laboratórios do chão de fábrica, responsáveis por ensaiar e certificar os equipamentos produzidos, como para-raios e fuselagem de aeronaves, como já apresentado nessa dissertação.

Em um nível acima nessa pirâmide deveriam existir laboratórios industriais ou científicos com SMAs acreditados para ensaiar e certificar os para-raios. Estes laboratórios deveriam possuir padrões (SMAs) com níveis de incerteza de medição aceitáveis segundo as normas de ensaios aplicáveis ao para-raios. Os limites dos níveis de incerteza de um SMA, definidos no item 10.4.1 da norma IEC 62475[4], são apresentados na Tabela 8.

Tabela 8: Requisitos de um SMA

\begin{tabular}{c}
\hline \multicolumn{2}{c}{ Requisitos Gerais de um SMA } \\
\hline $\begin{array}{c}\left(U_{\max }\right) \\
\text { Valor máximo do Impulso } \\
\left(T_{1}, T_{2}\right)\end{array}$ \\
$\begin{array}{c}\text { Parâmetros de tempo } \\
u_{m} \leq 3 \%\end{array}$ \\
\hline $\begin{array}{c}\text { Exibir um offset de saída suficientemente baixo, de modo a } \\
\text { permitir o cálculo da carga do impulso de corrente e a integral } \\
\text { de Joule }\end{array}$ \\
\hline
\end{tabular}

$\mathrm{Na}$ camada 3 dessa pirâmide de rastreabilidade deveria existir um laboratório com SMR acreditado pelo Inmetro, ou acreditado por um instituto metrológico internacional e autorizado pelo Inmetro, estabelecidos pela norma IEC 62475 para SMRs, para aprovar os transdutores utilizados pelos SMAs. Estes laboratórios emitiriam selos de qualidade e comprovantes de rastreabilidade daquele transdutor.

Na camada 2 estariam os institutos nacionais de metrologia com nível de incerteza menor que os níveis de incerteza apresentados pelos laboratórios nacionais. Atualmente no quadro internacional os laboratórios acreditados pelo BIPM, como apresentado na sessão 6.1, são os laboratórios do MIKES e PTB, institutos nacionais da Finlândia e da Alemanha, respectivamente. Estes laboratórios emitem selos de qualidade e dão certificados de rastreabilidade para os padrões que por eles são calibrados. Os níveis de incerteza que estes laboratórios atingem atualmente são os menores do mundo. 
O INMETRO estaria nessa camada metrológica, como instituto nacional de metrologia do Brasil, mas ataulmente não possui infraestrutura para o ensaio com impulso de corrente.

Na parte superior da pirâmide está o BIPM, com os padrões internacionais do SI de menor incerteza.

Assim, apresenta-se na Figura 42 a seguir, a pirâmide de rastreabilidade do impulso de corrente utilizado nos ensaios de qualidade dos para-raios, dos revestimentos das aeronaves e no cálculo da corrente de fuga nos transformadores de potência, conforme descrito no capítulo 5 .

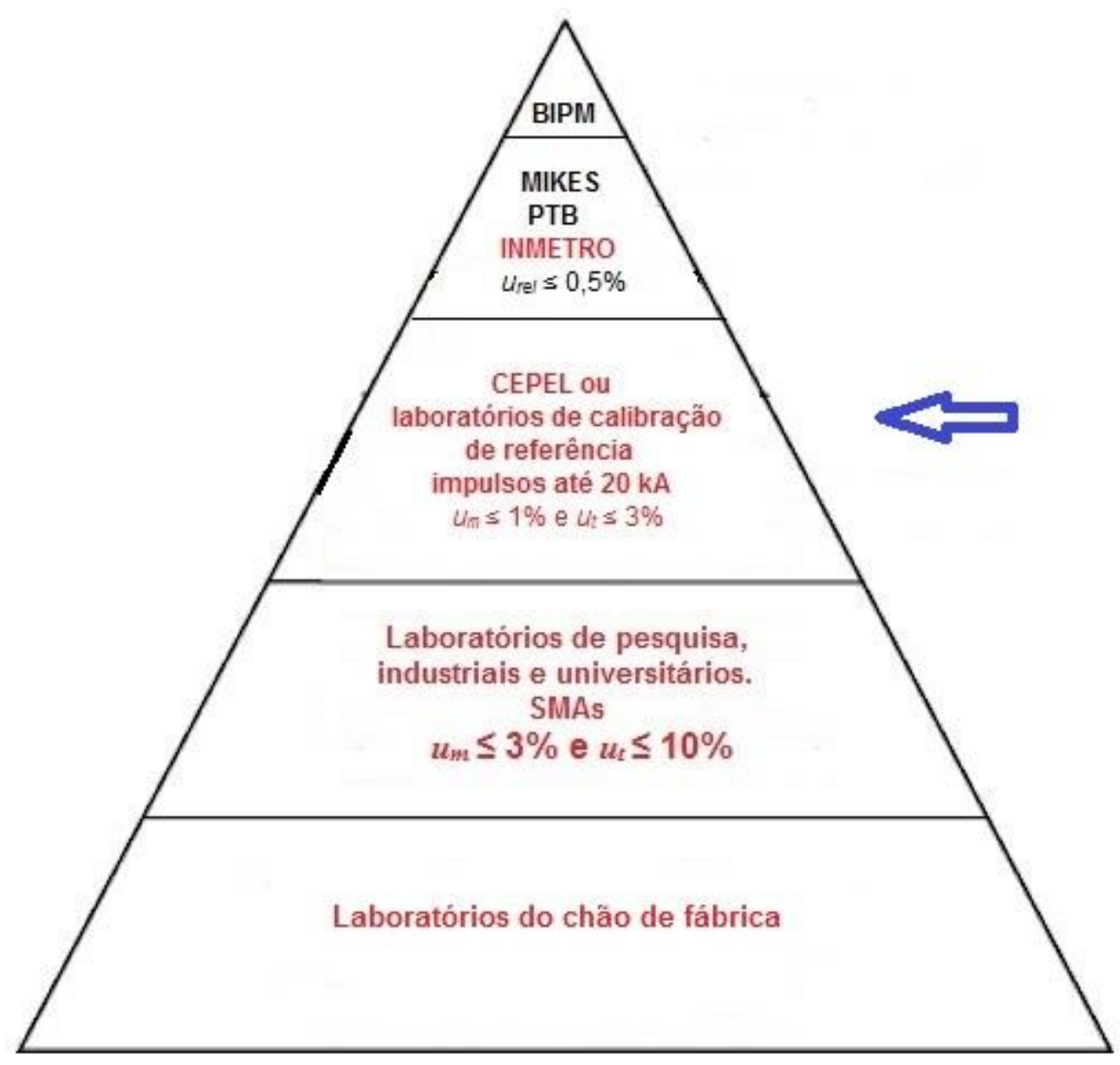

Figura 42: Pirâmide de rastreabilidade do impulso de corrente

$\mathrm{Na}$ Figura 42, os componentes indicados em vermelho atualmente não estão disponíveis no Brasil. Inicialmente, o desenvolvimento de um SMR no Brasil, correspondente à camada indicada pela seta azul, abriria o caminho para laboratórios industriais e científicos desenvolverem SMAs com baixa incerteza, 
que pudessem ser calibrados por este SMR, resultando em ensaios de qualidade e um produto final instalado no sistema elétrico nacional com confiabilidade e baixa taxa de perda de equipamento por sobretensão.

Os sistemas de medição aprovados (SMAs) com base no sistema de medição de referência (SMR) aqui descrito poderão ser posteriormente utilizados para ensaios de desempenho e verificação dos diversos equipamentos apresentados no capítulo 5 desta dissertação. Da mesma forma, os sistemas de medição aprovados poderão ser utilizados para calibrar instrumentos de medição em laboratórios científicos e industriais.

Para esclarecimento inicial, um laboratório que planeje montar a infraestrutura necessária para se caracterizar como um sistema de medição de referência necessitará de um gerador de impulsos de corrente para ensaios que alcancem no mínimo 5\% do nível de amplitude máxima à qual o padrão testado deve ser submetido quando em operação. Esse gerador não faz parte do sistema de medição, ou seja, ele é apenas a fonte dos impulsos de corrente que serão adquiridos e analisados pelo sistema de medição de referência e pelo sistema de medição a ser aprovado.

Na Figura 43 é apresentado um exemplo de gerador de impulsos utilizado em ensaios internos no laboratório de calibração do CEPEL. Esse gerador foi adquirido pelo laboratório de calibração CA2 do CEPEL com a finalidade de gerar impulsos de corrente com a forma de onda de $8 / 20 \mu$ s até $20 \mathrm{kA}$, ou seja, os impulsos que passarão pelo transdutor sob ensaio possuem $8 \mu \mathrm{s}$ de tempo de frente e $20 \mu \mathrm{s}$ de tempo de cauda, com amplitude máxima de até $20 \mathrm{kA}$, permitindo assim que padrões de até $400 \mathrm{kA}$ possam ser aprovados utilizando esse gerador como fonte de impulsos de corrente. 


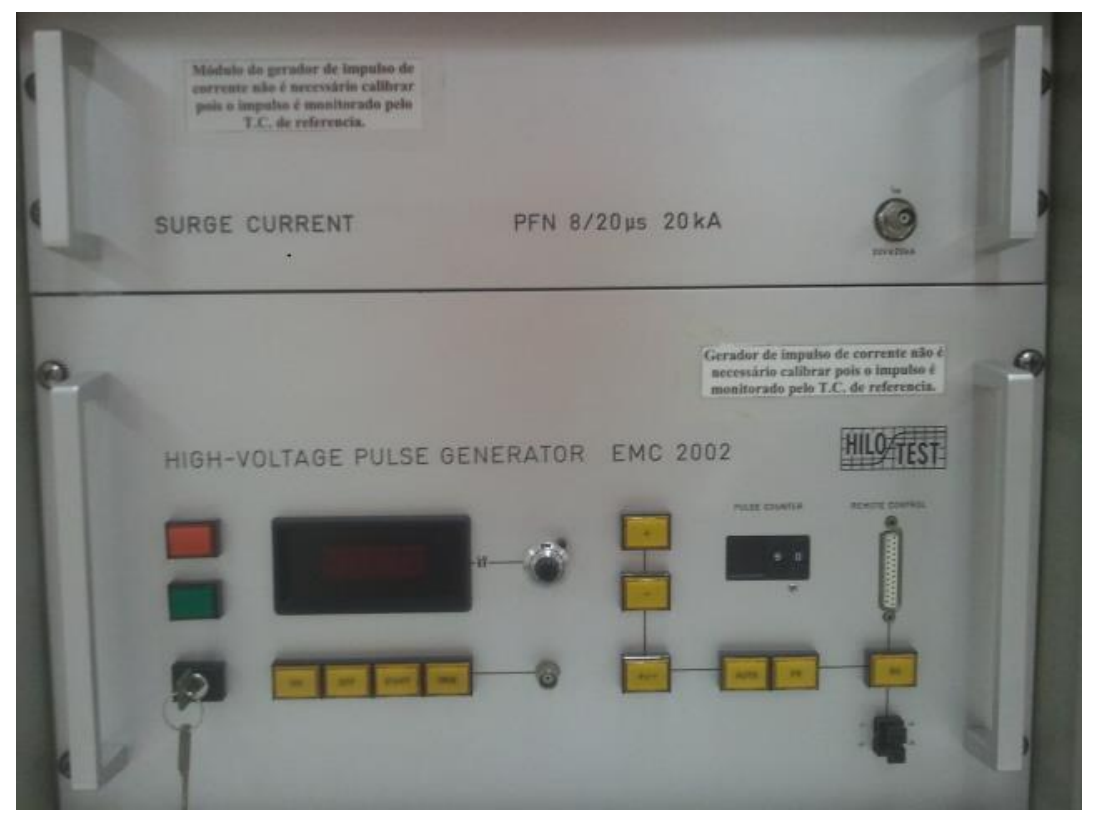

Figura 433: Gerador de impulsos EMC 2002

Após o gerador estar disponível, o sistema de medição pode ser definido. A primeira parte é o transdutor de corrente, um Shunt ou um TC, que é a peça chave para o sistema de medição. A Figura 44 apresenta um exemplo de sistema de medição para calibração de TCs montado no CA2.

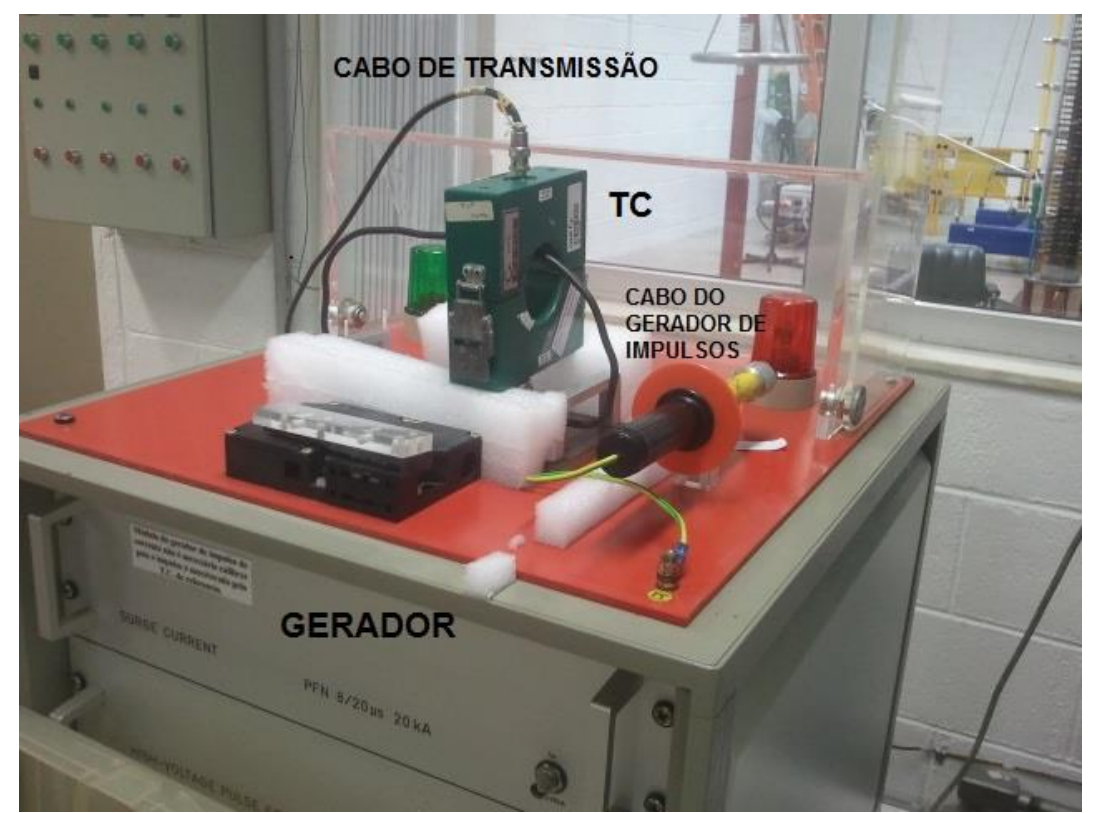

Figura 444: Transdutor do sistema de medição de impulsos de corrente

Como já apresentado nesta dissertação, o transdutor utilizado pode ser um TC, um Shunt ou um dos demais tipos de transdutores. Durante a pesquisa, 
identificou-se como melhor opção para um sistema de medição de referência algum transdutor formado de combinações das características e das qualidades entre as melhores especificações de cada um dos transdutores apresentados.

Um transdutor de corrente para ensaios de calibração necessita ser um transdutor de alta precisão, e para isso o transformador de corrente (TC) demonstra ter vantagem em relação ao Shunt, mas o TC comum possui baixa linearidade, um parâmetro necessário para um sistema de medição de impulsos de corrente com amplitude máxima podendo alcançar altos níveis. O transdutor de corrente que apresenta maior linearidade é a bobina de Rogowski, mas esta precisa ser utilizada associada a um integrador, adicionando assim mais um componente de incerteza no cálculo final dos parâmetros.

Com isso é necessário especificar um transdutor que possa alcançar os níveis de incerteza que são necessários para um SMR, ou seja, um transformador que mescle as especificações e características positivas dos diversos tipos de transdutores.

As empresas de tecnologia que fabricam transformadores de corrente, como a "Pearson Electronics" e a "Stangenes Industries", podem produzir projetos de transformadores personalizados, que possuem especificações para cada finalidade definida pelo cliente.

Exemplos de TCs fabricados sob encomenda são apresentados na Figura 45. Esses TCs da Pearson foram solicidados pelo CEPEL para realização de ensaio com impulso de corrente no laboratório de calibração, ou seja, era necessário um TC que, dentre suas características, possuísse: suportar altas potências, possuir linearidade nos resultados das medições e baixo nível de erro por repetitibidade, mantendo o nível de incerteza baixo, e portanto o laboratório solicitou a Pearson um transformador com essas especificações. Esses TCs possuem uma combinação de bobina ferromagnética mergulhada em fluido isolante, que permite que a bobina obtenha um funcionamento próximo à bobina de Rogowski, obtendo assim um transformador com maior linearidade. 


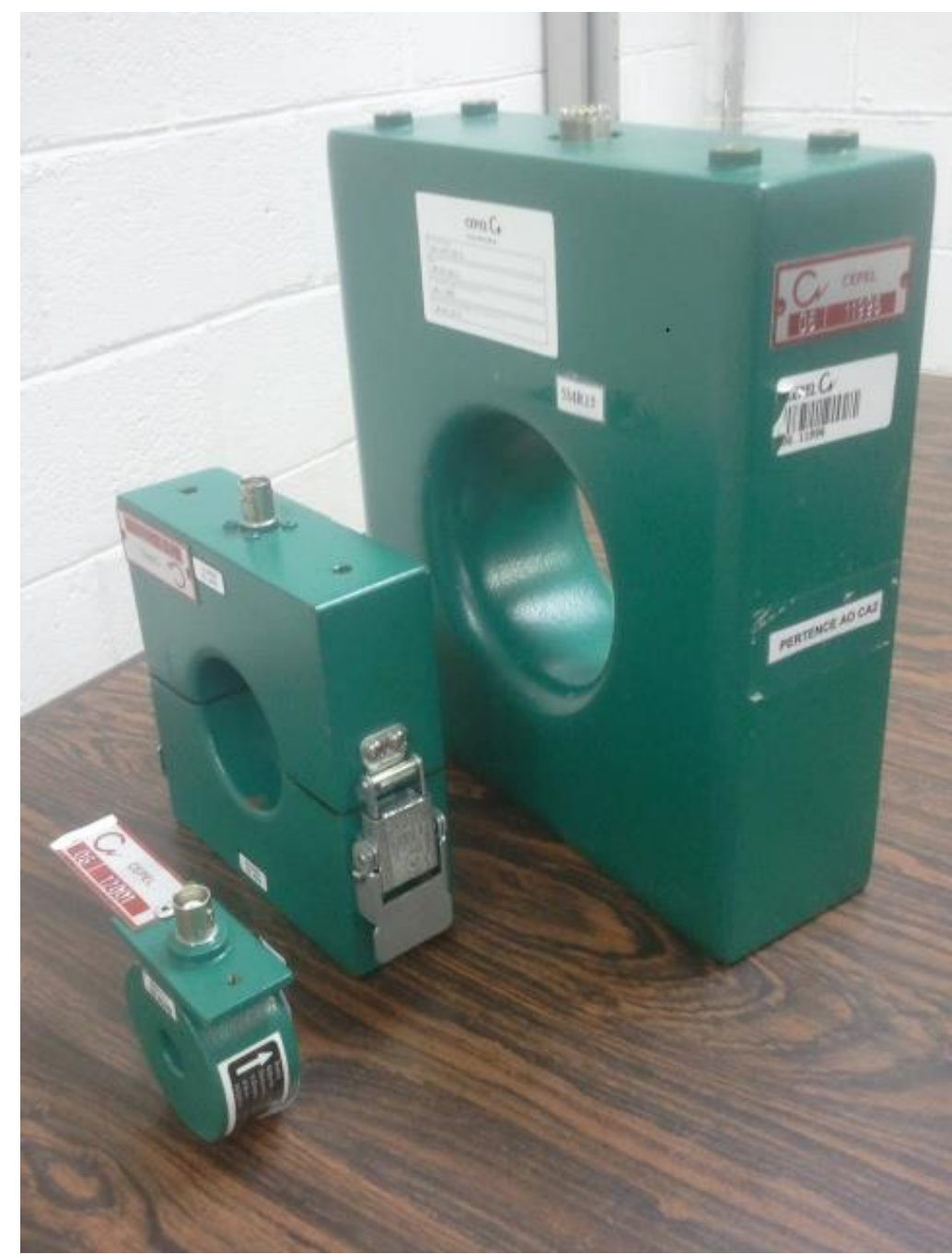

Figura 45: TCs encomendados pelo CEPEL sob especificações

Com a definição do transdutor que será usado no SMR, a próxima etapa é a definição do sistema de transmissão do sinal, que é a conexão entre o transdutor e o instrumento de medição.

A transmissão do sinal é feita por meio de um cabo coaxial de malha dupla ou simples, que dependendo da configuração do cabo pode ter uma impedância de 50 ou 75 ohms. Apresenta-se um exemplo de cabo coaxial de malha dupla na Figura 46. 


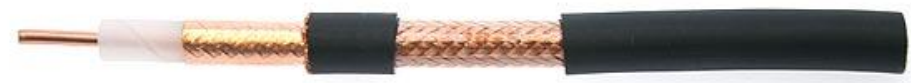

Figura 456: Cabo coaxial de malha dupla

O cabo coaxial de transmissão do sinal insere uma impedância no sistema e, para balancear essa impedância é necessário que um casador seja inserido no final do cabo de transmissão, com a impedância de $50 \Omega$ ou $75 \Omega$, balanceando com cabos de $50 \Omega$ ou $75 \Omega$ respectivamente. A Figura 47 apresenta um atenuador/casador de $75 \Omega$ montado e utilizado pelo CA2 para ensaios de impulso de tensão e corrente. É importante ressaltar que os resistores utilizados não podem ser indutivos, pois neste caso pode-se acrescentar reflexão e erros na medição do sinal.

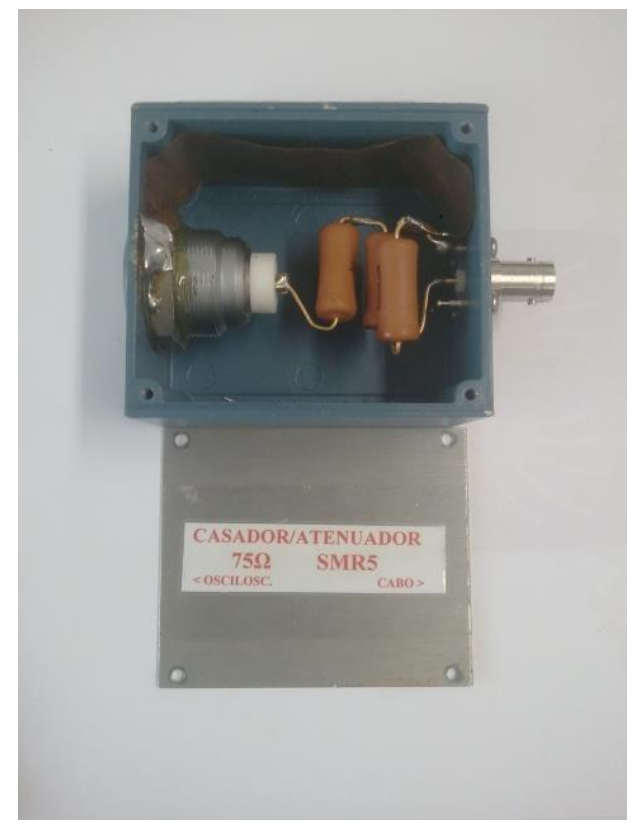

Figura 47: Atenuador/casador para cabos de $75 \Omega$

O próximo item do sistema de medição é o digitalizador e a interface gráfica, essenciais para a confiabilidade dos resultados. É aqui que serão executados os cálculos e em parte será definida a sensibilidade do sistema, que 
passará a ser tratado digitalmente e não mais de forma analógica. Para entender melhor essa estrutura, apresenta-se na Figura 48 um esquema montado utilizando um osciloscópio como interface gráfica do ensaio.

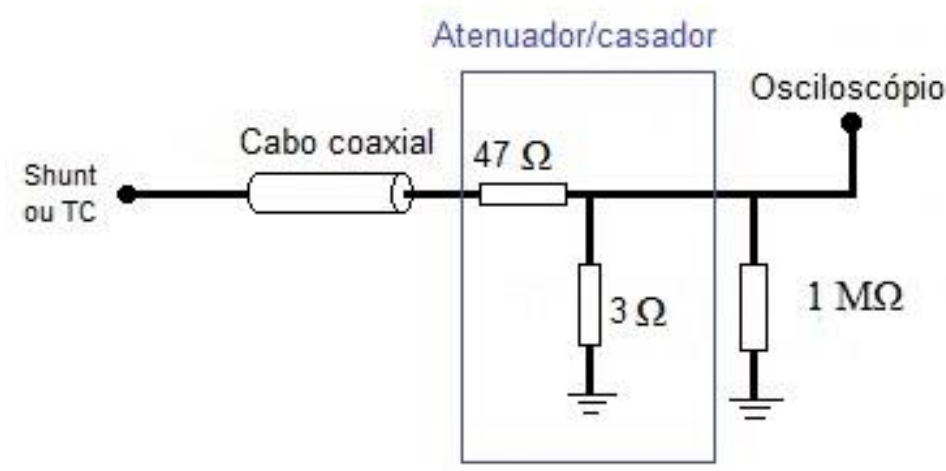

Figura 468: Sistema de medição utilizando osciloscópio

Como o sistema de medição considerado nesta seção é um sistema de medição de referência, cada item deve ser planejado buscando a melhor qualidade e exatidão. $\mathrm{O}$ digitalizador do sistema de medição é fundamental para estabelecer o nível de resolução do sinal enviado pelo transformador no momento do impulso de corrente. Conforme a norma IEC 61083-1 o digitalizador deve possuir características específicas para medir as pequenas variações que possam vir a ocorrer durante a duração total do ensaio.

Já foram apresentadas, no Capítulo 4, as taxas de amostragem e o nível de resolução necessária para ensaios de impulso em SMAs e SMRs. Como nesta seção da dissertação está sendo realizada a caracterização de um SMR nacional, as especificações do digitalizador devem ser [26]:

- Taxa de amostragem não menor que 30/Tx, onde Tx é o intervalo de tempo a ser mensurado,

- Resolução de 2-9 (0,2\% da escala total) ou melhor,

- Incerteza do valor máximo não maior que $0,7 \%$ (um $\leq 0,7 \%$ ),

- Incerteza dos parâmetros de tempo não maior que 3\% (ut $\leq 3 \%$ ).

Um dos sistemas mais utilizados e que demonstra possuir um desempenho estável e confiável é o sistema de aquisição e processamento dos dados chamado HiAS - High Resolution Impulse Analyzing System (Sistema de Análise de 
Impulsos de Alta Resolução) da empresa Haefely. O modelo HiAS743 é apresentado na Figura 49.

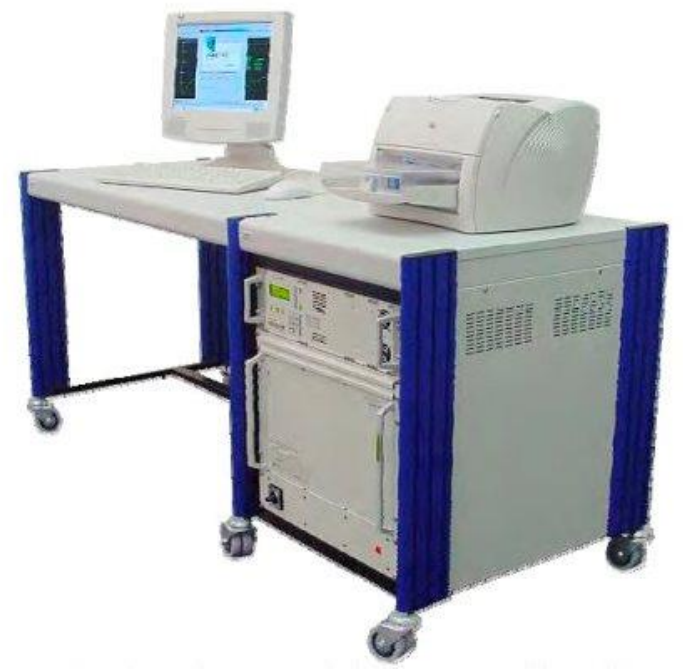

Figura 479: HIAS743

O Hias permite que o usuário realize a avaliação e a análise da medição de tensões e correntes, de acordo com as nórmas IEC 61083, IEC 60060, IEC 60076, IEC 60099, IEC 60230 e as demais normas relevantes para testes de impulso de alta tensão. Possui opção de avaliação automática das formas de impulso especificadas nas normas acima, e um modo de avaliação manual está disponível. As atualizações mais recentes dessa ferramenta já permitem que o usuário selecione a norma para impulsos de correntes IEC 62475 como critério para as avaliações dos ensaios de impulso de corrente [25].

O HiAS não necessita de um atenuador na sua entrada, pois o nível de tensão que ele suporta é alto, 1600 volts, mas mantém a necessidade de uma impedância de $50 \Omega$ para o casamento que vai filtrar o sinal, reduzindo o ruído na entrada e evitando problemas de leitura por reflexão no cabo.

Desta forma o sistema montado com o HiAS ficaria como apresentado na Figura 50: 


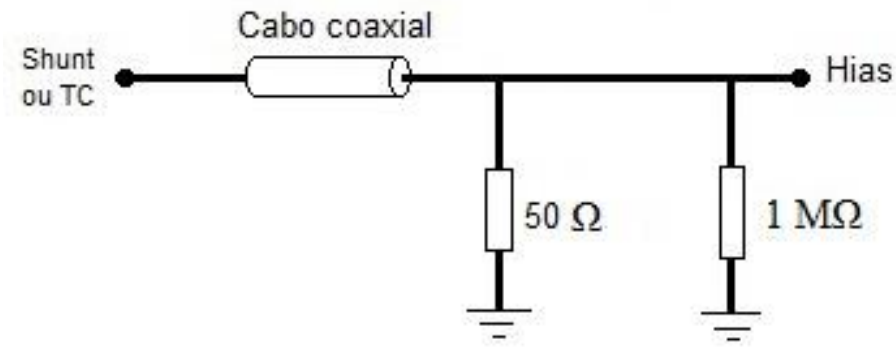

Figura 5048: Sistema de medição utilizando HiAS

Em comparação ao sistema de medição utilizando o Hias, existe o sistema de medição utilizando o osciloscópio para avaliação e análise dos dados de ensaio. Deve-se ter precaução com o nível de tensão na entrada do osciloscópio pois, como o nível máximo de tensão de entrada no osciloscópio é baixo, cerca de $80 \mathrm{~V}$, o atenuador de $1 \mathrm{M} \Omega$ da entrada deve estar sempre acionado. O osciloscópio permite que o usuário realize o ensaio e visualize na sua interface a forma de onda, mas o cálculo de alguns parâmetros pode necessitar de algum software externo ao osciloscópio. Esse software precisa estar em conformidade com a norma IEC 61083 e seus níveis de incerteza precisam estar na faixa aceitável para SMRs. 


\section{Conclusão e Trabalhos Futuros}

O sistema elétrico de potência, desde a geração, transmissão e distribuição até o consumidor final, recentemente se tornou alvo de discussão e críticas, em parte positivas devido ao grande crescimento e evolução que ocorreu ao longo dos últimos 20 anos em todos os setores do sistema elétrico nacional, mas em parte negativas devido afalhas nos órgãos de regulamentação e fiscalização [22].

Durante a parceria da PósMQI da PUC-Rio com o CEPEL, buscando o desenvolvimento e melhorias de software para adquirir e analisar os dados da resposta de ensaios de alta tensão com impulso de tensão [39,40,41,42], foi observada uma lacuna na estrutura metrológica do setor elétrico, que é a necessidade de um laboratório nacional de referência em ensaios de alta tensão com impulso de corrente.

Assim, esta dissertação buscou conhecer as camadas da pirâmide de rastreabilidade, liderada pelos laboratórios de referência acreditados pelo BIPM e completada por laboratórios internacionais e nacionais.

Uma das propostas desta dissertação foi apresentar a normalização e as peças que compõem um SMR, de forma que este trabalho possa servir de base para um laboratório nacional que deseje se estruturar, a fim de certificar e calibrar SMA ou equipamentos de ensaio com impulso de corrente.

A aplicação da norma IEC 62475 para a construção de um SMR nacional no Inmetro poderia gerar grandes benefícios e vantagens para o sistema elétrico de potência e, da mesma forma, poderia ser uma referência internacional para laboratórios da América Latina, certificando e ensaiando diversos sistemas de medição. Estes, por fim, poderiam calibrar e certificar com precisão os equipamentos que formam a demanda por sistemas de medição com impulso de corrente.

O para-raios, juntamente com aeronaves e outros equipamentos que necessitam ser ensaiados com impulso de corrente, foi identificado que possuiuma 
forte demanda, podendo sustentar e manter os laboratórios de calibração de sistemas de medição.

A conclusão que esta dissertação apresenta é que existe uma necessidade em nível de segurança industrial pela estruturação de um laboratório com SMR no Inmetro para que a rede de calibração nacional com impulso de corrente possa ser certificada.

A norma IEC 62475 foi desenvolvida com base na norma para impulsos de tensão IEC 60060, considerando algumas claras peculiaridades que envolvem os ensaios de corrente. Contudo, ao contrário do suposto no início dos trabalhos de pesquisa, um SMR para ensaios de impulso de corrente pode ser montado com baixo custo, por não necessitar de grandes capacitores e geradores de energia, como no caso dos laboratórios voltados para ensaio de desempenho e verificação de equipamentos.

Como trabalho futuro indica-se a iniciativa para a implementação dos requisitos da norma IEC 62475 em laboratórios de ensaio e calibração existentes no país. A capacitação dos laboratórios nacionais só será possível após os laboratórios do Inmetro passarem por essa implementação, gerando conformidade e confiabilidade nos padrões de transdutores utilizados nos ensaios e nas calibrações.

O CEPEL possui interesse em se estruturar e receber acreditação para a realização do ensaio de impulso e para a realização de calibrações de transdutores (Shunt e TC). Parte desta estruturação envolve o desenvolvimento de um software para avaliação automática dos parâmetros das formas de onda de impulsos de corrente, versão similar à já implantada nos laboratórios de alta tensão para ensaios com impulso de tensão (software IMPREAL, desenvolvido e implementado em parceria com o PósMQI da PUC-Rio).

Outro projeto de interesse do setor elétrico de potência é o projeto e desenvolvimento de padrões de transdutores para ensaios com impulso de corrente. 


\section{Referências Bibliográficas}

[1] OGLOBO, De 23 novas hodrelétricas planejadasna Amazônia, sete serão construídasem áreas intocadas, disponível em: http://oglobo.globo.com/economia/de-23-novas-hidreletricas-planejadas-naamazonia-sete-serao-construidas-em-areas-intocadas-6173007. Acesso em: $10 / 09 / 2014$.

[2] GLOBO.COM, Raio rompe cabo e provoca apagão em 20 municípios de Mato Grosso, disponível em: http://g1.globo.com/matogrosso/noticia/2012/10/raio-rompe-cabo-e-provoca-apagao-em-20municipios-de-mato-grosso.html. Acesso em: 10/09/2014.

[3] INSTITUTO NACIONAL DE METROLOGIA, QUALIDADE e TECNOLOGIA, INMETRO, VIM - Vocabulário Internacional de Metrologia. p.92. 2012b

[4] INTERNATIONAL ELECTROTECHNICAL COMMISSION - IEC. IEC 62475 ed.1.0 High-current test techniques - Definitions and requirements for test currents and measuring systems: 102 p. 2010-09.

[5] INSTITUTO NACIONAL DE METROLOGIA, QUALIDADE e TECNOLOGIA - INMETRO, SI - Sistema Internacional de Unidades. p.93. $2012^{\mathrm{a}}$

[6] BUREAU INTERNATIONAL DES POIDS ET MESURES - BIPM, dispinível em <www.bipm.org> Acesso em: 10/09/2014.

[7] RIPKA, P. Electric Current Sensor: a review. Measurement Science \& Technology, p. 23, 2010.

[8] OlIVEIRA, P. C. D. Análise de Transformadores de Corrente para Medição 2001.

[9] INTERNATIONAL ELECTROTECHNICAL COMMISSION - IEC, <http://www.iec.ch>. Acesso 10/09/2014.

[10] BARBOSA, F. B.; OLIVEIRA, M. J. D.; FRANCO, J. L. D. Apostila Páraraios Ensaios em pára-raios - Parte 1: Aspectos Gerais Eletronorte: CEPEL, 2007.

[11] FILHO, ORSINO OLIVEIRA; BARBOSA, FLÁVIO B; ROCHA, JOSÉ CARLOS DA; RODRIGUES, JOSÉ A. P.; LIBRANTZ, HELIO E NUNES, SIDNEY OSSES; Development And Certification Tests Of Lightning Direct Impact On Structural Parts Of Aircraft. Congresso: VII 
INTERNATIONAL SYMPOSIUM ON LIGHTNING PROTECTION, 2003, Curitiba. Proceedings. SIPDA. São Paulo: IEE-USP, 2003.

[12] NATIONAL METROLOGY INSTITUTE OF FINLAND, MIKES. http://www.mikes.fi/mikes/Esitteet/kalibrointiesitteet_eng_www.pdf\#page= 22. Acesso em: 10/09/2014.

[13] PHYSIKALISCH-TECHNISCHE BUNDESANSTALT - PTB. http://www.ptb.de/cms/en/fachabteilungen/abt2.html. Acesso em: 10/09/2014.

[14] INSTITUTO NACIONAL DE METROLOGIA, QUALIDADE e TECNOLOGIA.INMETRO, http://www.inmetro.gov.br/. 2014. Acesso em: 10/09/2014.

[15] CENTRO ELETTROTECNICO SPERIMENTALE ITALIANO - CESI, www.cesi.it; Acesso 10/09/2014

[16] HIGHVOLT PRÜFTECHNIK DRESDEN GMBH. http://www.highvolt.de/pt/desktopdefault.aspx/tabid-6/1589_read-6912/. Acesso em: 10/09/2014.

[17] CENTRAL POWER RESEARCH INSTITUTE - CPRI. http://www.cpri.in/about-us/departmentsunits/high-voltage-divisionhvd/impulse-current-laboratory.html. Acesso em: 10/09/2014.

[18] CENTRO DE PESQUISA DE ENERGIA ELÉTRICA DA ELETROBRÁS. http://www.cepel.br/servicos/ensaios.shtm\#Calibracao. Acesso em: $10 / 09 / 2014$.

[19] LABORATÓRIO DE ALTA TENSÃO DA UNIVERSIDADE DE ITAJUBÁ - LAT-EFEI, http://www.lat-efei.org.br/index.php/2014-07-0813-46-38/tipos-de-ensaios; Acesso 10/09/2014

[20] LABORATÓRIO DE ALTA TENSÃO DA FACULDADE DE ENGENHARIA ELÉTRICA DA UNICAMP - LAT-FEE. http://www.lat.fee.unicamp.br/ensaios.html. Acesso em: 10/09/2014.

[21] INSTITUTO DE ENERGIA E AMBIENTE DA UNIVERSIDADE DE SÃO PAULO - IEE-USP. http://200.144.182.130/iee/?q=ptbr/divis\%C3\%B5es-cient\%C3\%ADficas/tecnologia-de-sistemasel\%C3\%A9tricos/servi\%C3\%A7o-t\%C3\%A9cnico-de-altastens $\% \mathrm{C} 3 \% \mathrm{~B} 5$ es-e-descargas-atmosf\%C3\%A9ricas/laborat\%C3\%B3rio-depara-raios. Acesso em: 10/09/2014.

[22] ASSOCIAÇÃO BRASILEIRA DE DISTRIBUIÇÃO DE ENERGIA ELÉTRICA - ABRADEE, www.abradee.com.br/setor-eletrico/visao-geraldo-setor; Acesso 10/09/2014.

[23] COMPANHIA ENERGÉTICA DO MARANHÃO - CEMAR; CENTRAIS 
ELÉTRICAS DO PARÁ - CELPA. Pára-raios de distribuição. 03. 2013.

[24] DEHN INTERNACIONAL. http://www.dehn-international.com/en/testingrailway-systems-and-equipment-impulse-current-laboratory. Acesso em: 10/09/2014.

[25] HAEFELY HIPOTRONICS. http://www.haefely.com/pdf/LL_SSG.pdf. p. Impulse current test systemsType SSGA30 kA - 200 kA, Acesso em: 10/09/2014.

[26] INTERNATIONAL ELECTROTECHNICAL COMMISSION - IEC. IEC 61083-1 Instruments and software used for measurement in highvoltage impulse tests - Part 1: Requirements for instruments: $69 \mathrm{p}$. 2001 .

[27] INTERNATIONAL ELECTROTECHNICAL COMMISSION - IEC. IEC 61083-2 ed.2.0 Instruments and software used for measurement in highvoltage and high-current tests - Part 2: Requirements for software for tests with impulse voltages and currents: 65 p. 2013.

[28] LANDIM, R. P.; VENTURA, R.; TEIXEIRA, V. M. Sistema de calibração de fontes e medidores de tensão e corrente contínua de alta exatidão. IXSemetro: 6 p.

[29] INSTITUTO NACIONAL DE METROLOGIA, QUALIDADE e TECNOLOGIA, - INMETRO, Orientações para a acreditação de organismos de certificação, Disponível em: http://www.inmetro.gov.br/Sidoq/Arquivos/CGCRE/DOQ/DOQ-CGCRE12_01.pdf Acesso: 28/01/2015

[30] INSTITUTO NACIONAL DE METROLOGIA, QUALIDADE e TECNOLOGIA, - INMETRO, O que é acreditação. Disponível em: http://www.inmetro.gov.br/credenciamento/oqe_acre.asp Acesso: 28-012015

[31] Centro de Pesquisa de Energia Elétrica - CEPEL, http://www.cepel.br/ Acesso 10/03/2015

[32] ASSOCIAÇÃO BRASILEIRA DE NORMAS TÉCNICAS. NR 10: segurança em instalações e serviços em eletricidade, 1978

[33] Filipski P S and BoeckerM2006 AC-DC current shunts and system for extended current and frequency ranges IEEE Trans.Instrum.

[34] Filipski P S, Boecker M and Garcocz M 2008 20-A to 100-A AC-DC coaxial current shunts for $100-\mathrm{kHz}$ frequency range IEEE Trans. Instrum.

[35] Suomalainen E and Hallstrom J K 2009 Onsite calibration of a current transformer using a Rogowski coil IEEE Trans.Instrum. Meas. 
[36] Popovic R, Drljaca P and Kejik P 2006 CMOS magnetic sensors with integrated ferromagnetic parts Sensors Actuators A 129 94-9

[37] Benjamin Franklin's Inventions, Discoveries, and Improvements. Disponível em: http://www.ushistory.org/franklin/info/inventions.htm. Acesso em: $13 / 03 / 2015$

[38] MILITARY STANDARD: LIGHTNING QUALIFICATION TEST TECHNIQUES FOR AEROSPACE VEHICLES AND HARDWARE MILSTD-1757A, (17 JUN 1980)

[39] Faria, L.C. ; Costa Silva, E. ; Silva, M. T. F. ; Barbosa, C R Hall ; Azevedo, L. C. . Automated Evaluation of Dynamic Performance of Impulse Voltage Measurement Systems. Journal of Physics. Conference Series (Online), v. 575, p. 012011, 2015.

[40] BARBOSA, CARLOS R. HALL; HALLSTROM, JARI ; DA SILVA, MARCIO THELIO FERNANDES ; AZEVEDO, LUIZ CARLOS ; FARIA, LUCAS CASTRO . Tail-Chopped Lightning Impulses Time Parameters Estimated According to Standard IEC 60060-1:2010. IEEE Transactions on Instrumentation and Measurement $\mathrm{JCR}_{\text {, v. }}$ 64, p. 1-1, 2014.

[41] Faria, L.C. ; Costa Silva, E. ; Silva, M. T. F. ; Hall Barbosa, C. R ; Azevedo, L. C. . Steral 2.0 - Software para Avaliação de Desempenho Dinâmico de Sistemas de Medição Utilizados em Alta Tensão. In: XV ERIAC Encontro Regional Ibero-Americano do Cigré, 2013, Foz do Iguaçu. Anais do XV ERIAC, 2013.

[42] Barbosa, C R Hall ; Silva, M. T. F. ; Azevedo, L. C. ; FARIA, LUCAS CASTRO . Validation of a System for Evaluation of High Voltage Impulses According to IEC 60060:2010. IEEE Transactions on Instrumentation and Measurement JcR, 2015. 